\title{
A FRAMEWORK TO GUIDE POLICYMAKERS ON THE USE OF SCIENCE TO INFORM PUBLIC HEALTH POLICY AND LAW: IMMUNISATION AS A CASE STUDY
}

BY

\section{ALEXANDER SEBASTIAN PISHIEF}

\author{
A thesis \\ submitted to Victoria University of Wellington \\ in fulfilment of the requirements for the degree of \\ Master of Laws
}

Victoria University of Wellington (2019) 


\section{Contents}

I INTRODUCTION 1

II THE INTERFACE BETWEEN SCIENCE, SOCIETY, POLICY AND LAW ........ 8

A Science and the Public Health Policy Process .......................................................... 9

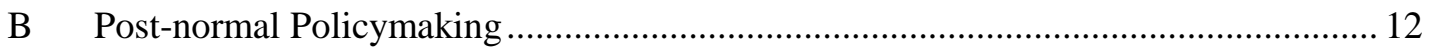

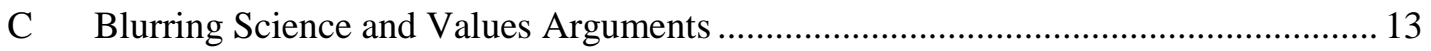

D Separating Science and Values - A Brief Introduction to the Framework ................... 14

III ISSUES WITH USING SCIENCE TO INFORM POLICY ................................. 15

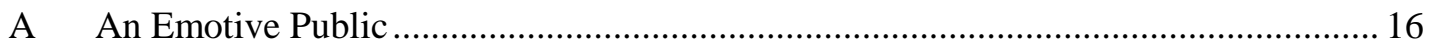

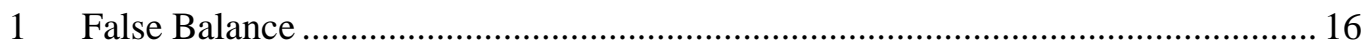

2 Abundance of, and Accessibility to, Information .............................................. 17

3 Knee-jerk Reactions Leading to Unnecessary Regulation..................................... 19

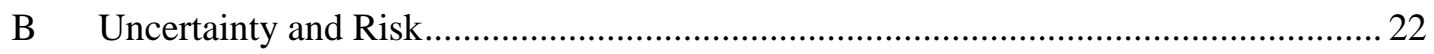

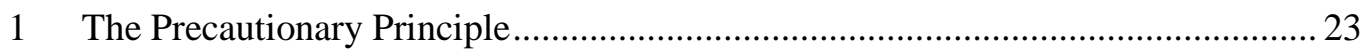

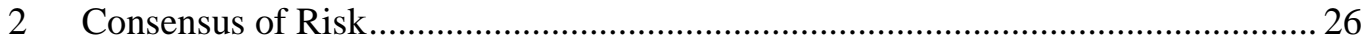

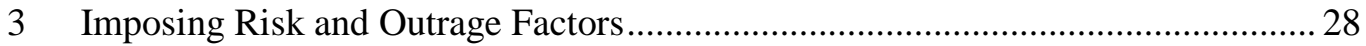

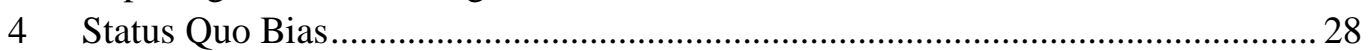

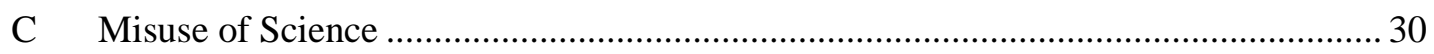

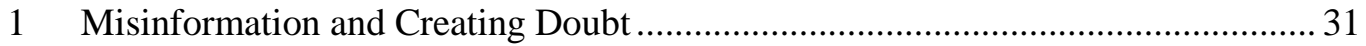

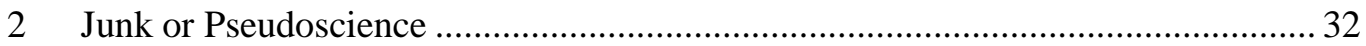

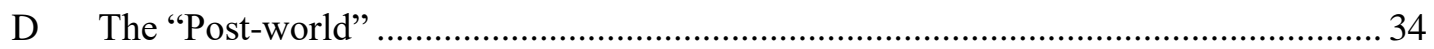

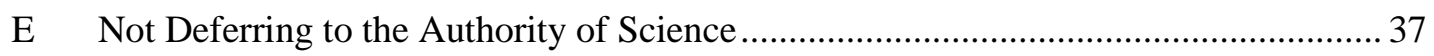

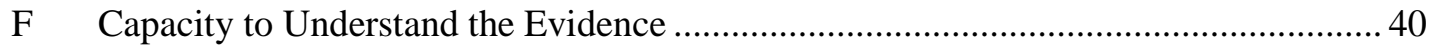

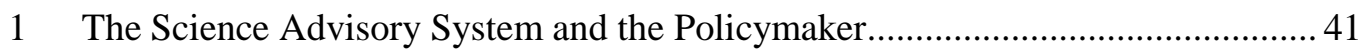

2 The Information Deficit Model ............................................................................. 42

IV VACCINE HESITANCY, BARRIERS, POLICY AND THE TREATY ................ 45

A Common Global Problems Behind Vaccine Hesitancy …........................................... 47

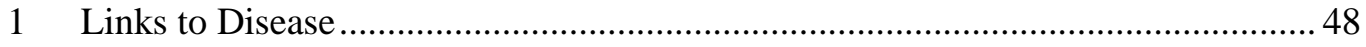

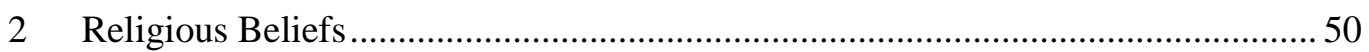

3 Distrust of Government and Medicine .................................................................5 52

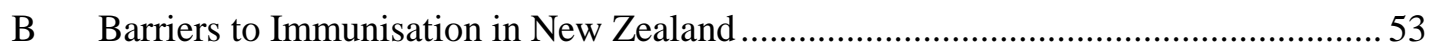

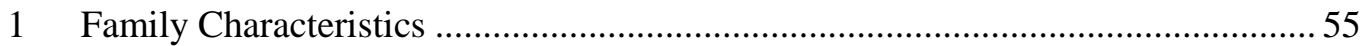

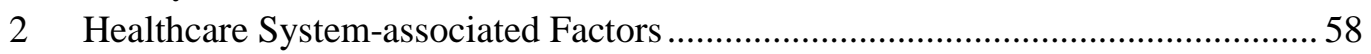

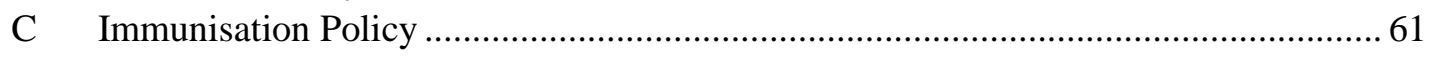

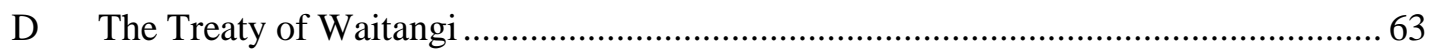

V DEVELOPING A DECISION-MAKING FRAMEWORK ..................................65

A Why it is Important for Policymakers to Understand Immunisation Coverage ............ 66 


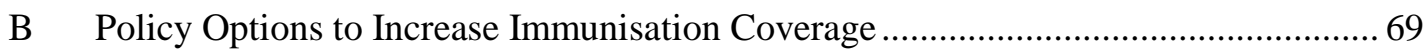

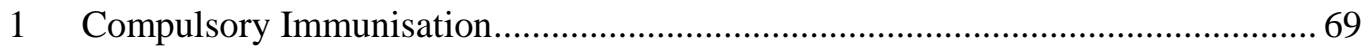

2 Linking Beneficiary Payments to Immunisation Status........................................ 70

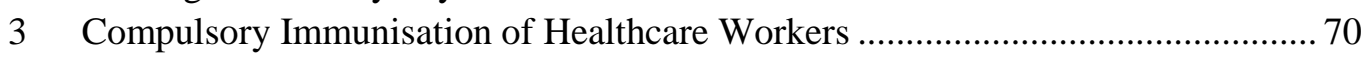

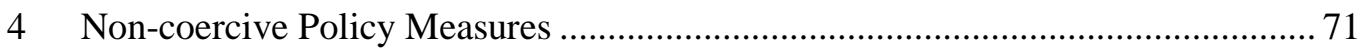

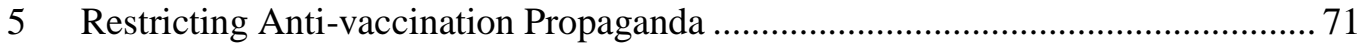

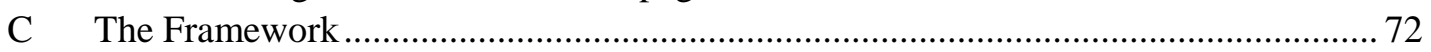

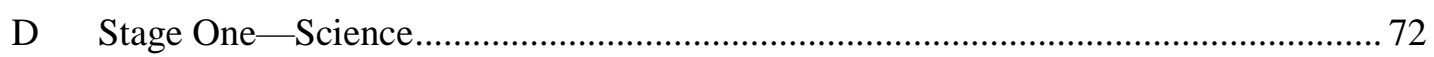

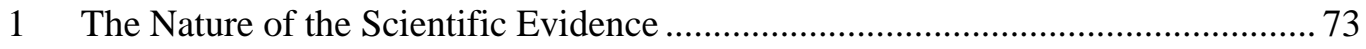

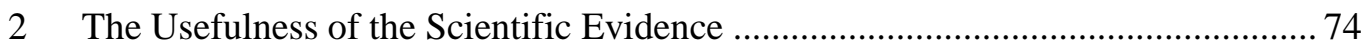

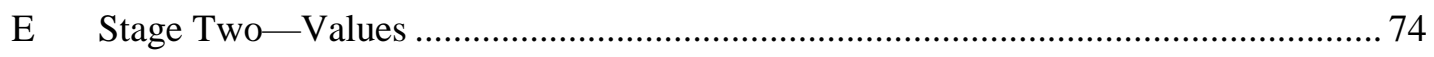

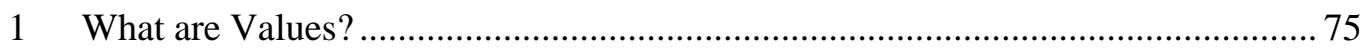

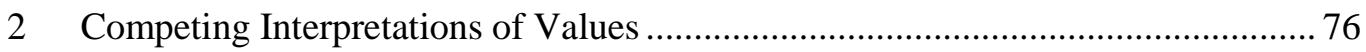

3 Making Use of the Courts' Interpretations of Values ............................................. 77

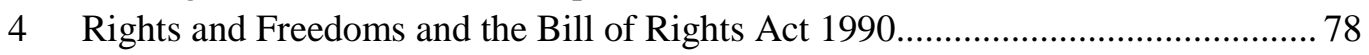

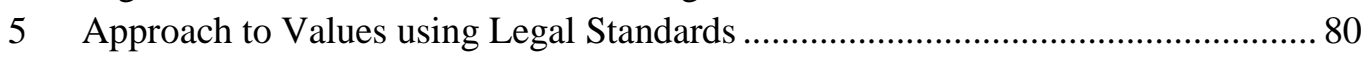

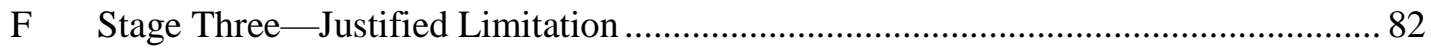

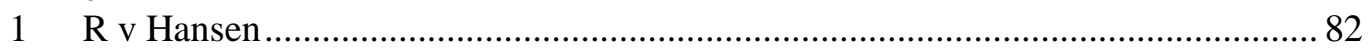

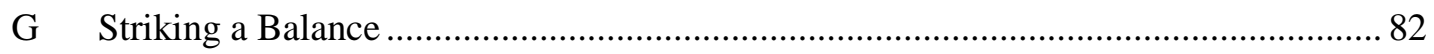

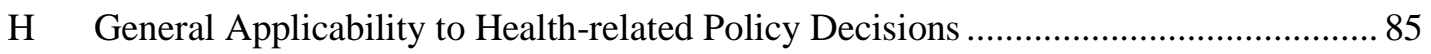

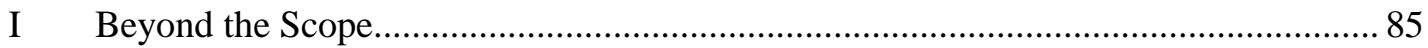

VI STAGE ONE: SCIENCE AND IMMUNISATION POLICY ................................... 86

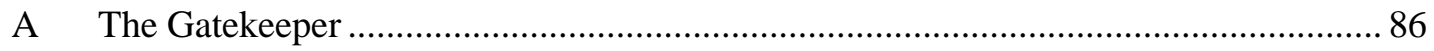

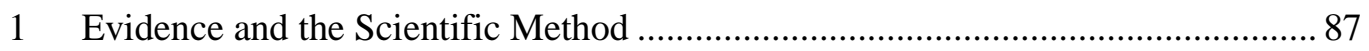

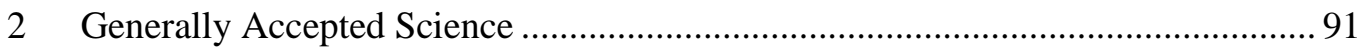

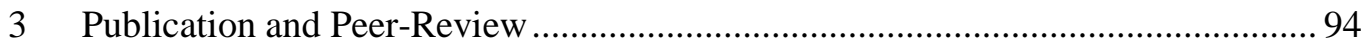

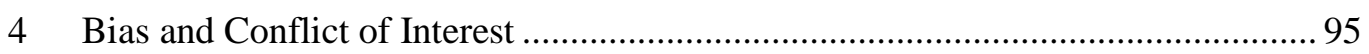

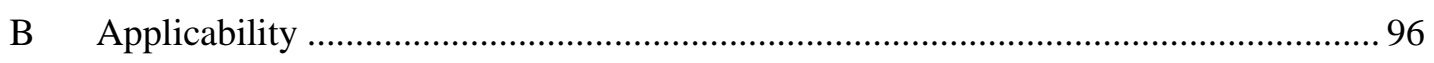

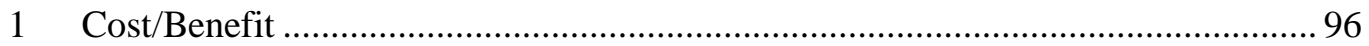

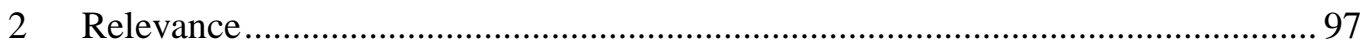

VII STAGE TWO: VALUES AND IMMUNISATION POLICY ................................99

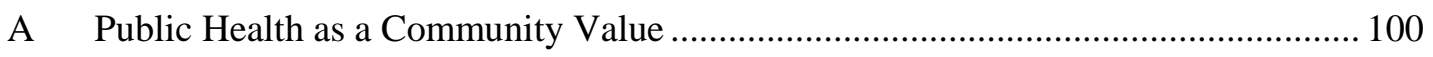

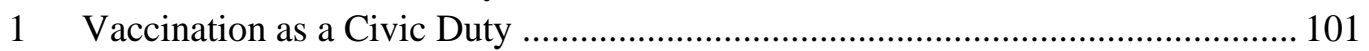

2 The Good Samaritan ........................................................................................ 103

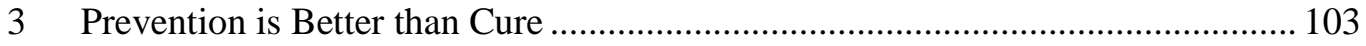

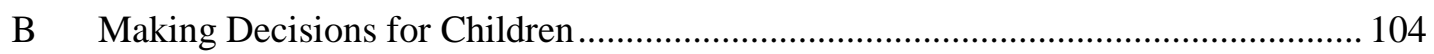

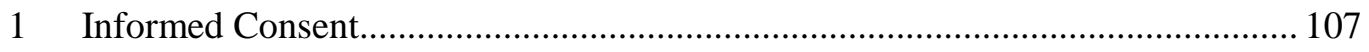

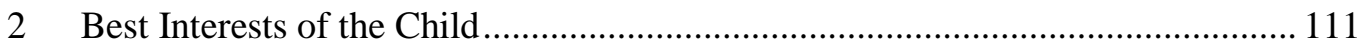

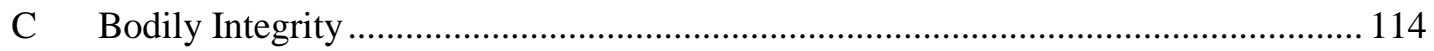

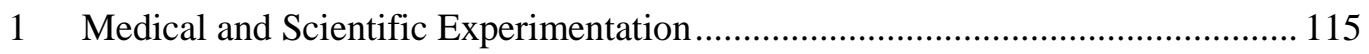

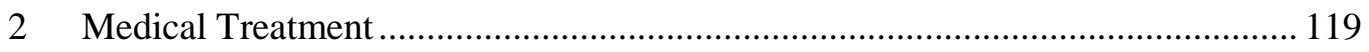

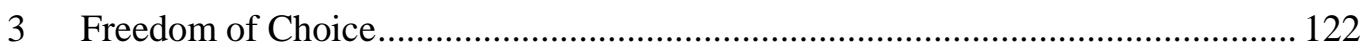




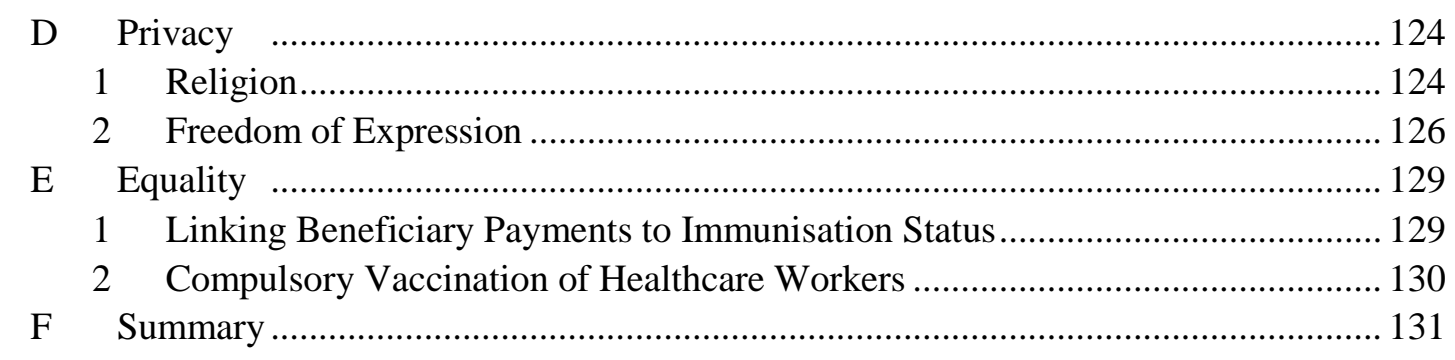

VIII STAGE THREE: JUSTIFIED LIMITATIONS ..................................................... 132

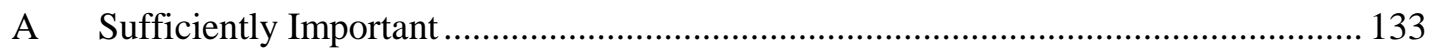

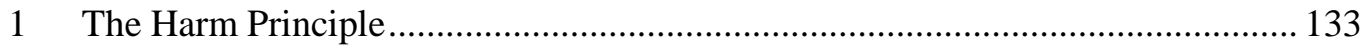

2 Different Diseases Require Different Approaches.............................................. 135

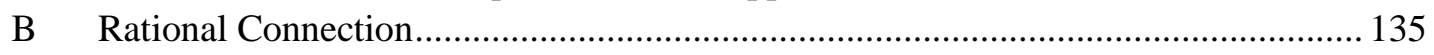

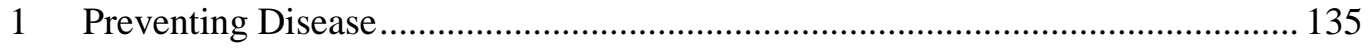

2 Targeting Subgroups of the Population …….................................................. 136

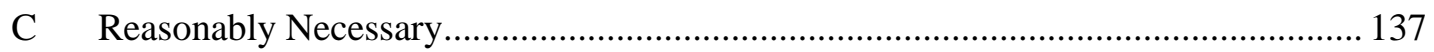

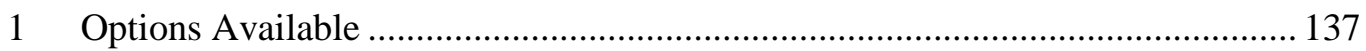

2 Police Powers During Times of Emergency ................................................... 138

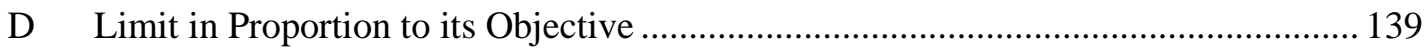

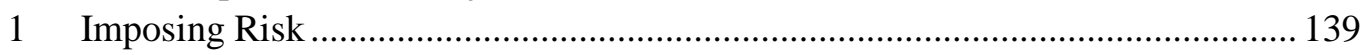

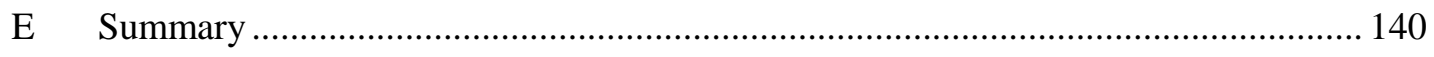

IX CONCLUSION ...................................................................................................................... 142

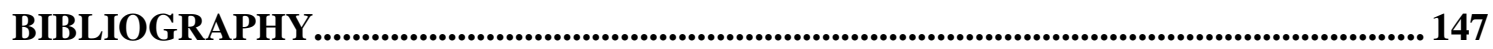




\begin{abstract}
This thesis examines the incorporation of science into public health policy/law. The key problem that the thesis tackles is the blurring of science and values arguments in the creation of policy/law. To overcome this problem, a decision-making framework is proposed that draws a distinction between arguments based on science and those based on values. The framework suggests categorising science as information obtained by adherence to the scientific method. Values, then, are those legally protected rights, freedoms and principles that do not follow scientific methodology. Examples include public health as a community value, informed consent, freedom of choice, and religious beliefs. The idea is that the acquisition of scientific knowledge through the scientific process provides the platform from which debate about values can begin. It is acknowledged that scientific methodology does not entail an absence of values, and the reality may be the separation is more of a continuum than two distinct groups. The shorthand labels (values and science) are used for functional purposes to describe the stages of the proposed framework. There are three stages to the framework. The first stage acts as a gatekeeper, preventing nonscientific components being confused with science. The second stage addresses values, particularly rights and freedoms protected by law. The third stage looks at whether a health policy option (which could involve new law) that restricts existing rights protected by law can nevertheless be justified. Examples relating to the immunisation of children are used to help describe how the framework could work when applied to a real-world public health policy issue.
\end{abstract}

\title{
Word Length
}

The text of this paper comprises approximately (not more than) 50,000 words excluding the bibliography.

\section{Subjects and Topics}

Health Law-Health Policy-Human Rights Law-Science 


\section{Acknowledgements}

I thank my supervisors, Kate Tokeley and Bill Atkin for their expertise and guidance, Elizabeth Pishieffor always emphasising the importance of different cultural perspectives, Stam Pishief for discussion of his first-hand experience in the medical field, Justin Pishief for being there to bounce ideas off in the early stages, and Kate Hooper and family for looking after the little fella when needed. Lastly, I thank Lolly and Leonardo. If it were not for Lolly, Leonardo would never have come to be, therefore, discussion at antenatal classes would not have eventuated, and, consequently, nor would have this thesis. 


\section{Introduction}

Nothing but the natural ignorance of the public, countenanced by the inoculated erroneousness of the ordinary general medical practitioners, makes such a barbarism as vaccination possible .... vaccination is nothing short of attempted murder. A skilled bacteriologist would just as soon think of cutting his child's arm and rubbing the contents of the dustpan into the wound, as vaccinating it in the same. ${ }^{1}$

This thesis examines the theoretical and practical ideas associated with the use of science to inform public health policy ${ }^{2}$ and provides a decision-making framework for policymakers. The term "policymaker" is used as a catch-all to describe both policymaking and law-making agents and relevant agencies involved in government decision-making processes. The immunisation debate and issues surrounding the New Zealand Government's role in the immunisation of children provides an excellent illustration of the challenges of using science to inform policy. For this reason, immunisation of children is used as an example to describe and explore the framework when applied to a real-world policy debate. In this scenario, it is imagined that the Government is considering a range of options to improve immunisation coverage, including whether legislative intervention is justifiable.

Childhood vaccination programmes are among the most cost-effective health strategies for the prevention of disease. ${ }^{3}$ Nevertheless, views like that espoused by George Bernard Shaw (above) continue to flourish. ${ }^{4}$ New Zealand has historically had poor immunisation

\footnotetext{
${ }^{1}$ George Bernard Shaw. Excerpt from a letter from George Bernard Shaw to Charles Gane (Secretary of the National Anti-Vaccination League) regarding vaccination policy (22 February 1906).

${ }^{2}$ Public health policy in this thesis refers to population-based public health interventions initiated by the State and includes both coercive (hard vaccination laws) and non-coercive (soft policy) measures.

${ }^{3}$ Centers for Disease Control and Prevention ("CDC") "Ten great public health achievements-United States, 1900-1999” (1999) 48(12) Morb Mortal Wkly Rep 241-243.

${ }^{4}$ See, for example, Lena Sun "Trump energizes the anti-vaccine movement in Texas" The Washington Post (online ed, Washington, 20 February 2017); see also, Charitha Gowda and Amanda Dempsey "The rise (and fall?) of parental vaccine hesitancy" (2013) 9(8) Hum Vaccin Immunother 1755-1762; GL Freed and others "Parental vaccine safety concerns in 2009" (2010) 125 Pediatrics 654-659.
} 
coverage and has shown disparity in vaccination rates among ethnic groups. Particularly, Māori and Pacific children and children from areas of poverty have shown the lowest immunisation coverage. ${ }^{5}$ Additionally, New Zealand continues to experience outbreaks of vaccine-preventable diseases, particularly pertussis ${ }^{6}$ and mumps. The Auckland Regional Public Health Service reports that approximately 1000 people contracted mumps in 2017 and states that low immunisation rates are fuelling the outbreak. ${ }^{7}$

Debate about how best to protect children from vaccine-preventable diseases is not new and raises difficult considerations for governments. These considerations include striking the right balance between individual and communal rights and State obligations. This balancing exercise includes finding a way to protect human rights, particularly the rights of parents to bring up their children how they see fit, bearing in mind their religious, ethical, cultural, and medical beliefs, and a government's responsibility to promote the health and well-being of its citizens.

While there can be a strong urge to defer to the authority of science to provide a solution to the polarising topic of immunisation of children, how best to incorporate science into public health policy is a challenge. Simply stating that there is scientific consensus that vaccines are safe and effective therefore compulsory immunisation is required is not an adequate response to such a morally complex topic. Nor does such an approach provide room for the incorporation of values that individuals and society hold dear. These are those values that are not grounded in scientific thought and process, that do not always have logical or rational components, and that are not always agreed among individuals.

\footnotetext{
$\overline{5}$ Cameron Grant and others "Eliminating ethnic disparities in health through immunisation: New Zealand's chance to earn global respect" (2009) 122(1291) NZ Med J 6-9; Ministry of Health "The National Childhood Immunisation Coverage Survey 2005" (Ministry of Health, Wellington, April 2007); Juliet Rumball-Smith and Timothy Kenealy "Childhood immunisations in Northland, New Zealand: declining care and the journey through the immunisation pathway" (2016) 129(1438) NZ Med J 15-21.

${ }^{6}$ Institute of Environmental Science and Research "Pertussis Report 14 October-10 November 2017" <www.surv.esr.cri.nz>.

${ }^{7}$ Auckland Regional Public Health Service "Managing the mumps outbreak" <www.arphs.govt.nz>.
} 
The term "values" is used as shorthand to describe legally protected rights, freedoms and principles. This definition includes informed consent, religious beliefs, public health as a community value and cultural factors, such as the Māori worldview, which is crucial in New Zealand, particularly in the context of the New Zealand Government's obligations in its partnership with Māori under the Treaty of Waitangi. Further, values are not only the values of the individual but are also communal or group values.

The term "science" is used as shorthand to describe knowledge obtained through adherence to the scientific method. The key identifier of science is the production of information derived via the scientific method. This is not to say that there is never values within the production of science; separating science and values does not entail an absence of any values that are inherent within the scientific method. The reality may be that the separation of science and values is more of a continuum than two distinct groups. The shorthand labels (values and science) are used for functional purposes for the two relevant stages of the policy process described in this thesis.

The term "policy" is used as shorthand and encompasses the policy process to a small degree and soft policy initiatives that flow from such (for example, removing barriers to vaccine uptake) as well as possible legislative intervention to increase vaccine coverage (for example, State-mandated vaccination). The mechanisms of the policy process are not canvassed in any real detail; the focus being on the development of the decision-making framework.

A chief difficulty with using science to inform public policy is that science, on its own, cannot provide a satisfactory and complete answer to a policy question. Even in an area where science is crucial, there are likely to be moral, ethical, and philosophical considerations that are beyond the capacity of science to answer. Science can tell us, with a degree of uncertainty, how the world is, but it cannot answer those normative questions that influence human views and behaviour. 
Adding a further layer of complexity to the challenge facing the policymaker is the changing socio-political environment in which a post-truth, post-trust, post-elite worldview is gaining momentum, and the changing nature of knowledge production and dissemination. This concept suggests that people are no longer looking to traditional sources of knowledge and authority (including both Western medicine and indigenous views and practices) to help guide health-related questions. Instead, there is a sense that, because of the vast tracts of information readily available, expert knowledge provides no better guidance than can be discerned from a layperson's own reading. When the problem is framed in terms of a person's own experiences and beliefs, it can be thought that expert judgment has nothing to offer.

People rightly expect to take part in decisions that impact their lives and that policymakers are honest and transparent with the information they are using to inform decisions. In democratic societies, policies are legitimate and accepted if they are justified and respectful of individual and group rights, ${ }^{8}$ and, if they use scientific evidence, then that evidence must be robust and reliable. Importantly, though, as argued in this thesis, the scientific evidence should not be thought of as being determinative; it does not trump all other considerations.

Governments must be aware that the implementation of policy, whatever form that may take-whether promoting vaccines, increasing access to vaccine providers, legislating for compulsory immunisation of all, or targeted immunisation of subgroups - throws up difficult legal issues, including compatibility with existing laws and international obligations, and legal principles. These legal and policy implications can have spill-over effects that impact on wider individual or group rights and freedoms.

These factors create a very real tension when trying to achieve the right balance of science and values in policy and law. On one hand, policymakers must avoid a situation in which

${ }_{8}^{8}$ David Budtz Pedersen "The political epistemology of science-based policy-making” (2014) (51) Soc Sci Public Policy 547. 
experts rule over society, a term called "epistocracy" by David Estlund. ${ }^{9}$ On the other hand, measures are needed to prevent vulnerability towards irrational behaviour and the influence of special interest groups who promote their own agenda at the expense of the health and well-being of others.

The thesis begins by discussing problems associated with the science-policy-society interface that require consideration when seeking to use science to inform policy. Several issues are canvassed, including: an emotive public and the abundance of information; kneejerk reactions and unnecessary regulation; uncertainty and imposing risk; misuse of science, misinformation and creating doubt; and not deferring to the authority of science. How these problems manifest in the immunisation debate is then considered. This includes looking at the drivers behind low immunisation coverage and vaccine hesitancy. Some of the current policy initiatives aimed at increasing immunisation coverage are then outlined. Following this, the Government's obligations under the Treaty of Waitangi in the context of Māori health are outlined.

A three-stage framework is proposed that addresses these problems and provides guidance to policymakers to help them avoid potential pitfalls. These potential pitfalls, if not avoided, undermine the use of science in policy, the public's trust in both science and policy, and, importantly, the policy itself.

The framework aims to prevent values from either directing scientific knowledge (using values to guide conclusions about scientific data) or being confused with science (mixing scientific and values arguments together). The idea is that the acquisition of scientific knowledge through the scientific process provides the platform from which debate about values can begin.

The first stage of the framework requires the policymaker to consider the nature of the scientific evidence. This is a two-limbed examination comprising a gatekeeper analysis and

\footnotetext{
${ }^{9}$ Ibid, discussing David Estlund Democratic Authority: A Philosophical Framework (Oxford University Press, Oxford, 2011).
} 
an assessment of the applicability of the evidence to the problem. This approach prevents the inclusion of misinformation, poorly conducted science, or pseudoscience from guiding policy decisions and assures the policymaker that only the most reliable and relevant science is being used.

This stage also prevents values from impacting on the validity and usefulness of the science. This is achieved by examining how scientific knowledge is collected. By grounding the assessment of scientific evidence in an examination of scientific process, values are removed to their rightful place: the second stage of the framework.

The second stage of the framework is an examination of values and involves moral, ethical, and philosophical considerations framed within the existing structures of law that govern the interactions between the State and its citizens. This analysis also includes consideration of the impact of legal intervention, including the benefits and limitations of scientific evidence to inform legislative options.

As values are written into law in many cases (for example, human rights legislation), any course of action determined by the policymaker must be considered against this background. It is noted that while there are circumstances in which an action could be contrary to the Bill of Rights Act 1990 and still be legitimate, they do require careful consideration. To this end, common arguments in the immunisation debate are pinned to statutorily protected rights and freedoms. Arguments include those grounded in personal autonomy and bodily integrity; for example, not being subject to scientific or medical experimentation without consent, and the right to refuse to undergo medical treatment. This stage identifies whether, prima facie, a right or freedom is being impinged by proposed legislative intervention.

The third stage of the framework considers whether an immunisation policy that imposes limits on rights or freedoms protected by law can nonetheless be demonstrably justified in a free and democratic society. 
Sheila Jasanoff writes: "The strength of the common-law system historically has been to promote the integration of expert knowledge with lay perceptions of facts and values." is how this integration can be made in the public health policy environment, particularly the consequences of legislative tools, that this thesis examines. Better policy decisions will be made by applying this three-stage framework to the use of science to inform policy.

Differentiating science from values and examining the fundamental characteristics of each in isolation means that there will be no blurring of boundaries, nor will one usurp the other; for example, deferring to the authority of science to answer complex questions with strong values components. It also means that the policymaker correctly examines all pertinent considerations relevant to the problem being addressed. Such an approach should allow for better policy decisions to be made in this changing world where the complexity of science is intertwined with disputed and controversial values.

This thesis does not seek to provide an answer to the best way to protect children from disease. It does not argue for or against compulsory immunisation or immunisation of select subgroups of the population, nor does it suggest changing the New Zealand model from an opt-in model to an opt-out model ("informed choice") ${ }^{11}$ as seen in other countries. What this thesis does examine are the principles, concepts, and complications associated with the use of science to inform policy. It seeks to draw the policymaker's attention to those factors that require careful consideration when determining immunisation policy, and it discusses the difficulties associated with the incorporation of science into policy.

\footnotetext{
${ }^{10}$ Sheila Jasanoff "Knowledge elites and class war" (1999) 401 Nature at 531.

${ }^{11}$ Jessica Kerr "Immunisation and the law: Slippery slope to a healthy society" (LLB(Hons) Dissertation, Victoria University of Wellington, 2005) at 38-55.
} 


\section{The Interface Between Science, Society, Policy and Law}

This chapter provides an overview of the science, society, policy and law interface. Topics discussed are science and public health policy, post-normal policymaking, and blurring science and values arguments. How to separate science and values in policy and lawmaking - the key idea in this thesis - is then outlined by way of a brief introduction to the framework proposed.

Before beginning to discuss how science can inform policy, and consequently shape legislative initiatives, a rational connection between the two is required. In its simplest form, this connection can be made by saying that science is what we know (or perhaps more accurately, what we think we know) and policy is the process by which we decide what we ought to do with this knowledge. While it appears a simple connection, resolving the problems thrown up by these two components - the "is" (science) and the "ought" (policy/law)—is anything but.

The incorporation of well-developed scientific evidence should lead to better decisionmaking and outcomes. After all, science has the potential to greatly improve life on earth, if used appropriately. Further, as science is being viewed in a more utilitarian way, governments are investing more in science, and, consequently, they are expecting more in return to help guide policymaking. ${ }^{12}$ However, despite this increasing interest in the use of science to inform policy, ${ }^{13}$ when science is poorly applied or misused in the policy process it can result in bad decisions and undesirable outcomes, ${ }^{14}$ particularly when the policy has a real-world application and impact on people's lives. ${ }^{15}$

\footnotetext{
${ }^{12}$ Peter Gluckman "Scientific advice in a troubled world" Office of the Prime Minister's Chief Science Advisor <www.pmcsa.org.nz>.

${ }^{13}$ OECD Scientific advice for policy making: The role and responsibility of expert bodies and individual scientists (OECD Publishing, Paris, 2015).

${ }^{14}$ Roger Pielke Jr The Honest Broker: Making Sense of Science in Policy and Politics (Cambridge University Press, Cambridge, 2007) at 38.

${ }^{15}$ Ibid.
} 


\section{A Science and the Public Health Policy Process}

Public health policy is often misunderstood as involving a direct and linear link between scientific evidence and the formation of policy. ${ }^{16}$ Because the same virtues that make science work are the same as those that make democracy work, ${ }^{17}$ it is tempting to think that science should be assimilated uncontested into the policy process and provide sound policy. However, this is wrong both in practice and in principle.

The policy process is not simple and linear. It is complex and messy and involves a multitude of actors with ill-defined roles, often with competing interests, that form around an issue, all set within existing political structures. ${ }^{18}$ Some of these competing interests include public opinion, costs, experience, political ideology and evidence. ${ }^{19}$ Further, advancements in science and technology, the increasing number of people doing science, and the skyrocketing number of scientific journals all combined with the internet's ability to disseminate information at a rapidity not seen before create new problems for "evidencebased" guidance for policymaking. ${ }^{20}$

Complexity increases for issues that are perceived to be controversial or emotive, and the trade-off between competing interests can result in a diminished use of scientific evidence. ${ }^{21}$ Immunisation of children is one such issue, where science is frequently considered to take a back seat because it is perceived as interfering with rights and

\footnotetext{
${ }^{16}$ Paul Cairney The Politics of Evidence-based Policy Making (Macmillan Publishers, London, 2016) at 51.

${ }^{17}$ Jasanoff lists these values to be "a commitment to reason and transparency, an openness to critical scrutiny, a scepticism towards claims that too neatly support reigning values, a willingness to listen to countervailing opinions, a readiness to admit uncertainty and gathering according ignorance, and a respect for evidence to sanctioned best practices of the moment." Sheila Jasanoff "The sound conduct of science and the sound conduct of democracy both depend on the same shared values" (17 February 2009) <www.seedmagazine.com>.

${ }^{18}$ Peter Gluckman "How science informs current thinking in government" Office of the Prime Minister's Chief Science Advisor 〈www.pmcsa.org.nz>.

${ }^{19}$ M Bulmer and others "Evidence-based policy making" in H Bochel and S Duncan (eds) Making policy in theory and practice (Policy Press, Bristol, 2007) at 87-102.

${ }^{20}$ OECD, above n 13.

${ }^{21}$ Helen Wilson and George Thomson “'Balancing acts': The politics and processes of smokefree area policymaking in a small state" (2011) 101(1) Health Policy 79-86.
} 
freedoms. Notwithstanding strong evidence and consensus among the science community on the benefits of vaccines, immunisation is a topic where strongly held beliefs impact the way that vaccine science is disseminated, understood, and incorporated into policy decisions.

Adding a further layer of complexity is the ever-increasing global community. Issues now cross borders, so that multinational scientific cooperation to address problems requires input from myriad stakeholders.

This messy and often unpredictable policy process means that there is no single point at which to inject scientific evidence into the policy cycle. ${ }^{22}$ Science can help define the problem, determine how best to generate evidence, and identify and evaluate options. ${ }^{23}$ However, each stage of the process can be contested, and agents can present evidence to influence the policymaker at each stage.

Further, the decision to take a policy initiative through to the development of legislation is a complex and time-consuming process. Numerous steps are required, and the process involves many agencies and actors. These participants will all have different understandings of the usefulness of science. They will also interpret science differently or promote the science that best supports their preferred course of action.

Ultimately, public health policy is about choosing between different options that will have different implications for different groups of people, with the policymaker standing as the final decision-maker. To fulfil this role, they must understand the benefits and limitations of scientific evidence and, importantly, must balance that evidence with other significant factors, such as public sentiment on the issue.

\footnotetext{
${ }^{22}$ Paul Cairney "The politics of evidence-based policymaking” The Guardian (online ed, United Kingdom, 10 March 2016).

${ }^{23}$ Cairney, above n 16, at 53.
} 
The science-policy interface is therefore not simply how best to use science to inform policy but a complex set of interactions between the science community and policymakers, the science community and society, and policymakers and society.

The interaction between society and the science community is crucial. Discussions about science and policy would be incomplete without including interactions between science and society. Policy is not made and does not operate in a vacuum. Good policy decisions reflect the collective values and ideals of society and society's ideas about science and its implications.

Science may be able to guide on many issues that society wants addressed; however, it ought not to be determinative for issues where there are divergent worldviews, beliefs, and values or complexity in the science itself. Immunisation, fluoridation of water, climate change, genetic modification and gene editing are some of the contentious issues that have both strong science and values components that have resulted in a lack of agreement among members of society.

For childhood immunisation strategies, policy that uses science to inform the public of the dangers of failing to vaccinate a child is less contentious than legal intervention that enforces a scientific position. This is particularly so where national surveys have identified subgroups of the population as being more at risk.

The task facing the policymaker is how to implement immunisation strategies without treading on legally protected rights or going against established legal principles. Importantly, in the New Zealand context, any strategy must be designed within the framework of existing legal structures; for example, in accordance with the principles of the Treaty of Waitangi. ${ }^{24}$

\footnotetext{
${ }^{24}$ Treaty obligations and health policy are discussed further at Chapter IV(D).
} 
Legal policy and mechanisms play a distinct part not just in implementation of policy, but checks against legal principles, other legal rules, rights and freedoms contained within the Bill of Rights Act 1990 as well as other vetting process and administrative law. These ideas are picked up in detail in the later chapters.

\section{B Post-normal Policymaking}

The combination of complex and incomplete science with many uncertainties and strong public interest where opinions are divided are characteristics of what has been termed "post-normal policymaking", an extension of "post-normal science". 25 A post-normal approach calls for greater public deliberation on the assessment of risk as part of the wider public discussion on science in policymaking. ${ }^{26}$

Topics that fall within the ambit of post-normal require a different approach from those involving linear or reductionist science. The linear model of science can still offer guidance in many instances, but with science increasing in complexity and uncertainty, and the changing environment in which there is a plurality of legitimate social perspectives, the policy-science-society interface is becoming increasingly complex. ${ }^{27}$

A distinction can be made between the science of immunisation and vaccines, and vaccine hesitancy. The science of immunisation and vaccines could be classed as linear science: the cause and effect resulting from the initiation of the immune system in response to the introduction of an antigen (vaccination) is generally well understood and accepted, although it is, at times, complex. Vaccine hesitancy, the drivers behind the reluctance of some people to have their children immunised, however, could better be classified as requiring a "post-normal" approach: the science can be complex, the reasons for hesitancy are multifaceted, and values judgments play a determinative role.

\footnotetext{
${ }_{25}$ The term "post-normal science" was first described in Silvio Funtowicz and Jerome Ravetz "Science for the post-normal age" (1993) 25(7) Futures 739-755.

${ }^{26}$ Mary Footer "Post-Normal Science in the Multilateral Trading System: Social Science Expertise and the EC-Biotech Panel” (2007) 6 World Trade Rev 280 at 297.

27 Peter Gluckman "Towards better use of evidence in policy formation: a discussion paper" Office of the Prime Minister's Chief Science Advisor <www.pmcsa.org.nz> at 3.
} 
Dramatic changes in both the nature of knowledge production and changes in society require the policymaker to understand the complexities and problems that stem from the changes in these distinct but intertwined social constructs. Failure to do so can only result in poor decision-making and inadequate policy or law.

\section{Blurring Science and Values Arguments}

What this thesis attempts to resolve is the blurring of science and values arguments in the immunisation debate. Some issues, like immunisation, include both science and values components but the boundaries can be blurred and misunderstood by the public. Arguments that are prima facie directed at the science are better described as arguments about the conflict between individual or communal rights and values and how the State treats its citizens. For example, those attacking immunisation programmes argue about the safety ${ }^{28}$ and efficacy of vaccines and claim the dangers of vaccines are being clouded by "Big Pharma" who collude with governments to deceive the public. These arguments are not based on scientific evidence, they are about individual cultural values and beliefs, but can also include misunderstandings about the nature of science. They involve ideas about freedom of choice, bodily integrity, preventing the introduction of foreign material into the body without consent, the limits of State intervention and regulation, and forced medical procedures.

Vaccine hesitancy is a topic where a person's own moral values impact on the way the individual views the issues. Moral values, like science, can provide information about the world and guide behaviour. We change our behaviour as we learn more about the world and about right and wrong. Science tells about the pathology of disease and the principles of immunisation. Vaccine hesitancy, like science, is a social construct that varies across time and cultures. The important distinction to make, however, is that unlike science, the rules guiding moral or collective cultural values, in this case, vaccine hesitancy and its

\footnotetext{
$\overline{28}$ There have been incidents throughout history in which vaccine safety has been called into question. These incidents have strengthened the regulatory processes around the manufacture, testing and monitoring of vaccines, consequently increasing safety. The prime example is the Cutter Incident in 1955.
} 
implications, vary from individual to individual and among ethnic groups and are rarely agreed among members of society. The rules guiding science, however, provide a model where consensus can be reached, but only on the scientific component of vaccines.

\section{$D$ Separating Science and Values-A Brief Introduction to the Framework}

The separation of science and values raises questions that require careful thought and deliberation. For example, what is the best way to use evidence in policy, how can false, misleading, and manipulated evidence be prevented from being used in policy, and how can non-science factors relevant to policy be included. This thesis proposes a framework that addresses these topics.

The framework promotes clear separation of science and values and tasks the policymaker with examining each component in isolation. First the policymaker checks the quality of science that could be used to inform policy-ensuring only robust, evidence-based, and agreed science enters policy decisions. Second, the values that are important to individuals and society, such as freedom of choice, religious beliefs, and the health and well-being of children are considered. Finally, the policymaker considers whether a policy option that impinges rights and freedoms is nevertheless justified as a legitimate public health measure.

It is not possible to make good policy decisions that accommodate the interests of every single stakeholder. Divergent political and societal views mean that disagreement is likely on the best course of action. However, use of the framework will alert policymakers to the pitfalls and benefits of using science to inform policy and, importantly, of the values impacting immunisation decisions. Further, they will have correctly turned their mind to all relevant factors. Therefore, they are more likely to make the best decision possible on the available evidence, both scientific and societal. 


\section{Issues with using Science to Inform Policy}

This chapter is a collection of issues relevant to the science-policy-society relationship that can be troublesome. These issues underpin the problems associated with the sciencepolicy-society interface and go some way to explaining why it can be difficult to create good policy.

The issues are not specific to immunisation but are generally applicable to all policy questions at the science-policy-society interface. All decisions regarding the incorporation of science into policy must address these issues in one form or another. The issues manifest differently depending on the topic. For example, problems specific to immunisation arising from the issues are readily identifiable in the following chapter on international and national drivers behind vaccine hesitancy and low immunisation coverage. Once recognised, it is how these issues manifest in the immunisation debate that the framework seeks to resolve.

Some of the issues will be generally applicable across the policy ecosystem and will therefore be useful for policy other than immunisation; however, specific questions require specific analysis. For example, determining policy to increase immunisation coverage requires a different approach to, say, tackling the growing obesity epidemic. Although both are health-related questions, the former addresses the multifactorial drivers behind vaccine hesitancy and barriers to vaccine uptake, while the latter involves careful consideration of economic implications of options, a sugar tax, for example. However, both involve an understanding of how science can be used to inform policy decision-making.

A further point to note is that the issues do not always sit comfortably under one subheading as grouped in this chapter but may be relevant across many. This could perhaps be indicative of the intertwining nature of those factors requiring consideration and the complexities of the policymaking process. 


\section{A An Emotive Public}

Subjective and emotive opinions exist on the topic of childhood vaccinations. Parents, both those supportive of vaccination programmes and those opposed, are motivated in their choices by nothing other than what is in the best interests of their children. Policy arguments that are heavily reliant on scientific assessment and rational judgments about risk cannot easily accommodate emotive public reactions and understandings about vaccines.

There are many inter-related factors that contribute to the emotionalization of public perceptions of vaccines and immunisation programmes. How immunisation is portrayed in the media and the abundance of information freely available on the internet are two particularly problematic factors. These factors can influence public understanding and belief about vaccines and may act as a catalyst for calls for legislative action. However, knee-jerk reactions by a government to an emotive public can result in more harm than good. These points are discussed below.

\section{$1 \quad$ False Balance}

An emotive public can be influenced by how science is communicated in the media. Sensationalist media reporting of vaccine-related issues can have undesirable effects on the popular imagination, none more so than "false balance". False balance is a term used to describe a situation where the media present opposing opinions on a topic in an attempt to remove the appearance of bias in reporting. However, this approach can be misleading and can be particularly harmful to topics of public importance. While balance is an important journalistic norm, ${ }^{29}$ false balance can occur when a viewpoint supported by an overwhelming body of evidence is presented alongside another viewpoint with less or no supporting evidence. False balance creates the erroneous impression that there is debate or scientific uncertainty on a topic. This allows special interest groups to cherry-pick the

\footnotetext{
${ }^{29}$ Chris Clarke "A question of balance: The autism-vaccine controversy in the British and American elite press" (2008) 30 Journal of Science Communication 77-107.
} 
science that suits their cause and disseminate weak viewpoints. ${ }^{30}$ This is particularly relevant to vaccination science, where promoters of anti-vaccination or "pro-choice" can paint a misleading picture of the science. ${ }^{31}$

The idea of equal time in the media for opposing sides makes sense for issues that are up for debate and no scientific consensus has yet been reached; however, it does not work in situations where commentators are voicing their opinion. Science is not about opinion; it is about evidence. It is about claims that can be and have been tested through research, experiments and observation. Research must have been critically reviewed by the scientific community. Statements that have either not gone through the process, or have been through it and failed, cannot claim to be scientific evidence. It follows that they do not deserve equal time in debates about science. ${ }^{32}$

A real problem with false balance is that it can pit the minority view against the overwhelming majority and give inappropriate media coverage to a point of view.

\section{Abundance of, and Accessibility to, Information}

Making the situation more difficult is the expansion of knowledge production over recent years. While the reasons for this expansion are complex, Gluckman writes that they are driven, in no small part, by the "expansion of the tertiary education sector worldwide and by the greater utilitarian expectations that governments place on the science enterprise". 33 The requirement for academics to publish research as the primary form of performance assessment in some universities has resulted in vast tracts of information being made

\footnotetext{
30 Shaun Hendy Silencing Science (Bridget Williams Books, Wellington, 2016) at 55.

${ }^{31}$ Cherry-picking is not limited to anti- or pro-vaccination groups. The same technique can be used by scientists either pushing their own agenda or by honestly but mistakenly including their personal values with the scientific advice they offer. This latter point is perhaps reflective of the lack of knowledge by some scientists in the policy-making process.

${ }^{32}$ Naomi Oreskes and Erik Conway Merchants of Doubt: How a Handful of Scientists Obscured the Truth on Issues from Tobacco Smoke to Global Warming (Bloomsbury Press, New York, 2010).

${ }^{33}$ Gluckman, above n 12.
} 
available that have minimal real-world impact, yet policymakers have to work their way through the jumble and separate the reliable from the unreliable. ${ }^{34}$

Another factor driving change at the science-society-policy interface is the accessibility of information in the increasingly networked world. Social media are behind some of the more difficult trends that policymakers must contend with. These include a decrease in the power of the State, loss of personal privacy and autonomy, and changing social structures. ${ }^{35}$ Increased accessibility to unmediated information has allowed both reliable and unreliable information to receive equal weighting on social media platforms, and because of the sophisticated nature and ubiquitous spread of information by special interest groups, it can be very difficult to discern legitimate science from non-science, or distinguish facts from alternative facts.

Manipulation for gain is nothing new, but in today's world, the process has simply become faster, easier, more persuasive. This means policymakers need to be aware of the impact that social media can have on political processes and policymaking.

Countering misinformation would appear a sensible option to increase public knowledge, and it is intuitive to think that doing so would help people make better decisions. However, pushing knowledge on people has been found to be counterproductive and can entrench those with divergent views. ${ }^{36}$ Furthermore, for many people, achieving peace of mind is more desirable than anxiety, even if the decision they make is based on incomplete or inaccurate information that is not backed up by the evidence. ${ }^{37}$

Improving decision-making, and therefore the outcome (better choices that maximise wellbeing), often requires improving the information on which decisions are based or improving the use of the information. In the context of immunisation policy, improving the

\footnotetext{
${ }^{34}$ Ibid.

${ }^{35}$ Ibid.

${ }^{36}$ Gluckman, above n 12.

${ }^{37}$ Pielke Jr, above n 14, at 26.
} 
use of information can be particularly challenging for policymakers because, putting aside emotive responses, there can exist conflict about the best way to achieve the desired outcome, this being protection from vaccine-preventable diseases.

Different stakeholders may each have different, yet legitimate, ideas on the benefits and desired outcomes of a course of action. For example, doctors may emphasise the benefits of vaccines without regard to the costs of the immunisation programme or individual rights. Governments, however, may find it desirable to expand or limit immunisation coverage to subsets of the population who are more vulnerable to disease, and for which benefits can be clearly observed, measured and promoted. Benefits include reduced costs of immunisation programmes and reduced costs associated with healthcare by avoiding disease compared with treatment and recovery.

\section{Knee-jerk Reactions Leading to Unnecessary Regulation}

Although some groups may voice loud and strong opinions and demand immediate responses to topical issues in the popular media, it is thought that the wider population favours flexibility and consideration of the implications of regulation, regardless of delays or other inconveniences. There is a very real problem with knee-jerk reactions to emotive situations. Paul Nurse, on the topic of nuclear power and proper assessment of the risks and benefits, observes: "It is not sensible to respond in a knee-jerk way without evaluation of data concerning real environmental damage and health risks, as against perceived damage and risks." 38

Unnecessary regulation can cause more harm, inadvertent harm, than good; it can create greater problems than it was enacted to alleviate. However, a government taking a precautionary approach without legislative action is enough to have a detrimental effect.

The human papilloma virus (HPV) vaccine was approved for clinical use in 2009 in Japan. A successful promotional campaign was conducted by the Japanese Ministry of Health,

38 Paul Nurse "The new enlightenment” (The Richard Dimbleby Lecture 2012, 28 February 2012). 
Labour and Welfare and vaccination rates reached $70-80 \%$ of the targeted age group by 2012. ${ }^{39}$ In April 2013, the HPV vaccine was added to the National Immunisation Program schedule for Japanese girls aged 12-16 years old. By June 2013, there were reports in the Japanese media concerning potential adverse effects claimed to be associated with the HPV vaccine, which created a strong state of public distrust. ${ }^{40}$ Despite finding no evidence to suggest the HPV vaccine was responsible, the Ministry issued a directive advising prefectural governors not to actively recommend the vaccine and to cease all HPV vaccine promotion. ${ }^{41}$ Consequently, immunisation rates dropped to $1 \%$.

Numerous studies have reported no association between the HPV vaccine and the claimed adverse events, particularly, complex regional pain syndrome. ${ }^{42}$ Yet, the decision in Japan has had a negative impact on HPV vaccine uptake not only in Japan but also in other countries. $^{43}$

The Japanese Government removing their recommendation may be seen as a sensible and practical response, allowing time for requisite testing and further studies to be conducted. However, such action causes concern among the public and is pounced on by antivaccination groups who use it as an example of the dangers of vaccines. ${ }^{44}$ The same was

\footnotetext{
${ }^{39}$ Yutaka Ueda and others "Japan's failure to vaccinate girls against human papillomavirus" (2015) 212 Am J Obstet Gynecol 405-406; SL Hanley and others "HPV vaccination crisis in Japan" (2015) 385 Lancet 2571; M Sekine and others "Japanese crisis of HPV vaccination" (2016) 2(2) Int J Pathol Clin Res 1-3.

${ }^{40}$ Masaaki Sawada and others "HPV vaccination in Japan: results of a 3-year follow-up survey of obstetricians and gynecologists regarding their opinions toward the vaccine" (2018) 23(1) Int J Clin Oncol $121-125$.

${ }^{41}$ Stuart Gilmour and others "HPV vaccination programme in Japan" (2013) 382(9894) Lancet 768; Heidi J Larson and others "Tracking the global spread of vaccine sentiments: the global response to Japan's suspension of its HPV vaccine recommendation" (2014) 10(9) Hum Vaccin Immunother 2543-2550. Interestingly, Gilmour notes that the Vaccine Adverse Reactions Review Committee voted 3:2 to suspend the HPV vaccine programme without presentation of adequate scientific evidence.

${ }^{42}$ See, for example, N Kash and others "Safety and efficacy data on vaccines and immunization to human papillomavirus" (2015) 4(4) J Clin Med 614-33; World Health Organisation ("WHO”) "Safety update of HPV vaccines" < www.who.int $>$.

${ }^{43}$ Rose Wilson and others HPV vaccination in Japan: The continuing debate and global impacts April 2015 (Report of the CSIS Global Health Policy Center) at 10-14.

${ }^{44}$ Wilson and others, above $n 43$, at 7 .
} 
seen with the removal of thimerosal (a mercury-based preservative) from vaccines in the United States. $^{45}$

Once a course of action is taken, regardless of best intentions, it can be very hard for authorities to backtrack and regain the trust of the public. As noted by the World Health Organisation, “... policy decisions based on weak evidence, leading to lack of use of safe and effective vaccines, can result in real harm." $" 46$

Heidi Larson, Director of the vaccine confidence project at the London School of Hygiene and Tropical Medicine, talking about the lack of confidence in the HPV programme in Japan, neatly sums up the themes relating to an emotive public: ${ }^{47}$

The dramatic drop in vaccine acceptance has been influenced by aggressive negative social media, mainstream media that has been biased towards the negative personal stories, as well as, and very importantly, the government not standing up for the vaccine and the vaccine science in the face of public anxiety and uncertainty.

What does all this mean for the policymaker? The policymaker should not be too quick to be swayed by emotive arguments for or against inclusion or exclusion of scientific evidence. This does not mean that public opinion has no place in the policymaking process. Regardless of how the public respond to a new media-hyped study, the goal of science is to provide dispassionate evaluation of (possibly competing) hypotheses to describe observed phenomena. The policymaker must act accordingly. A considered course of action provides a better result than a knee-jerk reaction to public pressure.

\footnotetext{
${ }^{45}$ CDC "Thimerosal in vaccines" <www.cdc.gov>.

46 WHO "Global Advisory Committee on vaccine safety statement on safety of HPV vaccines" (17 December 2015) <www.who.int>.

47 Ian Sample "Doctor wins 2017 John Maddox prize for countering HPV vaccine misinformation" The Guardian (online ed, United Kingdom, 30 November 2017).
} 


\section{B Uncertainty and Risk}

With the advances in science and technology and the impact they have on nearly every aspect of society, using science to inform policy is now more relevant than ever. However, because of the increasing complexity of the issues being addressed and the interactions between science, society, and policymaking, scientists have moved from providing certainties to only providing probabilities. Gluckman provides an explanation of the changing nature of science: ${ }^{48}$

... enormous computational and statistical advances [have changed] the nature of the scientific questions that can be asked. ... [T] oday's science is more about probabilities than certainties, ... Scientific findings are now being placed more and more into the context of social, environmental, ecological and human systems, where there remain many unknowns.

Because of the complicated policy environment, the uncertainty associated with postnormal science and policymaking, competing priorities of the decision-maker, and the speed at which decisions often need to be made, a full range of options with clear risks, benefits and outcomes is very rarely a reality for the policymaker. More often policymakers base decisions on ambiguous and uncertain knowledge. This is a central difference between the policy and science environments. Where scientist can fall back on the mantra "more research is required", policymakers do not always have this luxury. ${ }^{49}$

More research, paradoxically, can create more uncertainty. More science results in more papers being published and invariably results in more information being available to the policymaker who uses it to inform policy options. F David Peat explains: ${ }^{50}$

The ways we represent the world, in everything from language to art and science, deeply influence the ways we structure our world and understand ourselves. During

\footnotetext{
${ }^{48}$ Gluckman, above n 12.

49 Ibid.

${ }^{50}$ Pielke Jr, above n 14, at 66, as cited in F David Peat From certainty to uncertainty: the story of science and ideas in the twentieth century (Joseph Henry Press, Washington, DC, 2002) at 97-98.
} 
the twentieth century many of these means of representation underwent change from certainty to uncertainty, and today our world is more tentative and open to doubt and uncertainty.

Science by its very nature is uncertain, which provides ample opportunity for special interest groups to provide research that backs an argument for a competing interest, ultimately resulting in potential confusion for the policymaker. This means that, in some circumstances, science can increase confusion and uncertainty about policy options and the best course of action. ${ }^{51}$ Some of the issues that arise with uncertainty and risk are discussed below.

\section{The Precautionary Principle}

Uncertainty, or misrepresentation, can stem from a change in definition or categorisation of scientific information.

Dr Mike Joy, responding to the Government's proposed changes to water quality and swimmable rivers in New Zealand, said that it “... was pulling the wool over people's eyes by changing the goalposts on the allowable level of $E$. coli, essentially lowering the standards for what qualifies as excellent swimmability." 52 The Government had proposed weakening the standards for quality waterways by increasing the acceptable level of $E$. coli from less than 260 per $100 \mathrm{~mL}$ of water to 540 per $100 \mathrm{~mL}$ more than five percent of the time. Graham McBride, NIWA principal scientist of water quality said that the new measures were less precautionary than before: "What we have had has been quite precautionary, that is, we'll assume the worst unless you can demonstrate that that's not the case. ${ }^{, 53}$

\footnotetext{
${ }^{51}$ Pielke Jr, above n 14, at 36, as cited in Daniel Sarewitz "Science and environmental policy: an excess of objectivity" (2001) in Robert Frodeman (ed) Earth matters: The earth sciences, philosophy, and the claims of the community (Prentice Hall, Upper Saddle River, NJ, 1999) at 79-98. See also, Pielke Jr, above n 14, at 59-67 for discussion on how uncertainty can be used in the political process to support a viewpoint.

${ }^{52}$ Kate Gudsell "Water quality measure 'less stringent"” (online ed, 24 February 2017) Radio New Zealand News <www.radionz.co.nz>.

${ }^{53}$ Ibid.
} 
What McBride is referring to is an approach to policymaking called the precautionary principle. The precautionary principle legitimises the use of preventive measures to address potential risks to the public or the environment that are associated with certain activities or policies. ${ }^{54}$ Put simply, "Better safe than sorry". ${ }^{55}$ Despite its widespread adoption by many official sources, it has been criticised and remains controversial. ${ }^{56}$

Regardless, the precautionary principle is an important concept for policymakers to understand. Although there are numerous definitions, the formulation provided in the Rio Declaration provides a useful starting point: ${ }^{57}$

Where there are threats of serious or irreversible damage, lack of full scientific certainty shall not be used as a reason for postponing cost-effective measures to prevent environmental degradation.

Although stated in the context of environmental protection, the precautionary principle has come to inform much of European Union policy, including consumer policy, food legislation, and human, animal, and plant health. ${ }^{58}$

In New Zealand, the precautionary principle is mentioned in the Hazardous Substances and New Organisms Act 1996, which reads: ${ }^{59}$

\footnotetext{
${ }^{54}$ Charlotte Epstein Encyclopaedia Britannica (online ed, 3 November 2016): Precautionary principle.

${ }^{55}$ Frank B Cross "Paradoxical Perils of the Precautionary Principle" (1995) 53(3) Wash Lee Law Rev 851928 at 851.

${ }^{56}$ The precautionary principle has been criticised for promoting a risk-adverse approach to policy-making where the policy decision involves risk as part of the process and scientific uncertainty is acute. See, for example, Erik Persson "What are the core ideas behind the Precautionary Principle" (2016) 557-558 Sci Total Environ 134-141. But compare Cross, above n 55, at 859, where the author writes that the precautionary principle has received little criticism perhaps because it is presented as a matter of common sense.

${ }^{57}$ Rio Declaration on Environment and Development, Principle 15, (Rio de Janeiro, 3-14 June 1992).

${ }^{58}$ European Commission "Communication from the Commission on the precautionary principle" <eurlex.europa.eu>.

${ }^{59}$ Hazardous Substances and New Organisms Act 1996, s 7.
} 


\section{Precautionary approach}

All persons exercising functions, powers, and duties under this Act ... shall take into account the need for caution in managing adverse effects where there is scientific and technical uncertainty about those effects.

It is arguable that the precautionary principle would apply to vaccines, as one of the purposes of the Act is to protect the health and safety of people "by preventing or managing the adverse effects of hazardous substances and new organisms". ${ }^{60}$ Further, "the Authority may approve the importation, development, or field testing of any new organism into containment" for the purpose of producing "antigens, biopesticides, biopharmaceuticals, enzymes, hormones, or vaccines for release". 61

The precautionary principle can create a conundrum for policymakers considering the addition of newly developed vaccines. What harm is the policymaker protecting the public from? Should they err on the side of caution and prevent new vaccines from being added to the Immunisation Schedule, thereby protecting the public from scientific uncertainty about the adverse effects of the new vaccine? Or should they err on the side of caution and allow new vaccines to be administered, thereby protecting the public from a vaccinepreventable disease? This does not only apply to new vaccines being added to an immunisation programme. As noted above, problems arose when the Japanese Government took a precautionary approach to the HPV vaccine.

At the heart of the precautionary principle is the notion of risk. The perception of risk varies widely among both individuals and groups, and this impacts on the way scientific information about vaccines is understood, and the costs and benefits of each of the available options. This means that many risks are hard to quantify and involve subjective judgments of value. Nevertheless, policy still needs to be made and decision-makers (those that

\footnotetext{
${ }^{60}$ Section 4.

${ }^{61}$ Section 39(f).
} 
society trusts to make decisions on our behalf) need a way to weigh the options and assess the costs and benefits. ${ }^{62}$

The core question is: what degree of risk is acceptable or perhaps tolerable? What is the level of risk that both the government and the public are prepared to live with to achieve the benefits of a healthy society free from vaccine-preventable diseases? This is a complex question that cannot be solved by science alone. Yes, science can provide statistical data on the likelihood of adverse effects following administration of a vaccine, but science cannot provide an answer to whether individuals and society are prepared to accept a risk, albeit rare and remote, if there are severe consequences. This is because risk is viewed individually through "the lens of emotions and intuitive reactions, rather than technical or rational assessments of likelihood". ${ }^{63}$

\section{Consensus of Risk}

Science does play a different role in situations where there is consensus in risk perception and little scientific uncertainty. Such situations provide a clear path to the desired outcome and make the choice easier for the policymaker. For example, the compulsory use of seatbelts and bike helmets in New Zealand. ${ }^{64}$ Both seat belts and bike helmets reduce the likelihood of serious harm in the event of an accident. A combined study of physics, particularly kinematics, and various fields of biology and medicine, particularly anatomy, physiology and injury mechanics or biomechanics, as well as vast tracts of empirical evidence from the examination of traffic accidents, puts beyond doubt the devastating effects of road accidents on the human body. There is scientific consensus that harm results from humans colliding with objects. There is also a public consensus of risk. The effects of accidents are not difficult for a layperson to understand at the observational and

\footnotetext{
${ }^{62}$ Peter Gluckman "Making decisions in the face of uncertainty: Understanding risk" Office of the Prime Minister's Chief Science Advisor (November 2016) <www.pmcsa.org.nz>.

${ }^{63}$ Ibid, at 6.

${ }^{64}$ At the time of writing, there was renewed opposition to the compulsory use of bike helmets, with calls for legislative change. A protest ride from Civic Square to Parliament was organised. Prior to the ride, there was a strong sense of support for the removal of mandatory bike helmet legislation in the media. The protest ride was attended by approximately 25 people.
} 
physiological level. Memories about accidents are generally readily available to all. Most can draw on past experiences of the pain experienced when falling from a bike as a child, and it is not difficult to magnify that hurt to what could be sustained in a car accident. ${ }^{65}$ The restriction to human rights or individual autonomy are accepted by everyone desiring safe travel. In this example, there is no scientific uncertainty and people's individual perceptions of risk align. Regulation of the use of bike helmets and seatbelts is clearly the best course of action.

This is an example of what Thaler and Sunstein describe as "the availability heuristic". 66 Assessment of the likelihood of risk is made based on how readily examples come to mind. If people can easily think of an example, they are more likely to be concerned than if they cannot. Familiar risks are considered more serious than unfamiliar risks. The availability heuristic helps to explain public and private risk-related behaviour, including decisions to take precautions; for example, vaccinating a child. Vaccine complacency can be present where the risks of vaccine-preventable diseases are perceived to be low and where vaccination is not considered essential. ${ }^{67}$

Basing decisions on biased assessments influence how people and, importantly, governments, respond to crises, the choices they make, and political processes and can affect policy. This is because policymakers implement policy and allocate resources in ways that fit with the public's perception of fear rather than on the most probable danger.

\footnotetext{
${ }_{65}$ People generally estimate the seriousness of a risk based on their own experiences and prominence in their consciousness - how easily they can recall negative experiences and envisage harmful consequences: DM Kahan "The cognitively illiberal state" (2007) 60(1) Stanford Law Rev 115-154; noted in Gluckman, above n 62 , at 8 .

${ }^{66}$ Richard H Thaler and Cass R Sustein Nudge: Improving decisions about health, wealth, and happiness (Penguin, London, 2009) at 27-28.

${ }^{67}$ Dewesh Kumar and others "Vaccine hesitancy: understanding better to address better" (2016) 5(2) Isr J Health Policy Res 2.
} 


\section{Imposing Risk and Outrage Factors}

The situation is more difficult when a risk is seen as being imposed involuntarily, as is the case of compulsory immunisation or fluoridisation of water. Such instances challenge our personal views of risk and can provoke outrage. ${ }^{68}$ These are emotion-based perceptions that influence risk acceptability. The chance of outrage increases when those creating the risk do not bear the burden of the possible negative consequences, or if the benefits are not distributed evenly between those imposing the risk and those subject to it. Outrage can also arise from the risk of the unknown. Here there can be uncertainty about the possible impact of exposure to a risk; for example, long-term effects of multiple vaccines over time, or the potential health risks associated with genetically modified food. ${ }^{69}$

Outrage factors can influence whether the public grants social licence for the implementation of a policy even when the risks are well understood and supported by scientific evidence. Social licence is essential if the public is to accept a course of action. To achieve social licence, the policymaker may impose standards or regulations on activities that carry real or perceived detrimental individual or social risks. ${ }^{70}$ An example is regulation and imposition of standards for the manufacture, transport, storage, and administration of vaccines. ${ }^{71}$

\section{Status Quo Bias}

Another consideration is that people tend to favour inaction over action in the face of uncertainty. Ideas about avoiding loss can mean that people stick to what they already know

\footnotetext{
${ }_{68}$ PM Sandman "Hazard versus outrage in the public perception of risk" (1989) in VT Covello and others (eds) Effective risk communication: The role and responsibility of governmental and non-governmental organizations (Plenum Press, New York, 1989).

${ }^{69}$ Gluckman, above $\mathrm{n} 62$.

${ }^{70}$ Ibid.

${ }^{71}$ See, Medicines Act 1981; Hazardous Substances and New Organisms Act 1996; Medicines Regulations 1984; Health Practitioners Competence Assurance Act 2003; Ministry of Health National Standards for Vaccine Storage and Transportation for Immunisation Providers 2017 (Ministry of Health, Wellington, 2017).
} 
rather than trying something new and uncertain, a concept termed "status quo bias". ${ }^{72}$ This can lead to an underestimation of the risk of doing nothing; the risk of inaction may be greater than the risk of action. Parents not immunising a child out of fear of adverse effects is an example. By avoiding a small action with great potential to mitigate one risk, they create the potential for another larger risk to be realised: their child contracting and spreading an infectious disease. ${ }^{73}$

It may be possible for the policymaker to exploit the status quo bias - that is, people's tendency to stick with the current situation-to improve immunisation coverage. It is suggested that, by changing from an opt-in to an opt-out model of immunisation in New Zealand, the hurdles that people would have to jump to prevent their child being immunised would make opting-out too troublesome for all but those most opposed to vaccination. ${ }^{74}$ The United States has adopted this opt-out model of immunisation. Such a model creates a legal presumption in favour of vaccination before a child is enrolled in school. ${ }^{75}$ Each state determines its own vaccination requirements and there are exemptions on medical, religious, and philosophical grounds. ${ }^{76}$

Risk, fear, and doubt are normal emotions for parents to feel when uncertain about the best course of action for the health of their child. Doubt is also central to science and the scientific method. Healthy scepticism, testing and revising hypotheses, and scrutiny by peers within the scientific community validate science. However, doubt makes science vulnerable to manipulation and misrepresentation because it is easy to take uncertainties out of context and create the impression that there is doubt amongst the scientific community and that the science is unresolved. ${ }^{77}$ Uncertain science is not the same as

\footnotetext{
72 Thaler and Sustein, above n 66, at 37, as cited in William Samuelson and Richard Zeckhauser "Status quo bias in decision making" (1988) $1 \mathrm{~J}$ Risk Uncertain 7-59.

${ }^{73}$ Gluckman, above n 62, at 9.

${ }^{74}$ See, for example, Kerr, above n 11, at 38-44.

${ }^{75}$ For example, CO Rev Stat $\S 25-4-901$; W Va Code $\S 16-3-4$; NDCC $\S ~ 23-07-17.1$.

${ }^{76}$ For example, Ala Code $\S 16-30-3$; HRS $\S 302 \mathrm{~A}-1156$.

${ }^{77}$ Oreskes and Conway, above n 32. Climate change sceptics have used this tactic to great effect to delay public acceptance of climate change.
} 
misinformation. There is a difference between uncertain science - that is, science for which no consensus has yet been reached by the scientific community—and pseudo or junk science that is being used for inappropriate means.

When using science to inform policy, it must be recognised that experimentation is one of the central tenets of scientific epistemology. Since scientific facts are revisable, any policy based on the incorporation of scientific evidence may also require revision. ${ }^{78}$ Failing to acknowledge the uncertain nature of science could cause serious problems if, for example, law was enacted based on scientific evidence that was later revised. This is a central problem with determining immunisation policy exclusively on scientific evidence.

\section{Misuse of Science}

There is concern that using the words "empirical" or "research" when describing information or ideas or prefacing a sentence with "a study reported" will result in that information being accorded undue and inappropriate value by a naïve decision-maker, whether policymaker or member of the public. Additionally, the pace that misinformation is spread in today's technological age means that it can no longer be taken for granted that deliberative enquiry and verifiable facts are being used as the basis for reasoned arguments underpinning our democratic process. ${ }^{79}$

This section discusses how misinformation and pseudoscience can be misused by special interest groups to create doubt in the mind of the policymaker and public and produce the erroneous impression that the science is more uncertain than it is. Creating doubt suggests that there is room for debate and can be an effective tool to delay or prevent legislative action.

\footnotetext{
${ }^{78}$ Susan S Silbey and Patricia Ewick "The Architecture of Authority: The Place of Law in the Space of Science" in Austin Sarat, Lawrence Douglas, and Martha Umphrey (eds) The Place of Law (The University of Michigan Press, Ann Arbor, 2006) 75 at 78.

${ }^{79}$ Gluckman, above $n 12$.
} 


\section{Misinformation and Creating Doubt}

The spread of vaccine misinformation has serious implications for public health. It undermines public health programmes and presents challenges for governments and health agencies in maintaining adequate immunisation coverage. ${ }^{80}$

Decision theory suggests that correcting misinformation is particularly difficult to achieve, despite the use of well-researched, rational, factually correct counter-arguments or retraction of articles by scientific journals. ${ }^{81}$ This is because of inherent confirmation biases: "People generally see what they look for, and hear what they listen for." 82 Their own personal beliefs and ideas are reinforced in the echo chambers of social media where views are validated by like-minded individuals of the peer-group. Furthermore, as social media reach deeper into people's lives, traditional sources of information are replaced by those that only provide information that is pre-selected to a person's biases.

Special interest groups have developed strategies to take advantage of people's biases and to undermine the credibility of scientists. An example is provided by the discussion on the addition of folic acid to bread. ${ }^{83}$ The benefits of folate are well-established scientifically but there was the suggestion (based on weak evidence) that high levels of folate might cause adverse effects in some people. Yet dissenting views on the benefits of folate are used to introduce uncertainty. By pointing to a small number of studies that support an argument that folate might be harmful, special interest groups are able to exploit a common misunderstanding about the way science works: this is that science is never certain. Statistics tell us that some individual studies will provide evidence of harm by chance. The uncertain nature of science means that groups can find studies to sow seeds of doubt even when the weight of the evidence is against them.

\footnotetext{
${ }^{80}$ Robert Field "Vaccine declinations present new challenges for public health" (2008) 33 P T 542.

${ }^{81}$ Gluckman, above n 12 . See, for example, the controversy still circulating around the measles, mumps and rubella vaccine and autism link despite numerous scientific studies finding no link and the journal retracting the original article.

${ }^{82}$ Harper Lee To Kill a Mockingbird (Arrow Books, London, 1997) at 192.

83 This example has been taken from the interesting book Hendy, above n 30, at 37-40.
} 
Creating doubt also allows groups to take advantage of the perceived variability in opinion among experts and to misuse science by cherry-picking studies that bolster their argument. These studies, or "scientific facts", are then incorrectly used in complex societal discussions that are about values rather than scientific debate. The tobacco industry used this strategy to great effect to delay public acceptance of the link between tobacco smoke and lung cancer. ${ }^{84}$ The same strategy has been used for arguments about the safety of genetically modified foods and by climate change deniers. Doubt can result in the public seeing the science as less probable than it is.

The creation of doubt and the spread of misinformation can be aggravated by a misinformed sense of balance in the media, which can give credibility to views either not supported by the science or not supported by consensus within the scientific community, and by those who distort science with ideology and religion. ${ }^{85}$

\section{Junk or Pseudoscience}

Complicating matters is the type of evidence that is proffered to support a position. Troublingly, accurate scientific and medical information can get lost amongst misinformation, and it can be difficult to discern legitimate science from pseudoscience. The problem is that there is no clear demarcation between the two.

Pseudoscience is ideas or practices that are mistakenly thought to be based on science or fact yet do not follow accepted scientific methodology. Pseudoscience can include information that has been proved to have no scientific validity, cannot be tested, or lacks any real evidence to support a claim. Examples include information proclaimed by antivaccination groups, climate change deniers, modern flat-earth believers, intelligent design creationists and followers and practitioners of alternative medicine.

Information proclaimed by anti-vaccination groups, intelligent design creationists and followers and practitioners of alternative medicine are particularly applicable to the

\footnotetext{
${ }^{84}$ Oreskes and Conway, above $\mathrm{n} 32$.

${ }^{85}$ Nurse, above $n 38$.
} 
immunisation debate and are topics worth mentioning in a little more detail. These topics, grouped as junk or pseudoscience, manifest as drivers behind vaccine-hesitancy, and are particularly evident in the later discussion on religious beliefs, links to disease, and distrust of government and medicine.

Alternative medicine is relevant to the discussion on vaccination choices and is a topic that finds a comfortable fit within the health and well-being philosophy of many people opposed to vaccination using conventional medicine. Alternative medicine, also called alternative therapy or complementary medicine, is often described as being natural, organic, or holistic. ${ }^{86}$ The non-standard medical practices of alternative medicine use a range of approaches including dietary supplements, herbs, biological agents, mind-body interventions, manual healing, and bioelectromagnetics. ${ }^{87}$

Nutritionists fall into the category of alternative therapists but "have somehow managed to brand themselves as men and women of science" ${ }^{88}$ Ben Goldacre describes this group as more dangerous than homeopaths because the errors they make have "a grain of real science to them ... [and] they systematically undermine the public's understanding of the very nature of evidence." 89

Many celebrities have adopted an alternative approach to health and well-being, including Oprah Winfrey, Jenny McCarthy, Gwyneth Paltrow, Dr Oz, and Tom Cruise. While the argument may be made that the celebrity is merely presenting information or sharing their personal view, a celebrity's approach to a product or treatment cannot be separated from the influence they have on an impressionable public..$^{90}$ Celebrity endorsements are a well-

\footnotetext{
$\overline{86}$ Roland J Lamarine "Alternative medicine: more than a harmless option” (2001) 71(3) J Sch Health 114.

${ }^{87}$ Workshop on Alternative Medicine Alternative medicine: Expanding medical horizons: A report to the National Institutes of Health on alternative health medical systems and practices in the United States (The Office of Alternative Medicine, Report, September 1992).

${ }^{88}$ Ben Goldacre Bad Science (Fourth Estate, London, 2009) at xi.

${ }^{89}$ Ibid.

${ }^{90}$ PH Viale "Celebrities and medicine: a potent combination" (2014) 5(2) J Adv Pract Oncol 82-4; JH Tanne "Celebrity illnesses raise awareness but can give wrong message" (2000) 321(7269) BMJ 1099.
} 
established and popular marketing strategy. ${ }^{91}$ Such endorsement signals to the consumer that the claims of the goods or services are credible because the celebrity is associating themselves with it. They are putting their reputation on the line. The influence of the celebrity redirects the focus of the consumer away from the facts and towards its more superficial aspects.

Celebrity endorsement can be particularly problematic as members of the public no longer put their trust in traditional sources of health advice, and turn instead to prominent social personalities, regardless of their expertise on the matter. Celebrities opposed to vaccination include Donald Trump, Jim Carrey, Robert F Kennedy Jr, Alicia Silverstone and Jenny McCarthy. ${ }^{92}$

\section{The "Post-world"}

An important issue with the use of science to inform policy is the "tension between ideals of equal access on the one hand, and deference to expertise on the other."${ }^{.93}$

The term "post-world" is used to encompass the current post-truth, post-trust, post-expert, post-elite environment. While opposition to authority and science is not a new phenomenon, the current socio-political environment is creating very real complexities for policymakers and goes some way to explaining the underlying drivers behind contemporary vaccine hesitancy.

Briefly, the experience of many in the Western world over the past years has been a feeling of being forgotten, being marginalised and missing out. This growing resentment has been directed at traditional sources of authority and knowledge production, as evidenced by

\footnotetext{
91 Johannes Knoll and Jörg Matthes "The effectiveness of celebrity endorsements: a meta-analysis" (2017) 45(1) J of the Acad Mark Sci 55-75; BZ Erdogan "Celebrity endorsement: a literature review" (1999) 15(4) J Mark 291-314.

92 Jane Ridley "10 anti-vaccine celebs who should come with a surgeon general's warning" New York Post (online ed, New York, 9 February 2015).

${ }^{93}$ Nick Enfield "We're in a post-truth world with eroding trust and accountability. It can't end well" The Guardian (online ed, United Kingdom, 16 November 2017).
} 
political events in recent years. Dov Seidman, quoted in The New York Times, suggests that what we are experiencing "is an assault on the very foundations of our society and democracy — the twin pillars of truth and trust".${ }^{94}$ Sheila Jasanoff notes that “... the sound conduct of science and the sound conduct of democracy both depend on the same shared values". ${ }^{95}$ Undermining these values has a dramatic effect on both science and democracy.

The problem is exacerbated by globalisation and the influence of social media, with the sheer volume of non-validated information and non-expert opinion taking the place of previous slower and reliable sources of information. Social networking tools allow people to retreat into echo chambers, where reinforcement of their own values and beliefs by peergroups permit the creation of moral outrage towards any perceived injustice, no matter how far-fetched. News feeds providing information based on a prior interests limit exposure to new ideas and different worldviews and reinforces biases. People like to have their views validated and are increasingly getting their information from sources that entrench their opinions and beliefs.

Access to information and transparency in institutions has, paradoxically, had a detrimental effect on trust in traditional sources of knowledge and authority. This has contributed to increased individual and societal awareness of perceived unmet health needs and the confidence to question current scientific wisdom. The availability of conflicting scientific evidence, irrespective of motive, and health organisations revising best practice guidelines have combined to erode public confidence and add validity to differing scientific conclusions. This has led to people seeking alternative therapeutic options. Furthermore, accessibility to information brings with it the temptation to assume reading something for oneself is sufficient, and that there is therefore no need to defer to experts for skilled interpretation and validation.

\footnotetext{
${ }^{94}$ Thomas Friedman “Where Did 'We the People' Go?” The New York Times (online ed, New York, 21 June 2017).

${ }^{95}$ Jasanoff, above n 17.
} 
Deferring to experts can be a double-edged sword. It can instil trust and confidence in the interpretation of the data. However, where the self-importance of an expert is elevated above the science, it can also undermine the trust and respect in those usually tasked with sorting fact from fiction. ${ }^{96}$

There is the need to draw the distinction between disinterested science - that is, science that has been done without an ulterior motive or gain - and science that has been conducted or commissioned for a specific purpose by a party who seeks to benefit. This is not to say that the science done in the latter instance is bad science; merely that it must be scrutinised with a sceptical eye as there is the greater possibility of bias. ${ }^{97}$ In the context of this thesis, such analysis is equally applicable to pro-vaccination groups as it is to anti-vaccination groups. Drug companies fall into the former and have significant incentive to promote the use of vaccines. Indeed, sales of the drugs they research, develop and manufacture is their sole purpose for existence, regardless of what altruistic motivations they may otherwise proffer in attempts to remove the negative stigma attached to "Big Pharma" in the eyes of a sceptical public.

Drug companies suspending or ending immunisation programmes further erode public confidence in the manufacture, testing and administration of vaccines. Halting a programme may be in the best interests of public health and safety, but it does not sit comfortably in the minds of those unsure about vaccines to begin with.

It must be remembered that science is process, and over time more reliable evidence may become available; however, care must be taken when dealing with such an emotive and polarising topic as immunisation. This means policymakers must tread lightly when considering a course of action that could impinge on other values (such as the restriction to human rights with compulsory immunisation), especially if they relied on science to inform a decision that is later revised.

\footnotetext{
${ }^{96}$ Gluckman, above $\mathrm{n} 12$.

${ }^{97}$ Susan Selby (ed) Law and Science (Aldershot, Burlington, VT, 2008) at 437.
} 
An example is provided by the suspension of a public immunisation programme for dengue fever in the Philippines. ${ }^{98}$ Sanofi, the manufacturer of the vaccine, announced that, following a long-term study, subsequent infection of the dengue virus in those who had received the vaccine could worsen the disease in people not previously infected. ${ }^{99}$ If immunisation was compulsory, then the authorities would be in serious trouble for exposing people to harm. Importantly, they would have very real difficulties in both restoring the trust and confidence of the public and in gaining public support for any future controversial decisions. Consequently, suspension of the dengue fever vaccination programme has resulted in a dramatic loss of trust and confidence in vaccines by the public in the Philippines. Unfortunately, this loss of confidence is not only with the vaccine for dengue fever but has had widespread impact on many immunisation programmes for preventable diseases, including polio, chicken pox and tetanus, with immunisation rates for these diseases falling. ${ }^{100}$

\section{E Not Deferring to the Authority of Science}

Most, if not all, policy issues will have a range of possible solutions. A difficulty lies in determining which solution is best. In choosing a solution, thought needs to be given to who is in the best position to make the decision. Some people hold the unrealistic belief that the scientific profession, which identifies problems and assesses the consequences of employing various policy options, is in the best position to determine which solution is appropriate. ${ }^{101}$ However, deferring to the authority of science usurps the role of the policymaker and the policy process, and removes the public from the democratic process.

Briefly, modern science had its beginnings in the Enlightenment and ascended to dominance throughout the twentieth century. Along with law, the rise of science has been achieved in competition against religious interpretations of human interactions and nature.

\footnotetext{
${ }^{98}$ BBC "Philippines to probe dengue vaccine scare" BBC News (online ed, London, 4 December 2017).

${ }^{99}$ Sanofi Pasteur "Sanofi updates information on dengue vaccine" $<$ www.sanofipasteur.com $>$.

${ }^{100}$ Dr Enrique Domingo, above n 98.

${ }^{101}$ Cairney, above n 16, at 52.
} 
The power that has come to be vested in both is a radical shift from traditional sources of authority. Roger Berkowitz notes that along with the social crisis ${ }^{102}$ of the seventeenth century, there arose "a spiritual crisis of authority that touched politics and law every bit as much as philosophy and religion." ${ }^{" 103}$ Berkowitz describes this crisis as a crisis of unity, with man, being a free individual, asserting himself against the authority of the church and the State. Seventeenth century thinkers like Francis Bacon and Thomas Hobbes thought that science "offered the potential for the creation of a "New Atlantis". 104

Science continues to be revolutionary. Advances in science and technology have given us improved knowledge on health and well-being, but with these advancements come consequences. Nurse, discussing implications stemming from advances in science, notes: ${ }^{105}$

Advances will have consequences for our views on free-will, justice and diversity. How much choice do we really have when we make decisions? Is punishment for certain criminal behaviours right if they are strongly influenced by an individual's genes? Will work in neuroscience influence how we educate our children? What will we learn about genetic differences between individuals, genders, and populations, and how might that influence our ideas of equality?

These are issues of crucial significance, but can only be properly addressed if we enjoy a healthy relationship between science and society.

Importantly, Nurse recognises how critical it is for the values and views of society to be part of the democratic process. Regardless of whether there is scientific consensus that the benefits of vaccination outweigh the risks, communities and individuals still expect the right to have a say in public health decisions affecting them. Where freedom of choice is

\footnotetext{
${ }^{102}$ See generally, Paul Hazard The European Mind: The Critical Years (1680-1715) translated by J Lewis May (Yale University Press, New Haven, 1953).

${ }^{103}$ Roger Berkowitz The Gift of Science: Leibniz and the Modern Legal Tradition (Harvard University Press, Cambridge, MA, 2005) at 12.

${ }^{104}$ Ibid.

${ }^{105}$ Nurse, above n 38 .
} 
pitted against collective well-being, scientific evidence alone is never enough to be determinative.

Yet, increasingly, science and scientists are being asked to contribute to the needs of society when the problem being addressed has some sort of relationship to science; for example, health and disease. ${ }^{106}$ For such problems, it can be tempting to defer to science to provide answers or a course of action and to obviate the need for political discussion.

Turning policymaking into a technical exercise without regard for political debate is a concept that has been termed "technocracy" or "scientization". ${ }^{107}$ This concept suggests that differing political opinions or options can be resolved by evaluating them against objective scientific criteria. This moves the responsibility of the policymaker onto the scientist or expert under the "expectation that reliance on these experts will eliminate the need for politics". ${ }^{108}$ Technocratic policymaking attempts to reduce a problem to scientific components in the belief that removing scientific uncertainty will result in a reduction of political uncertainty and that, consequently, consensus will be reached on the correct course of action.

This approach is not appropriate because science cannot be the sole determinant of policy. Scientific evidence will be most effective in the policymaking process when its limits and its benefits are understood and there is no attempt to use science to usurp the role of the policymaker. It is for the policymaker to weigh all competing considerations and decide among the options, all of which will involve trade-offs in one form or another. Democracy dictates that governments must integrate societal values, amongst other considerations, into policy formation. Failure to do so will result in real problems with implementation, adherence and effectiveness of the policy, and, subsequently, political longevity.

\footnotetext{
${ }^{106}$ Pielke Jr, above n 14, at 30-34.

107 Ibid, at 34, citing Sheila Jasanoff The Fifth Branch: Science Advisors as Policy-makers (Harvard University Press, Cambridge, MA, 1990).

${ }^{108}$ Pielke Jr, above n 14, at 34.
} 
Another problem is that the science of complex issues, by its very nature, is uncertain. Calls to defer to science result in calls for more research on a topic to clarify the nature of the problem and to provide options. More research invariably results in more papers being published, and can, paradoxically, result in more uncertainty. Consequently, stakeholders are provided with more information, more scientific material, on which to sustain arguments with competing political views. ${ }^{109}$

Immunisation is a topic in which it can be difficult to separate normative questions and personal values from scientific process and scientific evidence. For the scientist, this could manifest subconsciously in the way in which a hypothesis is formulated or the way in which they present their evidence to the policymaker. ${ }^{110}$ However, it is not the task of the scientist or expert to determine answers to normative questions. Policy decisions that depend on normative questions, those that have strong values components, are correctly left to the wider democratic community to determine. ${ }^{111}$ That is not to say that there is no room for science in the decision-making process. It is merely that science is not determinative. Deferring to the best-qualified expert or a body of scientific knowledge does not always prevent terrible events from taking place. ${ }^{112}$

\section{F Capacity to Understand the Evidence}

The final issue is the capacity of the policymaker and the public to understand evidence. Producing relevant and reliable research is of no value if it cannot be understood, particularly by the policymaker, who may be less likely to draw from it when considering policy formation. Public understanding is also important. If a person is not able to

\footnotetext{
${ }^{109}$ Pielke Jr, above n 14, at 36, referring to Daniel Sarewitz "Science and environmental policy: an excess of objectivity" in Frodeman, above n 51, at 79-98.

${ }^{110}$ See generally Pielke Jr, above $\mathrm{n} 14$, where the various roles that scientist can play in politics and policy are discussed. Pielke Jr emphasis that scientists are most useful in democratic decision-making when they not only present the facts but also attempt to expand the range of options and provide interpretations and possible consequences of each; a concept termed "The Honest Broker".

${ }^{111}$ K Kappel "Democratizing Science: What could it mean?" (Democratizing Science Conference 2012, University of Copenhagen, Copenhagen, 14 December 2012).

${ }^{112}$ Pedersen, above $\mathrm{n} 8$.
} 
understand complex information, they are more likely to dismiss it. The implications of public misunderstandings are bigger than the impact to the individual. Public understanding and acceptance can influence government decision-making in terms of policy and regulation. ${ }^{113}$

This section discusses the implications of a person's ability to make sense of complex scientific information.

\section{The Science Advisory System and the Policymaker}

A science advisory system was established in New Zealand in 2009. The science advisory system comprises the Prime Minister's Chief Science Advisor and Departmental Science Advisors. Additionally, a function of the Royal Society of New Zealand is to provide advice to the government and community. ${ }^{114}$

The Prime Minister's Chief Science Advisor is an independent role constitutionally established reporting directly to the Prime Minister. The responsibilities of the chief science advisor include, amongst others, enhancing the use of science in policymaking, promoting a public understanding of science, providing scientific advice to the Prime Minister, and commissioning deliberative advice on selected topics. ${ }^{115}$

Departmental Science Advisors have been appointed in selected Ministries. The responsibilities of departmental science advisors include providing strategic input within their ministries on the development and application of science-derived knowledge for public policy, quality assurance of internal and commissioned research, and the provision of advice as required. ${ }^{116}$

\footnotetext{
${ }^{113}$ Sara Brownell and others "Science Communication to the General Public: Why We Need to Teach Undergraduate and Graduate Students this Skill as Part of Their Formal Scientific Training" (2013) 12(1) J Undergrad Neurosci Educ E6-E10.

${ }^{114}$ Royal Society of New Zealand Act 1997, s 6(e).

115 Peter Gluckman "Briefing Note: The New Zealand Science Advisory System" Office of the Prime Minister's Chief Science Advisor <www.pmcsa.org.nz>

${ }^{116}$ Ibid.
} 
While there are agents in place to provide the policymaker with scientific advice, this does not negate the responsibility of the policymaker to understand the principles of science and the scientific method. Not all scientific evidence making its way to the policymaker will have come through established channels with quality control checks, nor will it necessarily be free from bias on the part of the scientist, science advisor or institution, whether conscious or otherwise.

It is the responsibility of those involved in the production of policy to have the capacity to understand and critically review research for scientific merit and robustness before applying it to policy formation. This is not to suggest that the policymaker must have a $\mathrm{PhD}$ in a scientific field, but they must be familiar and comfortable with scientific methodology.

Understanding scientific methodology serves two purposes. First, the policymaker is equipped with the skills to acknowledge both the benefits and limitations of the research, and, importantly, the limitations of their own expertise. Competency in identifying potential limitations of research, while maybe not fully understanding the implications, should direct the policymaker to seek further guidance and interpretation of the data by an expert or several experts. Furthermore, those providing research for consideration in the policy process may not be aware of their own cognitive biases. A policymaker who has knowledge of scientific principles and the scientific method will more readily identify whether information is being presented impartially. Second, teaching critical appraisal skills has been consistently identified to improve a decision-maker's capability to use evidence. ${ }^{117}$

\section{The Information Deficit Model}

The capacity to understand the evidence is not restricted to the policymaker. How the public interpret scientific data is equally important. Susan Silbey and Patricia Ewick write

\footnotetext{
$\overline{{ }^{117} \text { L Langer and others The Science of Using Science: Researching the Use of Research Evidence in Decision- }}$ Making (University College London, London, 2016) at 36.
} 
that as scientific knowledge has become even more technical, lay persons have become even less equipped to understand it. Yet, despite the inability, there exists a cultural understanding that scientific knowledge belongs to the community. ${ }^{118}$ The cultural understanding of the public ownership of scientific knowledge raises two competing points. The complex nature of scientific research can instil a sense of incomprehensibility and therefore scepticism and non-acceptance. Alternatively, accessibility to scientific information allows people to interpret results and form conclusions for themselves, despite lacking the requisite training and knowledge to make sense of complex data.

Taking scepticism and non-acceptance first. In the study of how science is understood by the public, the information deficit model assumes that public ignorance is to blame. Scepticism is because of a lack of understanding, resulting from a lack of information. The model suggests that countering public scepticism towards science can be achieved by providing more and better information; providing further science education and boosting scientific literacy. ${ }^{119}$ This model has been shown to be insufficient by social sciences studies, ${ }^{120}$ in part because people make decisions based on non-scientific factors, including experience, religious and ethical beliefs and cultural values. However, a survey of New Zealand mothers examining information about immunisation provided during the antenatal period reported that over half of those surveyed did not feel that they had been given adequate information on which to make a decision. ${ }^{121}$ Another study reported that, among parents who had not completed an immunisation programme, there was a small group who

\footnotetext{
${ }^{118}$ Silbey and Ewick, above $\mathrm{n} 78$, at 83.

119 Dietram Scheufele "Communicating science in social settings" (2013) 110(Suppl 3) Proc Natl Acad Sci USA 14040-14047.

${ }^{120}$ Tania Bubela and others "Science communication reconsidered" (2009) 27 Nat Biotechnol 514-518; MW Bauer "Survey research on public understanding of science" in M Bucchi and B Trench (eds) Handbook of Public Communication of Science and Technology (Routledge, New York, 2006) 111-129; MJ Simis and others "The lure of rationality: Why does the deficit model persist in science communication?" (2016) 25(4) Public Underst Sci 400-414.

${ }^{121}$ Helen Petousis-Harris and others "Immunisation education in the antenatal period" (2004) 31(5) NZ Fam Phys 303-306.
} 
had no awareness of the diseases and the vaccines that protect against them. ${ }^{122}$ The authors of both studies do note the limitations of the studies and advised caution when interpreting the findings to the general population.

Information about immunisation programmes and vaccines are frequently associated with vaccination decisions, but the association between the level of knowledge a person has on the topic and vaccine acceptance is not straightforward. ${ }^{123}$ Opposition to the information deficit model is not to say that improved scientific literacy of the public is not important or desirable, merely that increasing information may not achieve the desired results of a policy intervention.

The second point is that increased access to information has created the sense that experts are no longer needed, that they have nothing to offer. For vaccine hesitancy, this is driven in part by the plethora of anti-vaccination information available in the media, particularly on the internet. A common catch cry of promotors of anti-vaccination rhetoric is that they are not anti-vaccination but are pro-choice or informed choice. The argument goes that they are providing the other side of the story - the information the doctors, drug companies and governments do not want the public to know - and parents should do careful research, read the articles and decide for themselves.

Putting aside the echoes of conspiracy theory, informed consent (being provided with relevant and appropriate information) does have a statutory basis. ${ }^{124}$ The distinction must be made, however, between being provided with information that has been critically reviewed and, importantly, interpreted by the scientific community and being provided with a link to a scientific article for interpretation by a lay person.

\footnotetext{
${ }^{122}$ Helen Perousis-Harris and others "Barriers to childhood immunisation among New Zealand mothers" (2002) 29(6) NZ Fam Phys 396-401.

${ }^{123}$ Eve Dubé and others "Vaccine hesitancy: an overview" (2013) 9(8) Hum Vaccin Immunother 1763-1773 at 1768.

${ }^{124}$ See, for example, Code of Health and Disability Services Consumers' Rights 1996, Health and Disability Commissioner Act 1994, Health Information Privacy Code 1994, Privacy Act 1993, Privacy Amendment Act 2013.
} 


\section{Vaccine Hesitancy, Barriers, Policy and the Treaty}

The previous chapter identified issues at the science-policy-society interface. The first part of this chapter outlines how these issues create problems in the immunisation debate. Throughout this first part, which focusses on common global drivers behind vaccine hesitancy, defined as "a delay in acceptance or refusal of vaccination", ${ }^{25}$ the issues of the previous chapter will become evident. Vaccine hesitancy and immunisation coverage are used to highlight these issues. For example, distrust of government, medical professionals, and medicine generally is considered the vaccination form of the growing resentment and distrust in the post-elite, post-science, post-expert world - a turning away from traditional sources of trust and authority. Additionally, religious opposition to vaccination has roots that spread deeply into values judgments and raises important considerations for governments about identity and freedoms.

The second part of this chapter looks at some of the reasons for low immunisation coverage in New Zealand - those barriers that make it difficult or impossible for parents, willing or otherwise, to have their children vaccinated. This is a survey of interweaving socioeconomic, healthcare system and political factors that contribute to low coverage rates.

The third part of this chapter outlines some of the current policy initiatives aimed at increasing vaccination uptake as well as the New Zealand Government's obligations in its partnership with Māori towards Māori health.

Although vaccine hesitancy contributes to immunisation coverage, the approach taken is to discuss vaccine hesitancy in isolation and in the global setting. This allows for examination of the cultural, philosophical, ethical and moral grounds contributing to parental immunisation decision-making as well as focusing on existing legislation aimed at promoting a government's position. While the points discussed are also identified in the

\footnotetext{
125 Definition provided by the SAGE Working Group on Vaccine Hesitancy. See NE MacDonald; SAGE Working Group on Vaccine Hesitancy "Vaccine hesitancy: Definition, scope and determinants" (2015) 33(34) Vaccine 4161-4164.
} 
New Zealand environment, they are perhaps more readily discernible when framed internationally.

The reason for separating vaccine hesitancy and immunisation coverage is to provide a clear demarcation between parental choice and barriers to immunisation. This is important for two reasons. First, the science that explains these distinct but related topics needs to be evaluated and understood by the policymaker to determine appropriate actions to address them. Put another way, it is important for policymakers to understand both the reasons why people choose not to have their children vaccinated and to identify the barriers that make it difficult or prevent them from vaccinating their children. Second, although vaccine hesitancy has a scientific component, it is also underpinned by very strong values judgments.

Separation of science and values is a necessary requirement for the policymaker as it removes the potential for blurring boundaries between reliable science that can be used to inform policy and those other factors that make up the human condition, and which are vital to good policy. By adopting the decision-making framework described in this thesis, the policymaker will be able to differentiate the science and values components interwoven throughout the issues identified in the previous chapter and the problems specific to immunisation discussed in this chapter.

Importantly, identifying the reasons for low or improved immunisation coverage using reliable scientific methodology is a key component of this thesis. Both those factors driving parental immunisation decisions (vaccine hesitancy) and the barriers to immunisation must be considered when seeking to use science to inform immunisation policy.

Both low and improved immunisation coverage are relevant to immunisation policymaking. If policy has been implemented that has resulted in improved coverage for a target group, and if the mechanisms of the policy are measurable using scientific methodology — that is, it is reliable and robust evidence - then the questions become: how 
does that scientific evidence help inform future immunisation policy and how does it fit with values judgments?

Answers to these questions will help determine the options available to the policymaker. For example, if reliable evidence suggests that policies that have improved access to vaccine providers have resulted in increased immunisation coverage, and these policies have been considered against competing values and have been found to be justified, then the policymaker can be confident that continuing such a course of action is in the best interests of both the State and the individual. Public health goals are being met and human rights are not being unduly restricted, as would be the case with, for example, compulsory immunisation.

\section{A Common Global Problems Behind Vaccine Hesitancy}

Vaccines are overwhelming successful at decreasing morbidity and mortality. ${ }^{126}$ The Centers for Disease Control and Prevention rank vaccines among the top 10 greatest health achievements of the last century. ${ }^{127}$ Vaccines confer protection to both the individual and the community at large, a concept termed "herd" or "population immunity". ${ }^{28}$

Under the New Zealand Immunisation Programme, vaccines are administered to children, the final in the series being given at 11 or 12 years of age. ${ }^{129}$ Vaccines are readily available and free of charge, yet there remains a segment of society who are opting out of having their children immunised. Indeed, some people remain reluctant, or vehemently opposed, to vaccinations.

\footnotetext{
${ }^{126}$ SW Roush and TV Murphy; Vaccine-Preventable Disease Table Working Group "Historical comparisons of morbidity and mortality for vaccine-preventable diseases in the United States" (2007) 298(18) JAMA $2155-2163$.

${ }^{127} \mathrm{CDC}$, above $\mathrm{n} 3$.

${ }^{128}$ See generally, Stanley Plotkin, Walter Orenstein, and Paul Offit (eds) Vaccines (6th ed, Elsevier Health Sciences, London, 2012).

${ }^{129}$ One injection of Boostrix ${ }^{\mathrm{TM}}$ for tetanus, diphtheria, and pertussis; and two injections of Gardisil ${ }^{\circledR}$ given at least 6 months apart for those aged 14 and under: Ministry of Health Immunisation Handbook (2nd ed, Ministry of Health, Wellington, 2017).
} 
There has been opposition to vaccines ever since Edward Jenner inoculated 8-year-old James Phipps in 1796 using matter taken from a cowpox lesion on Sarah Nelms, a dairymaid. ${ }^{130}$ Yet reasons for contemporary vaccine hesitancy must be set against the backdrop of globalisation and the advent of the internet, which has made vast tracts of information, regardless of legitimacy, available at a person's fingertips. ${ }^{131}$

While vaccine hesitancy should always be "looked at in the historical, political and sociocultural context in which vaccination occurs", ${ }^{132}$ some common themes emerge, including fear of short-term effects such as pain and fever, ${ }^{133}$ links to disease, ${ }^{134}$ uncertainty of ingredients, ${ }^{135}$ distrust of government, medical professionals, and medicine generally, ${ }^{136}$ and peer pressure, ${ }^{137}$ and on more philosophical grounds, religious beliefs. ${ }^{138}$ A few of these themes are expanded below.

\section{Links to Disease}

No medical intervention is without risk. Vaccines are no exception. In New Zealand, adverse events to vaccines are recorded by the Centre for Adverse Reactions Monitoring.

${ }^{130}$ Stefan Riedel "Edward Jenner and the history of smallpox and vaccination" (2005) 18(1) Proc (Bayl Univ Med Cent) 21-25.

${ }^{131}$ See, for example, A Kata "Anti-vaccine activists, Web 2.0, and the postmodern paradigm-an overview of tactics and tropes used online by the anti-vaccination movement" (2012) 30(25) Vaccine 3778-3789.

${ }^{132}$ Dubé and others, above n 123, at 1763.

${ }^{133}$ A Kennedy and others "Vaccine attitudes, concerns, and information sources reported by parents of young children: results from the 2009 HealthStyles survey" (2011) 127(Suppl 1) Pediatrics S92-S99.

${ }^{134}$ See, for example, RE Spier "Perception of risk of vaccine adverse events: a historical perspective" (2001) 20(Suppl 1) Vaccine S78-S84; AL Benin and others "Qualitative analysis of mothers' decision-making about vaccines for infants: the importance of trust" (2006) 117 Pediatrics 1532-1541; Freed and others, above n 4. ${ }^{135}$ For example, thimerosal, an antifungal and antimicrobial, was removed from vaccines in the 1990 s, see generally, CDC "Thimerosal in vaccines" <www.cdc.gov>.

${ }^{136}$ Dubé and others, above n 123, at 1763.

${ }^{137}$ T Oraby and others "The influence of social norms on the dynamics of vaccinating behaviour for paediatric infectious diseases" (2014) 281(1780) Proc R Soc B 20133172.

${ }^{138}$ Chephra McKee and Kristin Bohannon "Exploring the Reasons Behind Parental Refusal of Vaccines" (2016) 21(2) J Pediatr Pharmacol Ther 104-109 at 106; A Imdad and others "Religious exemptions for immunization and risk of pertussis in New York State, 2000-2011” (2013) 132(1) Pediatrics 37-43. 
Commonly known and expected reactions including pain, swelling, redness and itching at the site of injection, raised temperature, headache and general malaise. ${ }^{139}$ In rare cases, severe adverse effects can occur. ${ }^{140}$ The reporting system allows for health professionals, parents or people immunised to report adverse events. The system is a catch-all system to ensure that any warning signs are picked up and can be evaluated and acted on, if necessary.

A significant factor contributing to contemporary vaccine hesitancy, and one that has had a very detrimental effect on vaccine uptake, was a fraudulent study that claimed a link between vaccines and autism. ${ }^{141}$ The study was later retracted, ${ }^{142}$ but the seed of doubt was planted in the public's mind and the damage was done. ${ }^{143}$ Compounding the problem, the ubiquitous influence of the internet allowed the more vocal of the anti-vaccination movement to seize such stories and disseminate misinformation with a global rapidity that would not otherwise have been possible with traditional media (newspapers, magazines). Furthermore, because the research was published in a reputable journal (The Lancet), people opposed to vaccination could lay claim to it being scientific evidence of a link with disease. Added to this are Web 2.0 functions, such as Facebook and Twitter, which have allowed people to share their own stories of adverse reactions to vaccines, ${ }^{144}$ further fanning the flames of the dangers of vaccination.

139 Ministry of Health "Adverse Event Information to be released to the Health Select Committee" $<w w w . h e a l t h . g o v t . n z>$.

${ }^{140}$ Ibid. At the time of writing, two infants in Samoa died within moments of each other after receiving a dose of a vaccine.

141 Andrew Wakefield and others "Ileal-lymphoid-nodular hyperplasia, non-specific colitis, and pervasive developmental disorder in children" (1998) 351 Lancet 637-641.

142 The Editors of The Lancet "Retraction-Ileal-lymphoid-nodular hyperplasia, non-specific colitis, and pervasive developmental disorder in children" (2010) 375 Lancet 445.

${ }^{143}$ KF Brown and others 'UK parents' decision-making about measles-mumps-rubella (MMR) vaccine 10 years after the MMR-autism controversy: a qualitative analysis" (2012) 30 Vaccine 1855-1864.

${ }^{144}$ Dubé and others, above n 123. 
Despite numerous studies finding no association between vaccines and autism, ${ }^{145}$ those who believe in links to disease may feel vindicated to a certain extent by the recent European Court of Justice decision in which it was determined that European Union laws do not stop courts from considering serious, specific and consistent circumstantial evidence in vaccine-related injury cases, alongside scientific evidence. ${ }^{146}$ Anti-vaccination supporters can also direct attention to the United States establishing a "vaccine court," which administers a no-fault system for determining vaccine-related injury claims. ${ }^{147}$ Additionally, the removal of mercury (thimerosal) from vaccines as a precautionary measure ${ }^{148}$ did not do much to alleviate fears about the safety of vaccines.

\section{Religious Beliefs}

In the United States, religious refusal to compulsory immunisation has "a long history, reaching back to those who rejected Edward Jenner's 1796 mode of smallpox vaccination as contrary to God's will". ${ }^{149}$ While the United States has laws requiring compulsory vaccination against specified diseases, most states provide an exemption on religious grounds..$^{150}$

An example of religious beliefs guiding vaccine decisions is Phillips $v$ City of New York. ${ }^{151}$ In that case, Ms Check challenged, on religious grounds, the city's vaccine policy that prevented unvaccinated children attending school when a schoolmate had a vaccine-

\footnotetext{
${ }^{145}$ See, for example, LE Taylor and others "Vaccines are not associated with autism: an evidence-based metaanalysis of case-control and cohort studies" (2014) 32(29) Vaccine 3623-3629.

${ }^{146}$ Case C-621/15 N.W, L.W, C.W v Sanofi Pasteur MSD SNC, Caisse primaire d'assurance maladie des Hauts-de-Seine, Carpimko (ECJ 21 June 2017).

147 The National Vaccine Injury Compensation Program, the official name for the vaccine court, establishes a compensation programme where cases of alleged injury or death resulting from administration of compulsory childhood vaccines are litigated.

${ }^{148}$ United States Food and Drug Administration "Thimerosal and Vaccines" <www.fda.gov>.

149 JD Grabenstein "What the world's religions teach, applied to vaccines and immune globulins" (2013) 31(16) Vaccine 2011-2013. A good overview of the history of compulsory vaccination of school children in the United States is provided in Rebecca Bucchieri "Religious freedom versus public health: the necessity of compulsory vaccination for schoolchildren" (2015) 25 BU Pub Int LJ 265.

${ }^{150}$ CDC "State School and Childcare Vaccination Laws" < www.cdc.gov>.

${ }^{151}$ Philips v City of New York 27 F Supp 3d 310 (2014).
} 
preventable disease. ${ }^{152}$ The New York Times, reporting on the case, quoted Ms Check's reasons for not wanting to vaccinate her child: ${ }^{153}$

Disease is pestilence, and pestilence is from the devil. The devil is germs and disease, which is cancer and any of those things that can take you down. But if you trust in the Lord, these things cannot come near you.

An extreme example of religious beliefs (also coupled with distrust of government) and a refusal to vaccinate is provided by the killing of polio vaccination workers in Pakistan by the Taliban. The Taliban, in 2012, issued a fatwa ${ }^{-154}$ declaring that polio drops were poison and banned all vaccination programmes in areas under their control. Religious leaders who shared the same anti-Western views as the Taliban echoed the threats. As they, along with the Taliban, saw polio drops as a Western conspiracy to sterilise Muslims. Compounding the problem was the belief that the "best form of medicine was an amulet against evil confected by local imams, science had no sway over religion". ${ }^{155}$

Such views provided by these two examples support Tim Dare's argument that when people lack shared standards and beliefs, rational arguments cannot proceed in the debate

\footnotetext{
${ }^{152}$ New York Codes, Rules and Regulations Title 10, 66-1.10 Exclusion in event of disease outbreak, subsection (a) <www.regs.health.ny.gov>.

${ }^{153}$ Benjamin Mueller "Judge Upholds Policy Barring Unvaccinated Students During Illnesses" New York Times (online ed, New York, 22 June 2014).

${ }^{154}$ The Islamic Supreme Council of America explains fatwā: "A fatwā is an Islamic legal pronouncement, issued by an expert in religious law (mufti), pertaining to a specific issue, usually at the request of an individual or judge to resolve an issue where Islamic jurisprudence (fiqh), is unclear. Typically, such uncertainty arises as Muslim society works to address new issues - issues that develop as technology and society advance <www.islamicsupremecouncil.org>.

${ }^{155}$ Tim McGirk "Taliban Assassins Target Pakistan's Polio Vaccinators" The National Geographic (online ed, 3 March 2015). The assassination of polio workers began after the CIA used a fake vaccination campaign for hepatitis B, not polio, to identify and gain access to Osama bin Laden's hideout in Abbottabad. See, for example, Jason Burke "Polio vaccination workers shot dead in Pakistan" The Guardian (online ed, United Kingdom, 18 December 2012). For a detailed discussion on the challenges facing eradication of polio in Pakistan, see Shoaib Fahad Hussain and others "Eradicating polio in Pakistan: an analysis of the challenges and solutions to this security and health issue" (2016) 12 Global Health 63.
} 
over mass vaccination programmes. ${ }^{156}$ As religious reasons for not immunising a child tend to be intentional and considered, it is difficult to dissuade these people from their views, which often involve a complete refusal to vaccination. ${ }^{157}$

\section{Distrust of Government and Medicine}

Vaccine hesitancy under this section may be better explained as a lack of trust in the traditional sources of authority, particularly governments and the scientific community. A study by sociologist Gordon Gauchat found that, despite increasing education, trust in the scientific community has been decreasing ${ }^{158}$ Atul Gawande, commenting on the study, notes: ${ }^{159}$

Today, we have multiple factions putting themselves forward as what Gauchat describes as their own cultural domains, "generating their own knowledge base that is often in conflict with the cultural authority of the scientific community."

Gawande continues: ${ }^{160}$

As varied as these groups are, they are all alike in one way. They all harbor sacred beliefs that they do not consider open to question.

To defend those beliefs, few dismiss the authority of science. They dismiss the authority of the scientific community. People don't argue back by claiming divine authority anymore. They argue back by claiming to have the truer scientific authority.

\footnotetext{
156 Tim Dare "Disagreement Over Vaccination Programmes: Deep or Merely Complex and Why Does It Matter?” (2014) 26(1) HEC Forum 43.

${ }^{157}$ McKee and Bohannon, above n 138.

158 Gordon Gauchat "Politicization of Science in the Public Sphere: A Study of Public Trust in the United States, 1974 to 2010” (2012) 77(2) Am Sociol Rev 167-187.

${ }^{159}$ Atul Gawande "The Mistrust of Science” The New Yorker (online ed, New York, 10 June 2016).

160 Ibid.
} 
Interestingly, while Ms Check's beliefs (discussed above) were grounded in religion, they do have similarities to the contemporary health movement, which has seen people become more interested in their own health decisions, with some turning away from reputable science and modern medicine and towards "natural" options; for example, paleodiets and homeopathy. ${ }^{161}$ The availability of information has contributed to the rise of "informed" individuals and has resulted in a shift of power away from the traditional health-related decision-makers (governments, health organisations, doctors) and empowered people to make their own decisions about their health. ${ }^{162}$

It may be, then, that "vaccination is victim of its own success". ${ }^{163}$ As people no longer see vaccine-preventable diseases (diphtheria and polio, for example), they begin to question current scientific wisdom, the legitimacy of vaccination programmes, and, interestingly, the authority of the scientific community itself.

\section{$B$ Barriers to Immunisation in New Zealand}

There has been considerable global decline in morbidity and mortality from several vaccine-preventable diseases since the introduction of mass immunisation programmes. New Zealand, however, has not achieved the same population health benefits as seen in other countries. Primarily, this is because immunisation coverage has not been at sufficiently high levels to reach population (or "herd") immunity. Timeliness of delivery of vaccine events are also important. Delay in receipt of the first vaccine dose in the primary series is a strong predictor of subsequent incomplete immunisation. ${ }^{164}$

This section discusses factors that have historically contributed to poor immunisation coverage and timeliness in New Zealand. Information provided here has largely been taken

\footnotetext{
${ }^{161}$ See generally, Jack the Insider "Paleo and the new Scientology" The Australian (online ed, 18 March 2015).

${ }^{162}$ Dubé and others, above n 123.

163 JL Schwartz and AL Caplan "Vaccination refusal: ethics, individual rights, and the common good" (2011) 38(4) Prim Care 717-728 at ix.

${ }^{164} \mathrm{~B}$ Guyer and others "Immunization coverage and its relationship to preventive health care visits among inner-city children in Baltimore" (1994) 94(1) Pediatrics 53-58.
} 
from the work of Dr Nicola Turner, Director of the New Zealand Immunisation Advisory Centre. ${ }^{165}$ Dr Turner's work encompasses 14 years of research and incorporates 29 peerreviewed papers. Her aim was to document and analyse the reasons behind the improvement in infant immunisation coverage and the reduction in socio-economic and ethnic gaps that have been occurring since 2000 .

In 1991-1992, New Zealand undertook a national survey to measure immunisation coverage for children. ${ }^{166}$ Prior to this, there was no systematic approach to reporting. The results of the survey reported less than $60 \%$ immunisation coverage for all children by the age of 2 years, and that there was significantly lower coverage for children from poorer backgrounds and among ethnic groups, particularly Māori. The next national survey occurred in 2005, the year that the National Immunisation Register was implemented, and reported that $77 \%$ of children were fully immunised by 2 years old. Similar ethnic disparity remained. ${ }^{167}$

The results of the two national surveys as well as an additional survey conducted in Northland in $1997^{168}$ suggested that predictive factors for low levels of immunisation coverage were household poverty, younger age of the principal carer, delayed start to the immunisation programme, later birth order in the family, ethnicity of the principal caregiver being Māori or Pacific, and families with high mobility.

\footnotetext{
${ }^{165}$ Nikki Turner "Factors associated with immunisation coverage for the childhood immunisation programme in New Zealand: 1999 to 2012" (PhD, The University of Auckland, 2014).

166 Paul Stehr-Green and others "Immunisation coverage in New Zealand: Results of the regional immunisation coverage surveys" 1992 92(Suppl 2) Communicable Diseases NZ.

${ }^{167}$ Ministry of Health, above $\mathrm{n} 5$.

${ }^{168}$ Based on mathematical modelling that a measles epidemic was imminent and concerned over a lack of data on immunisation coverage, North Health Regional Health Authority funded a survey of children in their region. See D Lennon and others "Immunisation coverage in North Health. Comparative results from North Health's 1996 immunisation coverage survey" (Northern Regional Health Authority, Auckland, 1997). The two national surveys and one regional survey can be validly compared because the three surveys used the same methodology recommended by the WHO.
} 
From 2005, there has been progressive improvement in immunisation coverage as well as a reduction in traditional equity gaps and improvement in timeliness of delivery. However, factors associated with low immunisation coverage remain, potentially leaving children at risk for vaccine-preventable diseases. In New Zealand, these factors follow international research and can be broadly grouped as family characteristics, healthcare systemassociated factors and immunisation policy. ${ }^{169}$

\section{Family Characteristics}

Family characteristics associated with immunisation coverage include socio-economic factors, ethnicity issues, access to providers, and family beliefs and trust and confidence in vaccine providers.

Socioeconomic factors appear to be strong drivers behind immunisation decisions. ${ }^{170}$ Some factors contributing to disparity have been reported to include larger household sizes, households with single parents, household mobility, and geography. ${ }^{171}$ Also at higher risk of lower immunisation uptake are babies born pre-term, children with chronic or recurrent illness, children to younger mothers, and children of parents with lower education levels. ${ }^{172}$

Interestingly, there is conflicting international evidence on both parental education levels and socioeconomic status and vaccine decisions.

For education levels, studies have reported that parents with less formal education have greater distrust in the medical community, are less likely to believe in the necessity and

\footnotetext{
169 Taskforce on community preventive services "Recommendations regarding interventions to impose vaccination coverage in children, adolescents, and adults" (2000) 18(Suppl 1) Am J Prevent Med S92-S96. ${ }^{170} \mathrm{~S}$ Mueller and others "Measuring disparities in immunisation coverage among children in New Zealand" (2012) 18(6) Health Place 1217-1223.

${ }^{171}$ Felicity Goodyear-Smith and others "Determining immunisation coverage rates in primary health care practices: a simple goal but a complex task" (2008) 77(7) Int J Med Inf 477-485.

172 Turner, above n 165, at 252.
} 
efficacy of vaccines, and have greater concerns about vaccine safety. ${ }^{173}$ To the contrary, parents with higher education levels were nearly four-times more likely to be concerned about vaccine safety compared with parents with lower education levels. ${ }^{174}$ Another study reported that refusal of all vaccines were more common among college-educated parents compared with parents with a lower level of education. ${ }^{175}$

For socio-economic status, there appears to be conflicting associations between income level and immunisation acceptance, possibly reflecting beliefs about vaccines that vary by socio-economic strata. ${ }^{176}$ It has been suggested that the contradiction could be associated with differing perceptions of what "vaccine safety" means among parents from different socioeconomic backgrounds. ${ }^{177}$ That study noted that further research is needed to understand what the terms "side effects," "safety", and "adverse events" mean to different populations of people.

Geography impacts immunisation coverage. Like-minded individuals may group together, with religious or other beliefs (cultural, for example) influencing immunisation decisionmaking. Such communities may be more susceptible to vaccine myths and vaccine concerns and can result in pockets of unvaccinated children. While not a physical location, this was identified in the context of social media, with users grouping together in echo chambers where like-minded views of the group reinforce individual beliefs.

$\overline{{ }^{173} \text { DJ Opel and others "Validity and reliability of a survey to identify vaccine-hesitant parents" (2011) } 29}$ Vaccine 6598-6605; R Prislin and others "Immunization status and sociodemographic characteristics: the mediating role of beliefs, attitudes, and perceived control" (1998) 88 Am J Public Health 1821-1826; IM Shui and others "Parents concerned about vaccine safety: Differences in race/ethnicity and attitudes" (2006) 31 Am J Prev Med 244-251; DA Gust and others "Parental perceptions surrounding risks and benefits of immunization" (2003) 14 Semin Pediatr Infect Dis 207-212; DA Gust and others "Parent attitudes toward immunizations and healthcare providers the role of information" (2005) 29 Am J Prev Med 105-112.

${ }^{174}$ Opel and others, above n 173.

175 PJ Smith and others "Children who have received no vaccines: who are they and where do they live?" (2004) 114 Pediatrics 187-195.

${ }^{176}$ Gowda and Dempsey, above n 4. See also IM Shui and others, above n 173; Gust and others, above n 173; Opel and others, above n 173; AM Kennedy and others "Vaccine beliefs of parents who oppose compulsory vaccination” (2005) 120 Public Health Rep 252-258.

177 Gowda and Dempsey, above $\mathrm{n} 4$. 
Healthcare, including vaccines, ${ }^{178}$ are funded in New Zealand for children under the age of 13 years. ${ }^{179}$ Yet geography can make access to a vaccine-provider difficult. A 2002 study ${ }^{180}$ surveyed New Zealand mothers with the aim of identifying potential and existing barriers that precluded children aged two years and under from completing the immunisation schedule. The study reported that while access to vaccine providers was not a problem, the effort involved was. Effort could include taking time off-work to take a child to receive a vaccine and the costs associated with travel or providing alternative child-care arrangements.

Barriers to immunisation can either be functional (for example, socioeconomic conditions) or perceptual (for example, the belief that vaccines are unnecessary). Parental perception is a key driver behind vaccine-hesitancy. As noted in Chapter 2, the media can influence vaccine decision-making. The way the message is framed, ${ }^{181}$ particularly in the headlines, ${ }^{182}$ can affect the way an individual, family or community thinks about vaccines.

Other drivers contributing to vaccine hesitancy are parental fears over perceived sideeffects, lack of perceived concerns over the effects of the disease and a belief that healthy living will provide protection from disease. ${ }^{183}$ These are all manifestations of issues at the science-policy-society interface discussed earlier. The issues include distrust of medicine and a belief in alternative therapy and nutrition, a lack of trust in traditional health authorities like doctors and thinking that reading something for oneself provides sufficient interpretation.

\footnotetext{
${ }^{178}$ Ministry of Health Immunisation Handbook (2nd ed, Ministry of Health, Wellington, 2017) at 12.

${ }^{179}$ Ministry of Health "Zero Fees for Under-13s" <www.health.govt.nz>.

${ }^{180}$ Helen Petousis-Harris and others, above n 122.

${ }^{181}$ Helen Petousis-Harris and others "Fact or fallacy? Immunisation arguments in the New Zealand print media" (2010) 34(5) Aust NZ Med J Public Health 521-526.

${ }^{182}$ Nikki Turner and others "The use and misuse of media headlines: lessons from the MeNZB immunisation campaign" (2009) 122(1291) NZ Med J 22-27.

183 Turner, above n 165, at 253.
} 


\section{Healthcare System-associated Factors}

Healthcare system-associated factors include healthcare provider systems and resources, and provider knowledge and attitudes towards vaccines.

In New Zealand, good work has been done to improve immunisation coverage rates, resulting in rates increasing nationally and disparity gaps closing. However, rates do continue to vary at the local level among general practices. ${ }^{184}$

For both immunisation coverage and timeliness, the most significant factors for variation among practices included the age at enrolment (the earlier the better), the use of practice management systems, and a stable practice with low staff turnover. ${ }^{185}$ A well-functioning and supported staff given dedicated time for immunisation delivery services as well as positive engaged relationships with families were also important, ${ }^{186}$ as was healthcare providers' confidence and knowledge, ${ }^{187}$ particularly a healthcare professional's ability to communicate effectively with parents. ${ }^{188}$ Part of the knowledge/communication loop requires that healthcare professionals understand true contraindications ${ }^{189}$ and do not miss

\footnotetext{
${ }^{184}$ Cameron Grant and others "Factors associated with immunisation coverage and timeliness in New Zealand" (2010) 60(572) Br J Gen Pract e113-e120; Nikki Turner "The challenge of improving immunization coverage: The New Zealand example" (2012) 11(1) Expert Rev Vaccines 9-11; Cameron Grant and others "Primary care practice and health professional determinants of immunisation coverage" (2011) 47 J Paediatr Child Health 531-549.

${ }^{185}$ Grant and others "Factors associated with immunisation coverage and timeliness in New Zealand", above n 184, at e118; Turner, above n 184, at 10.

${ }^{186}$ Grant and others "Primary care practice and health professional determinants of immunisation coverage", above $\mathrm{n} 184$.

${ }^{187}$ Felicity Goodyear-Smith and others "Comparison of general practitioner and practice nurse perceived barriers to immunization uptake" (2005) 32(3) NZ Family Physic 164-171.

${ }^{188}$ Helen Petousis-Harris and others "Family physician perspectives on barriers to childhood immunisation" (2004) 22(17-18) Vaccine 2340-2344.

${ }^{189}$ Contraindications, in the context of immunisation, are conditions in a recipient that increases the risk for a serious adverse reaction, and precautions to vaccination are conditions under which vaccines should not be administered: CDC "Contraindications and Precautions" < www.cdc.gov>
} 
vaccination opportunities. ${ }^{190}$ Additionally, families with high mobility can also result in a reduced continuity of care, increasing the risk for a child missing a vaccination event. ${ }^{191}$

At the provider level, a well-functioning system results in high immunisation coverage. Positive aspects include early enrolment, supply and costs to the provider, information systems, recording keeping and tracking and continuity of care. Incorrect or unavailable data, a lack of resources and poor data-sharing can lead to the vaccine provider losing trust and confidence in the system. ${ }^{192}$

Information provided to parents by healthcare professionals can impact immunisation coverage. Discouraging advice about vaccinations given by healthcare providers could be a cause for concern. The antenatal period has been identified as the most important time for parents when it comes to making immunisation decisions for their children. ${ }^{193}$ A policy brief on data from the Growing Up New Zealand study based at the University of Auckland Centre for Longitudinal Research reported that $11 \%$ of pregnant women described midwives as the source of discouraging information about immunisations and $8 \%$ received discouraging information in antenatal classes. ${ }^{194}$

Discouraging advice does not necessarily mean that it will be acted on, but it does not mean that it will not have an impact either. An interesting study in 1978 examined the placebo effect and noted that the way a doctor speaks about an intervention can influence the patient's belief in the effectiveness of that intervention. The study found that pills (a placebo) that were handed out with a positive message before a dental injection were

\footnotetext{
${ }^{190}$ Petousis-Harris and others, above n 188; Helen Petousis-Harris and others "Family practice nurse perspectives on barriers to immunising children” (2005) 23(21) Vaccine 2725-2730.

${ }^{191}$ Ministry of Health, above $\mathrm{n} 5$.

${ }^{192}$ Cameron Grant and others "Primary care practice and health professional determinants of immunisation coverage", above n 184; Nikki Turner and others "The cost of immunising at the general practice level" (2010) 1(4) J Prim Health Care 286-296.

193 AL Wroe and others "Understanding and predicting parental decisions about early childhood immunizations" (2004) 23(1) Health Psych 33.

${ }^{194}$ Growing Up in New Zealand "Who is saying what about immunisation: evidence from Growing Up in New Zealand" (Policy Brief 6, Auckland, June 2015).
} 
associated with less fear, anxiety and pain compared with pills handed out with a negative message. ${ }^{195}$ Positive interactions have been found to be important in maintaining confidence in vaccinations and can motivate a hesitant parent towards immunisation. ${ }^{196}$

Regardless of the effect on the individual, the beliefs of healthcare workers on the risks (or benefits) of vaccines can have a wider impact on the level of trust that the public places in the medical establishment and in vaccines, and, ultimately, government policy, either in the form of advice received personally or inferences drawn from what is portrayed in the media. The controversy surrounding the screening of an anti-vaccination film in Kaitaia in May 2017 provides an example. At the screening, Dr Lance O'Sullivan, 2014 New Zealander of the Year for his work in bringing health programmes to the disadvantaged in rural New Zealand, took to the stage to criticise healthcare workers who were attending. He said that they "... should not be here, it is incompatible for you to be here and watching this movie ...". ${ }^{197}$

This event, and the subsequent discussion in the media, could lead some to believe that, because healthcare workers were in attendance, then perhaps there is disagreement among medical professionals on the benefits and risks of vaccines. This issue emerged earlier, where special interest groups sowing seeds of doubt, coupled with time given to opposing views in the media, result in people thinking that the science is less well settled than it is. These factors undermine the trust and confidence that people have in established sources of authority and could result in public opposition to any future proposed immunisation policy that seeks to incorporate science into decision-making.

195 SL Gryll and M Katahn "Situational factors contributing to the placebos effect" (1978) 57(3) Psychopharmacology (Berl) 253-261.

196 J Leask and others "Communicating with parents about vaccination: a framework for health professionals" (2012) 12 BMC Pediatr 154.

197 Emily Cooper “Furious Dr Lance O'Sullivan asks why healthcare workers were at anti-vax film - 'It is incompatible for you to be here"” OneNewsNow (online ed, Auckland, 24 May 2017). 


\section{Immunisation Policy}

Immunisation policy includes governance and national schedules, funding and resourcing, and policies and communication approaches. New Zealand's approach to improving immunisation coverage has been one of enabling rather than prescribing, with the focus on removing barriers to immunisation uptake. This section outlines some policy initiatives.

In New Zealand, the Ministry of Health and the District Health Boards have the function of improving, promoting and protecting public health. ${ }^{198}$ One way that the health agencies seek to carry out this function is to continue to work towards increasing immunisation coverage. The Ministry of Health lists immunisation as one of six 2017/2018 health targets. The target is $95 \%$ of 8 -month-olds will have their primary course of immunisation (6 weeks, 3 months, and 5 months immunisation events) on time. This target is the same as $2014 / 2015$ but an improvement on previous years. The target in 2013/2014 was $90 \%$ and $2012 / 2013$ was $85 \%$. $^{199}$

The Ministry of Health acknowledges that increasing immunisation coverage requires improvements to the entire immunisation system, including early enrolment of infants in general practice and ongoing engagement with Well Child services. This approach has necessarily broadened to counter the negative influence of the vast quantity of antivaccination material and misinformation readily available on the internet.

The National Immunisation Register is a key tool in achieving New Zealand's immunisation goals. The Register provides accurate data on a child's immunisation status. The Register was implemented in 2005. Since then, it has enabled accurate measurement of immunisation coverage, both regionally and nationally, and has allowed those involved with immunisation programmes to gauge the effectiveness of national immunisation strategies. The Register has also allowed for the development of immunisation programmes targeting those most at risk for missing a vaccination event.

\footnotetext{
${ }^{198}$ Health Act 1956, s 3A; Public Health and Disability Act 2000, s 3(1)(a)(i).

${ }^{199}$ Ministry of Health "Health targets: Increased immunization" <www.health.govt.nz>.
} 
The Health (Immunisation) Regulations 1995 is the only legal instrument concerned with immunisation of children in New Zealand. The focus of the Regulations is on linking immunisation to childhood education by requiring early childhood centres and primary school centres to receive information from caregivers on vaccination status of children in the form of immunisation certificates. ${ }^{200}$ The Regulations also encourages caregivers to make an informed choice about immunisation. ${ }^{201}$

The importance of parents making an informed choice about immunisation is also stated in The Immunisation Handbook 2017..$^{202}$ The purpose of the Handbook is to provide clinical guidance to health professionals on the "safest and most effective use of vaccines" based on the best available evidence at the time. ${ }^{203}$

Safe and effective use of vaccines is supported by the National Standards for Vaccine Storage and Transportation for Immunisation Providers 2017. ${ }^{204}$ For an immunisation programme to be successful, it is vital that vaccines are stored and transported correctly. The Standards outline the requirements necessary for vaccine providers to achieve this goal.

Outreach Immunisation Services are an important tool for increasing immunisation coverage. The services ensure that "immunisation is available to children who are unable to access a general practice in a timely fashion for their immunisation events." 205

The Immunisation Advisory Centre is a nationwide organisation that provides information based on "international and New Zealand scientific research on vaccine-preventable

\footnotetext{
${ }^{200}$ Health (Immunisation) Regulations 1995, reg 4 and 5.

${ }^{201}$ Regulation 3(b).

${ }^{202}$ Immunisation Handbook, above n 178, at 41-43.

${ }^{203}$ At 1.

204 Ministry of Health National Standards for Vaccine Storage and Transportation for Immunisation Providers 2017 (Ministry of Health, Wellington, February 2017).

205 Ministry of Health "National Review of Outreach Immunisation Services: Summary and Recommendations (May 2016)" < www.health.govt.nz> at 1.
} 
diseases and the benefits and risks of immunisation" and "immunisation coordination and policy advice and research" on vaccines and vaccine-preventable diseases. ${ }^{206}$ Dr Nikki Turner, the Director of the Centre, provided the government with a 6-star plan to increase immunisation coverage, much of which has been implemented.

\section{$D$ The Treaty of Waitangi}

The New Zealand Government is in the unique position of being a partner with Māori to the Treaty of Waitangi. Therefore, Māori health has an impact in the policy and law-making processes. This partnership creates a special relationship between the State and Māori and raises important legal and moral aspects that must be considered

Partnership under the Treaty is a collaborative process between the Government and Māori to achieve the best health outcomes for Māori. Partnership means working together. The Government's overarching framework to achieve this end is He Korowai Oranga. The key components of He Korowai Oranga are supporting whānau, hapū, iwi and community development, supporting Māori participation in the health and disability sector, ensuring effective health service delivery and working across sectors.

Importantly, partnership requires recognition that Māori are not only individuals but also part of a whānau, hapū, iwi. This has bearing on health strategies as Māori have their own aspirations for health. Such cultural organisation and aspirations must be recognised in any immunisation policy, and must include Māori cultural beliefs, values and practices.

A key thread of He Korowai Oranga is rangatiratanga. This means that Māori, as whānau, hapū and iwi have control over their own health and well-being. The New Zealand Public Health and Disability Act 2000 recognises the importance of rangatiratanga, with s 23 of that Act providing that District Health Boards must "establish and maintain processes to enable Māori to participate in, and contribute to, strategies for Māori health improvement"

${ }^{206}$ Immunisation Advisory Centre "About" <www.immune.org.nz>. 
and "foster the development of Māori capacity for participating in the health and disability sector and for providing for the needs of Māori”.

The formulation of immunisation policy or law must include recognition of the principles of the Treaty of Waitangi. This means that a Government strategy cannot be formulated and implemented without consultation with Māori, and importantly must include the Māori worldview and cultural beliefs. It is also noted that New Zealand is home to a multitude of ethnicities, and it is vital that policy or law considers and reflects this. 


\section{$V \quad$ Developing a Decision-making Framework}

This chapter sets out the decision-making framework proposed in this thesis. The chapter begins by discussing why it is important for policymakers to understand vaccine hesitancy before suggesting some options to increase immunisation coverage. The framework is then described in greater detail to guide the reader through the subsequent discussion in Chapters VI-VII where the framework is applied to the immunisation debate.

Science can guide public health policy if based on a sound evidential foundation; however, any decision must allow room for non-science factors if it is to achieve the desired outcome and be accepted by the public. Both science and values are important to policy-formation but when science is presented in a values-laden way, it loses its privileged place in the policymaking process. Conversely, if science is ignored or misused it can result in decisions that are less likely to produce effective outcomes. ${ }^{207}$

How then can science best be used to inform public health policy? This research proceeds on the basis that science does not make policy, it can only inform policymakers about the options available to them. Gone are the views espoused by Robert Merton that science stands apart from the rest of society yet informs the ignorant public by preaching to them from a pulpit. ${ }^{208}$ Science is but one factor requiring consideration when determining immunisation policy — a multifactorial problem with both complex science and strong values components. To achieve justified and accepted immunisation policy, clear demarcation between science and values is required.

This thesis draws on scientific methodology, common law, legislation and jurisprudence to create a model that can be applied to help guide policymakers when faced with complex questions that involve science and values components.

\footnotetext{
${ }^{207}$ Peter Gluckman "Interpreting science - implications for public understanding, advocacy and policy formation. A discussion paper" Office of the Prime Minister's Chief Science Advisor <www.pmcsa.org.nz>.

${ }^{208}$ Robert K Merton "The Matthew Effect in Science” (1968) 159(3810) Science 56-63.
} 
Immunisation provides a context through which the different effects of science, particularly the public's understanding of science, and legal theories may be explored, and implications considered. In many cases, policy options that seek to incorporate or be guided by scientific evidence present legal questions that may be answered by reference to "different philosophies about the nature of law and its role in society". ${ }^{209}$

In this scenario, it is envisaged that a policymaker is considering policy options to increase immunisation coverage. Options include making immunisation compulsory for all children, making immunisation compulsory for subgroups of the population (beneficiaries or healthcare workers), non-coercive policy measures and restricting anti-vaccination propaganda.

\section{A Why it is Important for Policymakers to Understand Immunisation Coverage}

Developing appropriate measures to address immunisation coverage levels first requires recognition that there is a problem that requires a response. Understanding the multifactorial drivers behind vaccine hesitancy and low immunisation coverage is required before policymakers can begin framing a range of approaches to address public concerns about vaccines. These multifactorial drivers must be measured accurately to understand the scope of the problem. The data collected will be critical in designing evidence-informed strategies that are relevant and successful. ${ }^{210}$

Failure to accurately measure and understand the problem means that any policy initiatives, and this potentially includes using the coercive power of the law, can be applied only using a "best guess" approach with no real measurable indicators of success attributable to the intervention.

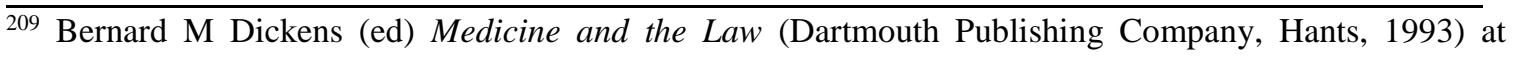
Introduction xi.

${ }^{210}$ Melanie Marti and others "Assessments of global drivers of vaccine hesitancy in 2014-Looking beyond safety concerns" (2017) 12 PLoS ONE e0172310.
} 
To change attitudes towards vaccination (if that is the desired goal), and to combat misinformation and scaremongering, it is important for policymakers to understand that vaccination decisions fall on a continuum, with full acceptance at one end and vehement refusal at the other. ${ }^{211}$ Adding a further layer of complexity are emotional, social, cultural, religious and geographical considerations. When determining strategies to increase coverage rates, "vaccination programs need to reflect and address these context-specific factors in both their design and evaluation". 212

Understanding the concerns people have about vaccines helps inform policy and can provide tools to counter vaccine hesitancy; for example, strategies to combat parental anxieties about the pain associated with vaccines could include quick administration, providing tactile stimulation and administering the most painful vaccine last. ${ }^{213}$ Such strategies could be included in health guidelines, such as the Immunisation Handbook. ${ }^{214}$

Approaches should not necessarily be confined to individual countries in isolation. Determining global themes behind vaccine hesitancy allows for multi-national and multistakeholder collaboration and a pooling of resources to determine the best way to develop and implement effective strategies or policies. ${ }^{215}$ This is particularly important with regard to infectious diseases and globalisation, and the profound impact that the volume, speed and reach of global travel and trade have had on the spread of disease in a "borderless world". ${ }^{216}$ The International Health Regulations 2005 provides an international framework

\footnotetext{
${ }^{211}$ Kumar and others, above n 67.

212 Ibid.

${ }^{213}$ Determined in a study by A Taddio and others "Reducing the pain of childhood vaccination: an evidencebased clinical practice guideline (summary)" (2010) 182(18) CMAJ 1989-1995, cited in Kathryn M Edwards and Jesse M Hackell; The Committee on Infectious Diseases; The Committee on Practice and Ambulatory Medicine "Countering Vaccine Hesitancy" (2016) 138(3) Pediatrics e20162146.

214 Immunisation Handbook, above n 178.

215 Ana Iltis and Kirstin Matthews "NTD policy priorities: Science, values, and agenda setting” (2017) 11(5) PLoS Negl Trop Dis e0005431.

216 Institute of Medicine (US) Forum on Microbial Threats Infectious Disease Movement in a Borderless World: Workshop Summary (National Academies Press, Washington DC, 2010) at ch 2.
} 
for member states of the World Health Organisation to prevent and control the spread of diseases between countries. ${ }^{217}$

Risk communication is also important. Transparency in policy decision-making and parents trusting governments and health professionals are vital to influencing vaccinerelated decisions. ${ }^{218}$ Trust can be developed by educating the public about how vaccines are made and tested, the benefits of immunisation, clearly detailing the risks and adverse effects and countering inaccurate information. An approach that seeks to alleviate or accommodate fears will build trust and be far more effective than applying a paternalistic blanket. $^{219}$

In the context of trust, or a lack of it, a problem facing the policymaker is how to accommodate irrational beliefs within public health considerations. If too much weight is placed on liberty, on the one hand, some people are at the mercy of anti-vaccination rhetoric. If too much weight is placed on rationality, on the other hand, it removes autonomy and limits options amongst which to choose. ${ }^{20}$ A better approach to countering inaccurate information or irrational beliefs and restoring trust in science and the scientific community may be to expose pseudoscience tactics that misled; giving people the tools to identify bad science and to make better decisions for themselves. ${ }^{221}$

Policy development and public health goals must be set within the wider social and democratic spheres, including human rights and parental responsibilities. Failing to understand, address and accommodate reasons for low immunisation coverage can only

\footnotetext{
${ }^{217}$ International Health Regulations (2005) 2509 UNTS 79 (opened for signature 23 May 2005, entered into force 15 June 2007).

${ }^{218}$ Benin, above $\mathrm{n} 134$.

${ }^{219}$ See generally, John Coggon and José Miola “Autonomy, liberty, and medical decision-making” (2011) 70(3) Camb Law J 523-547.

${ }^{220}$ Coggon and Miola, above n 219, at 524.

${ }^{221}$ Gawande, above n 159; see generally, J Cook and Lewandowsky The Debunking Handbook (University of Queensland, St Lucia, Australia, 2012). However, a growing body of research suggests that providing further information has the opposite effect; people's views become even more entrenched.
} 
result in implementation and enforcement problems with any vaccine programme, particularly compulsory immunisation, and people who were previously undecided or indifferent (those that could be "nudged" to make better choices) ${ }^{222}$ may push back against a utilitarianist approach.

Building trust through clear and transparent policy initiatives, educating the public about the safety and testing of vaccines, recording and analysing vaccine-related adverse events, listening to and alleviating parental concerns, and countering incorrect information are all possible options to reduce vaccine hesitancy and ensure that children are protected from vaccine-preventable diseases. Failing such initiatives, implementation of the coercive power of the law may be required.

\section{B Policy Options to Increase Immunisation Coverage}

This section outlines some policy options to increase immunisation coverage. This is not an exhaustive list. The options outlined are merely examples to help describe aspects of the decision-making framework in later chapters.

\section{Compulsory Immunisation}

Preferential weight being given to the concept of vaccination as a public good or civic duty to achieve disease elimination or control could result in some vaccines being required by law. Different options are available for the final shape of such a law. For example, vaccination could be a condition for entry into preschool or primary school.

\footnotetext{
${ }^{222}$ Marysia Laskowski "Nudging towards Vaccination: A Behavioural Law and Economics Approach to Childhood Immunization Policy" (2016) 94(3) Tex L Rev 601. For detailed discussion on the concept of nudges, see Thaler and Sustein, above n 66.
} 


\section{Linking Beneficiary Payments to Immunisation Status}

Tying government benefits to immunisation status as seen in Australia ${ }^{223}$ and an idea previously floated in New Zealand ${ }^{224}$ is another form a coercive immunisation policy could take.

Support for the proposition is framed in terms of reciprocal social obligations. A welfare working group recommended that recipients of a benefit should have to meet minimum health standards, including completion of the immunisation schedule. ${ }^{225}$

This approach would solve the difficult problem of how to enforce an immunisation law. Because beneficiaries are not in the financial position to oppose being singled out, and because most non-beneficiaries see payments as being, in the first instance, the legitimate property of the State, policymakers are less likely to encounter opposition. ${ }^{226}$

\section{Compulsory Immunisation of Healthcare Workers}

If one of the goals of immunisation is to protect those most at risk, requiring people working with the vulnerable to be vaccinated or show positive immunisation status could achieve this goal. This moves the immunisation debate from children, who are generally afforded greater legislative and moral protection, to adults.

\footnotetext{
${ }^{223}$ The federal parliament in Australia has passed the Social Services Legislation Amendment (No Jab, No Pay) Act 2015, abolishing the right to conscientiously object to vaccination for the purpose of eligibility to certain benefits provided under A New Tax System (Family Assistance) Act 1999 (Cth).

${ }^{224}$ Ministry of Health "Public Health Legislation: Promoting Public Health, Preventing Ill Health and Managing Communicable Diseases: Discussion Paper" (Ministry of Health, Wellington, 2002) at 33. See also, One News J D“Should Kiwi kids who aren’t vaccinated be banned from pre-school? Labour's Andrew Little says it's 'well worth looking at"' OneNewsNow (online ed, Auckland, 14 March 2017).

225 Welfare Working Group Reducing Long-Term Benefit Dependency (Welfare Working Group, Report, February 2011) at 12-16, 119.

${ }^{226}$ Kerr, above n 11, at 34 .
} 


\section{Non-coercive Policy Measures}

The World Health Organisation defines health as "a complete state of physical, mental and social well-being, not merely the absence of disease or infirmity."227 The New Zealand Government recognises that people's health is strongly influenced by factors outside the health system such as the home environment. Further, that the good health and mental wellbeing of parents help "the social development, educational outcomes and lifelong experiences of their children, and of their wider families and whanau".228

Outside influences and how they impact health, particularly immunisation decisions, were outlined in the early discussion on barriers to immunisation in New Zealand. Policies that reduce health inequalities and improve living conditions, such as reducing poverty and improved housing, are non-coercive means to improve immunisation coverage.

\section{Restricting Anti-vaccination Propaganda}

Restricting the spread of potentially harmful information opposing vaccination could be an option to increase immunisation coverage.

Governments rely on information provided by health professionals to parents about the benefits of vaccination. However, there is increasing anti-vaccination material readily available, particularly on the internet, aimed at moving parents away from vaccinating their children. This is problematic for governments as private provision of information does not always follow good information practices. That is, anecdote is commonly used in place of scientific information that follows proper scientific methodology, yet increasingly such information is held out as the "truth". It can be difficult for parents to discern the accuracy of information, particularly if websites cite journal articles of dubious quality in support of their comments.

\footnotetext{
${ }^{227}$ WHO "Constitution of the World Health Organization: Principles" <www.who.int>.

${ }_{228}$ Ministry of Health "New Zealand Health Strategy Future Direction” (Ministry of Health, Wellington, April 2016) at 4.
} 


\section{The Framework}

This thesis describes a three-stage framework that will help the policymaker make better decisions that have a strong evidential basis but do not undermine societal values, as the two can be confusingly tangled and may appear incompatible.

The first stage of the framework assesses the scientific evidence that may help inform policy. The second stage examines non-scientific values relevant to the decision-making process. The values discussed in the second stage include both legally protected rights and freedoms as well as those values that do not have a statutory basis but are generally accepted as desirable by the public. The third stage considers whether a restriction on values is none-the-less justified.

Each stage is briefly outlined in the following sections before being discussed more comprehensively in Chapters VI-VIII.

\section{Stage One-Science}

The first stage of the framework focuses on science. The important thing to keep in mind is that science should provide impartial knowledge regardless of where that knowledge has come from or why it is thought useful to policy. Although it may seem obvious that the best policies are those that are informed by scientific evidence, questions arise as to what exactly constitutes good evidence and where that evidence ought to come from. ${ }^{229}$ Because of the importance accorded science, it is critical that policymakers who rely on scientific evidence have justifiable and continuing confidence in it.

To overcome problems associated with the use of science in policy, and to determine whether the scientific evidence is acceptable, the policymaker should consider the evidence against several criteria. This is to ensure that the science is robust, reliable and applicable to the problem being addressed. If the science passes through this stage without difficulty,

\footnotetext{
${ }^{229}$ Pedersen, above $\mathrm{n}$ 8, citing WJ Sutherland and others "A Collaboratively-Derived Science-Policy Research Agenda" (2012) 7(3) PLoS ONE e31824.
} 
then the policymaker can be confident that the evidence that they are considering using to inform policy is acceptable and supports reasoned decision-making.

Underpinning this approach are the components of the scientific method. This is the foundation that gives science its validity and integrity, and why science is trusted as a dependable source for the generation of knowledge. At the centre of the scientific method is falsifiability: the ability to prove that something is not true. ${ }^{230}$ This distinguishes scientific evidence from other beliefs, such as religion and ideology, which place emphasis on faith and tradition. ${ }^{231}$ The idea is that the acquisition of scientific knowledge through process provides the platform from which debate about values can begin.

\section{The Nature of the Scientific Evidence}

The first stage of the framework requires the policymaker to turn their mind to the nature of the scientific evidence. This is a two-limbed examination comprising a gatekeeper analysis and an assessment of the applicability of the evidence to the problem. The twolimbed approach prevents the inclusion of misinformation, poorly conducted science or pseudoscience from guiding policy decisions and assures the policymaker that only the most reliable and relevant science is being used. The key idea here is that the scientific method can be used as a tool to differentiate science and values; it sorts fact from fiction. The underlying concept is that separation prevents non-science components interfering with scientific evidence.

Scientific evidence relating to immunisation can be contentious. Authoritative studies on the benefits of vaccines are called into question by other studies. The first limb of stage one resolves this tension by providing checks on the quality of the evidence. Using only evidence that is generally accepted by the scientific community and that has been published in a respectable peer-reviewed journal goes some way to ensuring robustness.

\footnotetext{
${ }^{230}$ See Karl R Popper The Logic of Scientific Discovery (Martino Fine Books, Mansfield, CT, 2014) at 40 42.

${ }^{231}$ Nurse, above n 38.
} 
Another ground for contention is bias on the part of the author of a study. The framework takes this phenomenon into account and asks the policymaker to look beyond the study to the agent submitting the research. Determining bias or a conflict of interest provides a further check on the quality of the research. It alerts the policymaker to potential skewing of information to support an agent's position.

\section{The Usefulness of the Scientific Evidence}

The second limb of stage one considers the usefulness of the scientific evidence. This limb tasks the policymaker with conducting a cost-benefit analysis and considering whether the evidence is relevant to the issue.

\section{E Stage Two-Values}

Once the validity and usefulness of the science has been examined, the second stage is where values are considered. Values are those factors that govern our individual and communal ideas, beliefs, and values - our worldviews. Values are not to be thought of as being something held by the individual in isolation. Māori, for example, have a more communal approach to identity and hold a different worldview from that of other predominate ethnic groups in New Zealand, such as Pākehā.

This stage is an analysis of the values relevant to immunisation decision-making and is an examination of the legal aspects underpinning individual, communal, cultural and State values and responsibilities. Taking an approach that considers values (those non-science aspects relevant to the decision-making process) is always relevant and widely applicable to any policy question.

Immunisation provides a useful case study as it raises many value questions that are common to other areas where science and health policy interact, such as human rights issues, particularly, bodily integrity, autonomy and privacy. Individual, communal and cultural values need to be balanced against the State's responsibility to protect the health and well-being of its citizens. Competing values create conflict between how the State can 
limit the rights of one person or cultural group to uphold the rights of another person or cultural group. ${ }^{232}$

\section{What are Values?}

Values are those things that individuals and communities believe are important to the way they live their lives. They help guide behaviour and decision-making and can serve as guidelines in our interactions with others. They can be used to determine good from bad or desirable from undesirable. Values denote the degree of importance that people individually, and society collectively, place on an action or an idea.

Values can be thought of in different ways. They can be thought of in economic, religious or philosophical terms. Values in this thesis are generally being considered in the legal context. The focus is on those values that are protected by law. Primarily, these are those values that protect the individual and communities from the power of the State and charge the State with looking after its citizens. Added to this is the importance of the State in protecting its citizens from harm from one and other. For example, protecting children, who are generally seen as most vulnerable, from the actions and decisions of their parents.

The term "values" is used to describe legal principles and concepts-legal standardstaken from international instruments, legislation and case law as terms of reference that can be applied to health policy decision-making.

While values in this thesis are mainly identified with the individual, values can also be communal or collective. For example, as noted above, the Māori worldview is based on whānau, hapū and iwi rather than the individual. Therefore, in New Zealand, values should be thought of as being both the values of the individual as well as those cultural factors that have a legal basis.

232 Andrew Butler and Petra Butler New Zealand Bill of Rights Act: A Commentary (2nd ed, LexisNexis, Wellington, 2015) at [6.6.33]. 
Legally protected rights may protect the individual against the State, which is partly true especially in the immunisation context, but they must also be seen as protecting the individual from others; for example, protecting children against parents/guardians who do not immunise their children (assuming that immunisation is a good thing).

Taking this point further, values are not just about legal rights but other legal principles. An example is the welfare of the child. While this can be thought of as a right, it is more about ensuring that the best interests of the child are promoted. This is coupled with the idea that parents and guardians primarily have responsibilities rather than rights (for example, under the Care of Children Act 2004) as do families and family groups (under the Oranga Tamariki Act 1989).

\section{Competing Interpretations of Values}

Values are diverse. They differ between countries and among communities within countries. Social, cultural and constitutional differences shape values. Differences in the way values are defined or interpreted can affect the balancing of individual values and community interests. ${ }^{233}$

The policymaker needs a way to calibrate values to a reasonable standard that is appropriate for their jurisdiction but also accommodates international ideas. A way to achieve this is to use domestic and international legislative tools that protect values and the courts' interpretation of the importance and scope of the values in the domestic setting.

Judicial interpretation provides a reasonable measure of a value. Both in developing case law and in interpreting legislation, judges are usually reluctant to compel individuals to act contrary to their own consciences, whether founded on their religious, social, political or other philosophical convictions, and will require contrary action only when vulnerable persons, such as children, are at medical risk of serious or irreversible harm. ${ }^{234}$ However, judges do need to make decisions.

${ }^{233} R v B$ [1995] 2 NZLR 172 at 183 per Richardson J.

${ }^{234}$ Dickens, above n 209, at Introduction xiv. 
In reaching a decision, judges will have considered competing arguments on topics such as religion, economics, political motivation, differing worldviews, cultural differences, international obligations and the prevention of harm. Further, because judicial interpretation builds upon precedent yet evolves over time to accommodate changing societal ideas about values, courts will have, at some stage, weighed broader policies or principles that have wide relevance and usefulness to how a problem should be dealt with in society.

Values are not all equally weighted in any balancing when they conflict with other competing interests. In some instances, the courts have been asked to determine which value wins out when two values are in competition. For example, both the right not to be deprived of life and the right to hold and manifest a religion are values protected by the Bill of Rights Act 1990. However, when the child of a Jehovah's Witness family required an urgent blood transfusion, the court had to weigh these competing values, ultimately curtailing the latter to save the life of the child. ${ }^{235}$

\section{Making Use of the Courts' Interpretations of Values}

The policymaker can be guided by judicial interpretations of values. Guidance does not place restrictions upon the policymaker. Turning to the courts for a standardised approach to values does not lead to judges assuming responsibility for determining the ultimate balancing of values. ${ }^{236}$ Where a court may have been constrained by having to follow or interpret a law, with the result resting somewhat uncomfortably, the same does not apply to the policymaker. They are free to make decisions after considering all competing factors and adopt a course of action that achieves the desired goal.

The argument could be made that judicial interpretation of values fails to understand that many thoughtful people would not want non-elected judges to confer upon others a

\footnotetext{
${ }^{235} \operatorname{Re} J$ (An Infant): $B \& B v D G S W$ [1996] 2 NZLR 134 (CA).

${ }^{236}$ Rt Hon Sir Ivor Richardson "The New Zealand Bill of Rights: Experience and potential, including the implications for commerce" [2004] Canta LR 10.
} 
curtailing of fundamental rights in the immunisation debate. Indeed, it has been suggested that such a morally complex topic is best left for determination at the highest level to "not only send a message about how seriously the government takes immunisation, but to ensure that the government is held accountable if the public disagrees with that message". ${ }^{237}$ This problem does not arise with the framework. The policymaker is using judicial interpretation as guidance only. The ultimate decision does indeed rest with the State.

\section{Rights and Freedoms and the Bill of Rights Act 1990}

Values in this thesis are mainly those human rights protected by law. In talking about rights and freedoms, commentators usually describe human rights in generations. ${ }^{238}$ The first generation of human rights are the civil and political rights. These rights emphasise the rights of the individual and communities and are the core of most human rights treaties. The second generation of human rights are social and economic rights. These rights impose duties on States to achieve results over time. For example, the right of everyone to the enjoyment of the highest attainable standard of physical and mental health. ${ }^{239}$ This requires governments to take steps in relation to child mortality, prevention and control of disease and provision of medical treatment. ${ }^{240}$ This is not a right that a government can simply deliver; it is going to take time.

In keeping with its international obligations, the New Zealand Government has enacted a range of domestic legislative tools to ensure the rights and freedoms of New Zealanders. For example, the civil and political rights of New Zealanders are protected by the Bill of Rights Act 1990. The Bill of Rights Act 1990 has as its purpose to affirm, protect, and promote human rights and fundamental freedoms in New Zealand and to affirm New Zealand's commitment to the International Covenant on Civil and Political Rights. ${ }^{241}$ The

\footnotetext{
$\overline{{ }^{237} \text { Kerr, above n 11, at 26-27. See generally Geoffrey Palmer and Mathew Palmer Unbridled Power: New }}$ Zealand's Constitution and Government (4th ed, Oxford University Press, Melbourne, 2004) at 207-212.

${ }^{238}$ Karel Vasak, (Speech given at the International Institute of Human Rights, Strasbourg, 1979).

${ }^{239}$ International Covenant on Economic, Social and Cultural Rights 999 UNTS 171 (opened for signature 19 December 1966, came into force 23 March 1976).

${ }^{240}$ Article 12(2).

${ }^{241}$ Bill of Rights Act 1990, long title.
} 
Act affirms many rights and freedoms that have long been recognised in the common law. ${ }^{242}$

The rights and freedoms contained within the Bill of Rights Act 1990 are expressed in general terms. Justice Glazebrook notes that the general wording allows for "easy adaptation to particular circumstances or changes in society". ${ }^{243}$ General expression aligns with the notion that human rights are not static. They grow and change and develop over time. The changing nature of human rights echoes the changing nature of scientific progress and understanding and appears to allow for protection of values in the face of changing scientific knowledge and scientific uncertainty.

The operative provisions of the Bill of Rights Act 1990 are ss 3-7. Section 3 provides that the Bill of Rights Act 1990 applies to all three branches of government and to all acts done that can be characterised as public. ${ }^{244}$ Section 4 prevents the courts from invalidating or declining to apply any provision of an Act by reason that it is inconsistent with the Bill of Rights Act $1990 .{ }^{245}$ Section 5 is a key provision of the Bill of Rights $\mathrm{Act}^{246}$ and is concerned with placing justified limitations on the rights and freedoms contained within the Act. ${ }^{247}$ Section 6 requires legislation to be read consistently with Bill of Rights Act 1990 where possible. Section 7 requires the Attorney-General to inform Parliament of any Bill that appears to be inconsistent with rights and freedoms in the Bill of Rights Act $1990 .{ }^{248}$

Inconsistency does not mean that a proposed law cannot be passed, but it does ensure that issues are known and discussed. The reporting requirement ensures that Bill of Rights Act considerations are a significant focus of government's "formulation of legislative policy

\footnotetext{
${ }^{242}$ Butler and Butler, above $\mathrm{n} 232$, at [3.3].

${ }^{243}$ Susan Glazebrook "The New Zealand Bill of Rights Act 1990: its operation and effectiveness" (Paper presented to the South Australian State Legal Convention, 22-23 July 2004) at [36].

${ }^{244}$ Bill of Rights Act 1990, s 3.

${ }^{245}$ Section 4.

${ }^{246}$ Butler and Butler, above $\mathrm{n} 232$, at [6.1.1].

${ }^{247}$ Bill of Rights Act 1990, s 5.

${ }^{248}$ Section 7.
} 
proposals" and that Parliament addresses issues of inconsistency "to the extent that it regards that inconsistency as a matter of public concern". ${ }^{249}$ Glazebrook describes the s 7 declaration as providing "a springboard for discussion of whether legislation is important enough to justify any incursion on rights". 250

\section{Approach to Values using Legal Standards}

The approach to values recommended in the framework proposed by this thesis is an analysis of a policy viewed through a s 7 lens. Consideration of the rights and freedoms contained within the Bill of Rights Act 1990 is often applicable to the policymaker in many arenas, particularly the implementation of new legislation. This thesis broadens the $\mathrm{s} 7$ approach to extend further than new legislation. In the context of immunisation policy, it is used as a tool that can provide guidance to help define and weigh values relevant to the immunisation debate. In this framework, s 7 is not limited to the implementation of new legislation, it forms part of the decision-making process for all policy options.

Formulating a discussion of values in the context of immunisation policy with reference to the Bill of Rights Act 1990 is not purely a hypothetical exercise. The Labour-led Government has approved, in principle, a move to amend the New Zealand Bill of Rights Act 1990 to give greater protection to the rights and freedoms contained within the Act. ${ }^{251}$ The amendment seeks to confer an express statutory power to the senior courts to make declarations of inconsistency under the Bill of Rights Act 1990. This would trigger a reconsideration of the issue by Parliament and require Parliament to respond.

A declaration of inconsistency is a formal statement by the courts that legislation is inconsistent with the Bill of Rights Act $1990 .{ }^{252}$ The declaration informs Parliament and

\footnotetext{
${ }^{249}$ Butler and Butler, above n 232, at [8.4.1].

${ }^{250}$ Glazebrook, above n 243, at [57].

${ }^{251}$ Hon Andrew Little and Hon David Parker "Government to provide greater protection of rights under the NZ Bill of Rights Act 1990” (26 February 2018) <www.beehive.govt.nz>.

${ }^{252}$ Only one declaration has been issued previously. In Taylor v Attorney-General [2015] NZHC 1706, [2015] NZHC 1706, the Court issued a declaration that disqualifying sentenced prisoners from registering to vote is inconsistent with voting rights conferred by the Bill of Rights Act 1990.
} 
the public that the court views the legislation to be inconsistent with fundamental rights and freedoms. The proposed amendment does not go so far as to allow the courts to strike down inconsistent legislation, thereby maintaining Parliamentary sovereignty. ${ }^{253}$ What it does do, however, is reinforce the expectation of the public that rights and freedoms are important and to be respected. It also provides the public with the advantage of being able to describe an action or behaviour of the State as inconsistent, rather than simply immoral. Inconsistency has a tone of objectivity and community support and is often more broadly about social consequences. The failure of the State to endorse or give effect to a right can create expectations that are politically difficult to ignore. Additionally, as the Bill of Rights encapsulates New Zealand's commitment to international treaties, failure at the national level could bring forth international criticism.

Assessing whether a proposed legislative immunisation policy option is contrary to the Bill of Rights Act 1990 requires a two-step approach.

The first step is to determine whether the proposed legislative action is prima facie contrary to an applicable right. Two approaches are available. These are scope balancing and justification balancing. ${ }^{254}$ Justification balancing is used in this thesis because it provides a more transparent analysis when difficult social policy issues are involved. ${ }^{255}$ Additionally, even though what a right protects stays the same over time, "whether an infringement of the ambit ... is a justified limit depends on the values of society at the time of infringement and those values can change over time". ${ }^{256}$

\footnotetext{
${ }^{253}$ A White Paper issued in 1985 by the Government proposed a "strong" Bill of Rights that would give the courts power to invalidate legislation that contravened it. Following review, a select committee recommended a weaker Bill that would not confer such power to the courts. The reason being concern about the redistribution of power from the legislature to the judiciary. See, for example, JF Burrows and RI Carter Statute Law in New Zealand (4th ed, LexisNexis, Wellington, 2009) at 332-333.

${ }^{254}$ For discussion on these two approaches, see Butler and Butler, above $\mathrm{n} 232$, at [6.6].

${ }^{255}$ At [6.6.8].

${ }^{256}$ Butler and Butler, above n 232, at [6.6.18].
} 
The second step is to determine whether the breach is nevertheless a reasonable limitation being "demonstrably justified in a free and democratic society". ${ }^{257}$ A not uncommon misconception is that human rights are somehow unequivocal. Section 5 recognises that the rights and freedoms contained within the Bill of Rights Act 1990 cannot be absolute. ${ }^{258}$ Rights can and are limited and qualified in their application. The question is: under what circumstances?

\section{F Stage Three-Justified Limitation}

The third stage of the framework considers whether a policy that restricts values protected by law may nevertheless be legitimate. After all, rights "may be subject only to such reasonable limits prescribed by law as can be demonstrably justified in a free and democratic society". ${ }^{259}$ How is the policymaker to determine whether a proposed restriction is reasonable? The case of $R v$ Hansen is helpful and the approach in that case is used in step three of the framework.

\section{$1 \quad R v$ Hansen}

Tipping $\mathrm{J}$ in $R v$ Hansen set out a summary of the approach to determine whether a limitation is justified. ${ }^{260}$ The following points are considered: (1) Does the limiting measure serve a purpose sufficiently important to justify curtailment of the right or freedom? (2) Is the limiting measure rationally connected with its purpose? (3) Does the limiting measure impair the right or freedom no more than is reasonably necessary for sufficient achievement of its purpose? (4) Is the limit in proportion to the importance of the objective?

\section{G Striking a Balance}

Public health policy can be used to modify behaviour and encourage, or promote, health and well-being and healthy activities. The more contentious activities are those that seek to limit the rights and freedoms of the individual to some degree in return for a public

\footnotetext{
${ }^{257}$ Bill of Rights Act 1990, s 5.

${ }^{258}$ Burrows and Carter, above n 253, at 368.

${ }^{259}$ Bill of Rights Act 1990, s 5.

${ }^{260} R v$ Hansen [2007] NZSC 7, [2007] 3 NZLR 1 at [94].
} 
health benefit. Vaccination falls into this category, along with fluoridation of public water supplies and taxes on products seen as unhealthy such as tobacco, or, more controversially, sugar tax on foods with little nutritional value.

A challenge, and one that cannot be overcome easily in determining health policy, is the balance to be struck between the use of legitimate science to guide policy and respecting legally protected values.

Scientific knowledge may be able to help guide on the question of vaccine hesitancy and increasing immunisation coverage rates, but it can never resolve the complex and divergent values, beliefs and worldviews that make up the human condition. The reason for this is that policy is based on normative positions about how a government ought to intervene in people's lives. Science alone cannot answer questions about what a government ought to do. Science provides one source of knowledge about the world. Policy tells us what we should do with this knowledge. Policymakers have the responsibility to acknowledge that science may suggest one course of action but that there is nevertheless no clear case for government intervention. This is because good policy involves numerous value judgments.

Balancing science and values is not the only task. The policymaker must balance competing values. Where values are in competition, the weight given to each is subjective. For the policymaker, the identification of a value and the weight to be assigned is less problematic where the value is singularly held by much of the public, that is, where there is a clear consensus. $^{261}$ Where there is no consensus, however, or where a value is not easily identifiable, decisions are more difficult.

Further, public health policy creates tension between the protection of individual freedoms and the protection of individual welfare. The State is obliged to protect the health and wellbeing of its citizens. However, the individual is free to make their own choices regarding their health, and those choices may not necessarily be in their best interests.

${ }^{261}$ Ivor Richardson "The role of judges as policy makers” (1985) 15(1) VUWLR 46-52 at 51. 
In applying the framework to the immunisation debate, the policymaker cannot escape the fact that immunisation policy will necessarily involve compromise among values and will not be the product of flawless logic. The compromise may involve curtailing human rights in favour of public health goals or may adopt a liberal approach at the expense of broader preventive healthcare. Regardless of the policy implemented, the reasoning supporting it will have some weak links. A weak link in this context could be how weight is assigned to competing values or the rationale used to balance values. The policymaker should not ordinarily place emphasis on the weakest link in the chain of reasoning. Instead, in the spirit of legal moralism, they should ascertain whether the reasoning "has woven together many strands of public opinion to represent a coming together of reasonable people who have reflectively considered each other's counter-arguments". 262

To assist in this balancing exercise, this thesis suggests that the policymaker scrutinise all relevant values as free from bias as possible and bear in mind that individuals of the same cultures or groups and that individuals of different cultures or groups hold diverse worldviews and ways of thinking. Different cultures or groups not only place more emphasis on those values that impact them and their background, but they may also interpret a value differently to how another culture or group interprets the same value. Bearing this in mind and approaching values with a broad multicultural view should allow for a more thoughtful and accommodating analysis.

Ideally, because the framework draws on legislative instruments and judicial interpretations, these points will have been considered. However, the policymaker cannot defer to others, they must consider and weigh all relevant factors for themselves. It is the responsibility of the policymaker to ensure that competing ways of interpreting a value have been considered and the right balance has been struck. Additionally, if it is necessary to accept one set of values and reject another, it is important that the policymaker articulate the reasons for the preference.

${ }^{262}$ Gary C Leeds “The abortion controversy” (1990) 35 Vill L Rev 581 in Dickens, above n 209, at 25. 


\section{H General Applicability to Health-related Policy Decisions}

The ideas in this thesis are not limited to immunisation. The points raised, and the proposed framework, have wide applicability to any scenario in which science can provide information on the benefits and limitations of options available to the policymaker during the decision-making process. Future controversial health-related public policy topics that require assessment of the input of science (for example, a sugar tax, gene editing or human cloning) will benefit from reflection on the ideas presented here.

Better policy or legal decisions will be made in these situations by adopting the proposed decision-making framework with possible modification. The words "with possible modification" are used because, depending on the question, modification to some factors contributing to the decision-making framework may be necessary as different public policy questions present slightly different issues. For example, immunisation and gene editing both raise questions about safety, but in different ways. Vaccine safety only affects the individual receiving the vaccine, whereas gene editing raises questions about the safety of genetic manipulation of the germline and the passing of these changes to future generations.

\section{Beyond the Scope}

It is beyond the scope of this thesis to discuss how politics impacts science; for example, structures in place governing science funding, or the competitive nature of funding for science activities and the problems that flow from such a model, or how the short political cycle can determine areas of research and the course of action adopted by the government on a matter. It is also beyond the scope to discuss the potential liability of scientists providing advice to the policymaker or any procedural or administrative tasks required to be carried out by the policymaker; for example, duty to consult other stakeholders, to serve notice, to publish the agenda, to hold oral hearings, to consult the public, and any declarations of interests. Finally, other policymaking considerations such as fiscal priorities and electoral considerations are not discussed. It is noted, however, that such features do have an impact on the formation of good policy and each point requires reflection during the policymaking process. 


\section{Stage One: Science and Immunisation Policy}

This chapter describes the first stage of the framework and discusses principles and ideas that policymakers should consider when assessing scientific evidence. Where appropriate, science relevant to immunisation is used as examples.

For immunisation, relevant science is not only the science of vaccines, that is the triggering of an immune response resulting in immunisation following administration of a vaccine, but, importantly, includes the drivers behind vaccine hesitancy and low immunisation coverage, or improved or improving coverage, that have been identified using scientific methodology and analysis. All scientific evidence - those data that have been collected and analysed using scientific methodology-require assessment by the policymaker. Such evidence includes not only basic and applied research and clinical and epidemiological studies but also quantitative, qualitative, exploratory, descriptive, longitudinal, crosssectional, policy-orientated, and comparative research. Research could encompass both natural and social sciences, and, interestingly, behavioural science approaches to guiding decision-making. ${ }^{263}$

\section{A The Gatekeeper}

The starting point of the framework is for the policymaker to conduct a gatekeeper analysis. The purpose of this is to prevent the incorporation of non-robust science making its way into the policymaking process. This part of the process can be thought of as a screening tool to check the evidence for reliability. These checks turn the policymaker's mind to the nature of the evidence and ensures confidence.

Some points to look for when considering evidence include: adherence to the scientific method; views of the scientific community; place of publication; availability of raw data to allow the scientific community to examine results; source (Crown Research Institute, commissioned by a government department, drug company); and likelihood of bias.

\footnotetext{
${ }^{263}$ A well-known behavioural science approach is the concept of nudging, which was brought to prominence by Thaler and Sustein, above n 66.
} 
The gatekeeper analysis is not to make definitive judgments free from subjectivity, as that is not possible. It is to alert the policymaker to the possibility that if these factors are not considered, then such failure could undermine the science being used to inform policy, and, consequently, undermine the legitimacy of the policy itself.

It is acknowledged that science can never be purely objective. Gone are the days when no one questioned the belief that "science left to its own devices was neutral, disinterested, and value-free". ${ }^{264}$ Science is, after all, a human construct, conducted by human actors in the creation of their hypotheses, observations, and the conclusions they draw. Such activities cannot be removed from inherent human preconditioning, biases and fallibility. However, if the policymaker is made aware of potential sources of error, then that may go some way to countering them.

\section{$1 \quad$ Evidence and the Scientific Method}

The use of science to inform policy requires that evidence - scientific evidence-is used.

Distinguishing true scientific evidence from a lay person's understanding of evidence is vital if the end policy is to stand up to scrutiny. To the non-scientist, the term "evidence" is often understood and used as a catch-all for any knowledge that might be derived from a person's own observations, beliefs (whether religious or otherwise), tradition, anecdote or local knowledge. Gluckman notes, “... personal observation and anecdote are by far the most compelling forms of 'evidence' to many non-scientists including those embedded in the political process." 265

An example is parents who base immunisation decisions for their children on past experiences. Experiences and observations are important to immunisation decision-making for the individual. If a parent notices, for example, that their child becomes unwell or appears to have a change in behaviour following administration of a vaccine, they may

\footnotetext{
${ }^{264}$ Sheila Jasanoff "The Life Sciences and the Rule of Law" (2002) J Mol Bio 319 at 92.

${ }^{265}$ Peter Gluckman "The role of evidence in policy formation and implementation" Office of the Prime Minister's Chief Science Advisor < www.pmcsa.org.nz>.
} 
attribute the illness or behavioural change to the vaccine. ${ }^{266}$ They may think that this experience - this information - is legitimate, relevant, and valuable evidence on which to base decisions about vaccinating their children in future. It may well be. However, this information is not scientific evidence. Association, or correlation, is not causation. ${ }^{267} \mathrm{~A}$ parent's experiences and observations tend to be emotional and selective, whereas scientific evidence has rational, logical and comprehensive qualities. ${ }^{268}$

Science is not the only way of acquiring knowledge about the world. Humans gain understanding through many other forms, including philosophical reflection, religious beliefs, anecdote, narratives or their own ideas about an issue. As noted, these types of information are important to immunisation decision-making for the individual, but they play a different role in the formation of policy informed by scientific evidence.

Anecdotal evidence shapes a person's beliefs and opinions and can be used to try and convince others of the dangers or benefits of vaccines to achieve their own means and to align another's view with their own. This is equally true for anti-vaccination groups as it is for pro-vaccination groups, including governments and health professionals, who actively promote the benefits of vaccines to achieve population and individual health. The policymaker must distinguish non-scientifically acquired anecdotal or observational evidence and experience from scientifically acquired evidence, and not be swayed by existing policy initiatives, prominent members of the community or pressure from lobby groups. In the context of this thesis, it is only scientific evidence that is under consideration at this stage of the process. Here is not the place for the incorporation of loudly voiced opinions based on personal experience, no matter how legitimate.

\footnotetext{
$\overline{266}$ Adverse effects following administration of a vaccine do occur. The nature of the adverse effect depends on the vaccine being administered and can range from mild to severe and common to rare. More common adverse effects are generally mild and include soreness at the site of injection or a low-grade fever. See, for example, CDC "Possible side effects from vaccines" <www.cdc.gov>; Immunisation Advisory Centre "Vaccine safety" <www.immune.org.nz>; WHO "Global vaccine safety"<www.who.int>.

${ }^{267}$ See, for example, Naomi Altman and Martin Krzywinski “Association, correlation and causation” (2015) 12(10) Nature Methods 899.

${ }^{268}$ Pielke Jr, above n 14, at 42-44.
} 
How best, then, to ensure that the policymaker is guided by only the most reliable evidence? Fortunately, science is grounded in rationality, logic and process. It is an organised process - known as the scientific method-for obtaining new knowledge and is not simply a collection of facts. ${ }^{269}$

In its broadest sense, the scientific method is a way of reconciling our stories about the world, our human desire to understand the world, with how the world around us works. The scientific method can be described as a systematic and analytical approach to scientific thought: a set of rules governing scientific inquiry. These rules might include principles of observation, experiment and reasoning. They are often also going to specify who we might trust to produce information and the types of tools that might be used. ${ }^{270}$ Critically, there must be a high level of integrity in analysing and interpreting the results. Two important foundations protect the accuracy of the information produced: replication and peerreview. ${ }^{271}$

What the scientific method does is produce trust. Trust in the scientific method allows people who are non-specialists in that field to be assured of the results because, even though they have not tested all the facts for themselves, they have confidence in the scientific process and the way the scientific community critiques the findings. ${ }^{272}$ Critique is what makes scientific knowledge robust.

\footnotetext{
${ }^{269}$ Gluckman, above $\mathrm{n} 207$, at 3 .

${ }^{270}$ Although the particular features of the scientific method are far from agreed upon, and there is debate as to whether one universal scientific method exists, several methodological operations can be regarded as common. These include: the identification of a problem; creating a hypothesis; testing the hypothesis; reporting the results; and analysing the results and framing a theory. See, for example, Jorge Wagensberg "On the existence and uniqueness of the scientific method" (2014) 9(3) Biol Theory 331-346; Chris Burton and Tom Love "The scientific method(s) of primary care" (2004) 54(504) Br J Gen Pract 553.

${ }^{271}$ Gluckman, above n 207, at 3 .

${ }^{272}$ Hendy, above n 30, at 48.
} 
It is not expected that every policymaker will have a science background, nor will they necessarily be able to critically analyse the data and the conclusions reached. What they can do, is look for evidence of guiding principles that show adherence to scientific methodology. ${ }^{273}$ This will help them judge whether the science is being interpreted correctly or whether it is being overstated or misused. It may also alert them to seek further guidance on the interpretation of the results and the validity of the science.

An important point should be made here about applying social science research to policy. Gluckman $^{274}$ notes that, despite the social sciences having systematic and empirical methods for the study of social phenomena, some misconceptions prevail. First, there is the incorrect assumption that because the social sciences examine society, values will inevitably be intertwined with interpretation of the results. Second, because the social sciences tend to use qualitative methods (case studies, surveys, interviews, statistical analysis of social measures), there is the perception that these methods are more open to personal judgment and bias by the researcher. Third, there is a misunderstanding that social science studies for policy can be undertaken by anyone regardless of whether they have undergone any formal research training.

The policymaker should not think of the social sciences as providing evidence that is of inferior quality. The methodologies used by the social sciences are subject to the same rules and professional standards as the natural sciences. The social sciences, as with all sciences, require training and skill, the ability to recognise hidden biases, and critical review by the scientific community. When done well, evidence from the social sciences provides a powerful contribution to policy development. ${ }^{275}$ An example is provided by those studies

\footnotetext{
${ }^{273}$ It is beyond the scope of this thesis to provide discussion on all factors that a person should consider when determining whether the science done is good science. The purpose of the thesis is to alert the policymaker to look a little deeper. A detailed discussion of things to look for when interpreting scientific results is provided in Gluckman, above $\mathrm{n} 207$.

${ }^{274}$ Gluckman, above n 265, referring to K Prewitt and others "Using science as evidence in public policy: report on the use of social science knowledge in public policy" National Research Council of the United States National Academies of Science (2012) <www.nap.edu>.

${ }^{275} \mathrm{Ibid}$, at 13 .
} 
discussed earlier that examined the factors contributing to immunisation coverage in New Zealand.

Identifying adherence to the scientific method by the policymaker is necessary as it removes non-scientific evidence from impacting on and confusing science-related assessments. It removes moral or faith-based arguments as generators of scientific evidence, and correctly consigns them, and other non-scientific evidence, to a consideration of values, not science. For example, intelligent design and creationism, despite attempts to classify them as science, cannot be science as they are not testable and reproducible using scientific methods. ${ }^{276}$

\section{Generally Accepted Science}

The changing nature and complexity of science means that it may not be possible for a policymaker to be presented with a complete picture of the evidence, options and outcomes for a matter requiring policy consideration; however, action may still need to be taken. Yet, despite necessity, the policymaker must not rush to implement policy informed by science in the absence of scientific consensus.

Often there is a tendency for science to be dismissed or misunderstood because it is complex or portrayed as uncertain or undetermined. This can give rise to the argument that you can find a scientist to support any position that fits with a person's agenda. However, such an argument misses a key component of the scientific process: scientific consensus. Gluckman explains: $:^{277}$

Scientific consensus is unlike social consensus - it is not a matter of the loudest voice or compromise; it is a more consultative process by which the expert community examines the currently available evidence and incorporates it into an understand that integrates what we know and acknowledges what we do not know.

\footnotetext{
276 See, for example, Science and Creationism: A View from the National Academy of Sciences (2nd ed, National Academies Press, Washington, DC, 1999) at 25.

277 Gluckman, above n 207, at 2.
} 
A single study may be of value and could suggest a possible course of action, but there are many difficulties with extrapolating from a single study — not the least where the study fits within an emerging body of knowledge - and impartial expert advice on the benefits and limitations is required, particularly drawing comparisons to other studies.

Additionally, scientists need time to check and re-check results. A fundamental tenet of the scientific method is reproducibility. It is the nature of the scientific method that once a discovery is made (and conclusions are drawn from the data) then the researcher, and the broader scientific community, should begin to question and doubt the results. Something can only be taken as close to approximating the truth when a hypothesis has been confirmed through repeated testing. There should be scientific consensus on a topic-the evidence should be generally accepted science-before a policymaker can consider using science to inform policy.

As a brief aside, if a policy seeks to curtail a fundamental right, as is the case with Statemandated vaccination, then the evidence in support of limiting that right should be robust and well-accepted within the scientific community. If the right was thought to be less significant, then the scientific evidence may be of a lesser standard. Where fundamental rights are in question, the level of scientific evidence should be high.

Recognition of the importance of consensus and not drawing conclusions from a single study is provided by a study reported by the BBC on the benefits of coconut oil. When asked about the surprising results (no increase in low-density lipoprotein cholesterol and a high increase in high-density lipoprotein cholesterol), Professor Khaw said: "This is just one study and it would be irresponsible to suggest changing dietary advice based on one study, however well conducted." 278

${ }^{278}$ Michael Mosley “Is coconut oil a superfood?” BBC (online ed, London, 9 January 2018). 
An example of multiple studies and the science community needing time to check results is the controversy surrounding the publication in the Lancet of Andrew Wakefield's study that the measles, mumps, and rubella vaccine may predispose children to behavioural regression and pervasive developmental disorder. Since publication, numerous epidemiological studies and meta-analyses have been conducted and no link has been found. ${ }^{279}$ Though it took time, through careful and critical studies and assessments, the scientific community reached a consensus that there is no link between the measles, mumps, and rubella vaccine and autism; this is the scientific method in action.

If the policymaker uses generally accepted science to inform decisions, then the likelihood of harm (bad policy) is greatly reduced. Generally accepted science alleviates many of the problems identified in the previous chapters. For example, the policymaker is not influenced by an emotive public demanding action following publication of a single study, generally one that has been sensationalised by the media. Generally accepted science also mitigates potential risks associated with uncertainty and the misuse of science by special interest groups who cherry-pick results that favour their own ends. Finally, generally accepted science prevents situations where a scientist is called on to provide advice on a topic where the scientific knowledge is in its infancy and is tentative.

Only after repeated testing does scientific knowledge become increasingly secure. While the public may want simple answers, this is not always possible. It is rare to find a simple answer to a problem as complex as immunisation of children.

\footnotetext{
279 See, for example, Y Uno and others "Early exposure to the combined measles-mumps-rubella vaccine and thimerosal-containing vaccines and risk of autism spectrum disorder" (2015) 33(21) Vaccine 2511-2516; A Jain and others "Autism occurrence by MMR vaccine status among US children with older siblings with and without autism" (2015 313(15) JAMA 1534-1540; V Demicheli and others "Vaccines for measles, mumps and rubella in children" (2012) Feb 15(2) CD004407 Cochrane Database Syst Rev doi: 10.1002/14651858.CD004407.pub3; LE Taylor and others "Vaccines are not associated with autism: an evidence-based meta-analysis of case-control and cohort studies" (2014) 32(29) Vaccine 3623-3629; Taylor and others "Autism and measles, mumps, and rubella vaccine: No epidemiologic evidence for a causal association" (1999) 353 Lancet 2026-2029; L Dales and others "Time trends in autism and in MMR immunization coverage in California" (2001) 285 JAMA 1183-1185; KM Madsen and others "A populationbased study of measles, mumps, and rubella vaccination and autism" (2002) 347(19) N Engl J Med 14771482 .
} 


\section{Publication and Peer-Review}

Publication in a reputable peer-reviewed journal is generally a reliable sign of quality, but it is not infallible. Where research has been published, and the reputation of that publisher is important. Publication is a vital part of the scientific process. However, publication alone is not sufficient. Peer-review is equally important. The two combined allow experts to analyse data and critique and confirm, or deny, the validity of the findings. They hold scientists and the scientific community to account.

Publication and peer-review does not mean that the policymaker can rest assured that the science they are considering using is good science. Further investigation is required.

Doubt can be cast over the publisher of credible and trustworthy scientific journals, as they are at risk of manipulation by those pushing their own agendas. Notwithstanding a journal's best efforts, they are at the mercy of the integrity of those who conduct peer-review. The problem has come under the spotlight recently with the Committee on Publication Ethics (COPE) issuing a statement warning on the inappropriate manipulation of the peer-review process. In it, COPE says that it has become aware of manipulation orchestrated by third party agencies that offer publishing preparation services to authors, including "fabricated contact details for peer reviewers during the submission process and then supplying reviews from these fabricated addresses". 280

While false reviews may be a new phenomenon, honest mistakes in peer-review are not. None more devastating than that infamous article published in The Lancet suggesting a link between the measles, mumps and rubella vaccine and autism. ${ }^{281}$ The article reduced vaccination rates following its publication in 1998, and understandably so. ${ }^{282}$ The Lancet was established in 1823, making it one of the oldest medical journals in the world, and it

\footnotetext{
280 Committee on Publication Ethics "COPE statement on inappropriate manipulation of peer review processes" < publicationethics.org>.

${ }^{281}$ Wakefield and others, above n 141.

282 United Kingdom Government "Measles, mumps, rubella (MMR): use of combined vaccine instead of single vaccines" <www.gov.uk>.
} 
is one of the most well-known and well-respected peer-review journals. However, despite taking time, the "self-correcting nature of the scientific process" 283 ensured that incorrect research did not remain in the science community.

\section{Bias and Conflict of Interest}

Two factors require assessment when considering the potential for bias and conflict of interest: where research has come from and who provided the research for consideration.

Research funded by a pharmaceutical company is more likely to report results that favour the company's drug. ${ }^{284}$ Medical researchers are encouraged to register their trials on clinical trial databases. This is so that negative results go on the public record. It is a requirement of many journals that a clinical trial registry identification number is provided during submission on a manuscript for publication.

Another consideration is checking that those speaking about the science are not going beyond their scientific field or deferring to the authority of science to closedown arguments that are outside their area of expertise. ${ }^{285}$ The evidence that the policymaker receives should be from the appropriate authority. The danger here is that a course of action could be initiated, and subsequent policy implemented, that incorporates science that is either substandard or proffered by an "expert" who is an expert in a different but possibly related field, giving it the appearance of reliable science.

\footnotetext{
${ }^{283}$ Gluckman, above $\mathrm{n} 207$, at 4.

${ }^{284} \mathrm{~J}$ Lexchin and others "Pharmaceutical industry sponsorship and research outcome and quality: systematic review" (2003) 326 BMJ 1167.

${ }^{285}$ On this point, see Hendy, above n 30, at 104-105, where Dr Hendy (Director of Te Pūnaha Matatini, a New Zealand Centre of Research Excellence) relates an incident early on in his career during a public talk: “... I didn't understand the technical part of his question ... but instead of just saying so, I responded ... that the scientists responsible for the observations had got a Nobel Prize and probably knew what they were doing. ... Instead of admitting that I didn't know ... I appealed to the authority of science to shut down a question that lay outside my expertise."
} 
A further point to consider is whether the scientist providing the advice is going beyond what is suggested from the evidence and promoting a course of action that aligns with their own cognitive biases and personal values, or whether they are pushing their own agenda.

Regarding personal bias, in Lewers v Northland District Health Board, a vaccine was administered at a school without a crash kit being set up, a standard procedure. While the case was an employment issue, the Judge observed how personal bias can influence decision-making, saying: "This is a matter of a senior and experienced person who considered herself an expert substituting her own judgment for that contained in a wellknown clinical standard."286

It is not always obvious to the policymaker that an agency or scientist is pushing their own agenda. The limited availability and competitive nature of research funding may encourage a scientist or agency to couch research in terms that align with the political viewpoint of the government of the day in the hope they will be looked on favourably during the next round of research funding. The nature of research funding creates tensions that the policymaker must be aware of if they are to ensure the credibility and integrity of the science they intend to use to inform policy.

\section{B Applicability}

The second limb of stage one requires the policymaker to conduct a cost-benefit analysis and to ensure that the evidence is relevant. This step involves the policymaker turning their mind to the applicability and usefulness of the evidence.

\section{Cost/Benefit}

Cost/benefit analysis is important for policy proposals. This section of the framework merely notes that a cost/benefit analysis is vital and directs the policymaker to such an analysis following recognised protocols. ${ }^{287}$

\footnotetext{
${ }^{286}$ Lewers $v$ Northland District Health Board [2011] NZERA Auckland 303 at [121].

287 The New Zealand Treasury provides high-level guidelines for fiscal and economic cost/benefit analysis. See The Treasury "Costing of Political Party Policies" <www.treasury.govt.nz $>$.
} 
A point to touch on briefly is that immunisation programmes require funding. However, long-term cost savings and economic growth arise from the prevention of mortality and morbidity. Additionally, savings are increased if multiple vaccines are delivered in a single injection. Further, combination vaccines have the benefit of better compliance, coverage and injection safety. ${ }^{288}$

\section{Relevance}

Because of the complex multifactorial drivers underlying vaccine hesitancy, increasing immunisation coverage will not be achieved by applying a simple public health approach that only extolls the merits of vaccine science. What is required is a multidisciplinary approach that combines different strategies and incorporates different branches of science, including social science. When considering the relevance of the science contributing to the decision, this must be borne in mind by the policymaker.

Evidence drawn from the social sciences may, prima facie, be unrelated to vaccine hesitancy, but on closer inspection could have a significant effect on options available to the policymaker. For example, social science strategies targeted at alleviating poverty and improving early childhood education could have a major influence on a child in later adult life. ${ }^{289}$ This influence could be in the form of their own health and mental development, which in turn could impact their views of health and science generally, and the benefits of vaccines specifically (both individual and herd immunity); consequently, they may be more likely to have their own children immunised, for the sake of both the child and the community. Dr Turner writes that governmental commitment aimed at "reducing social and economic inequalities, work and social services' responses to security of incomes, employment and improving parental education" could overcome challenges associated with timely childhood immunisation. ${ }^{290}$

\footnotetext{
${ }^{288}$ FE Andre and others "Vaccination greatly reduces disease, disability, death and inequity worldwide" (2008) 86(2) Bull World Health Org <www.who.int>.

${ }^{289}$ Peter Gluckman "Medical, life sciences and social sciences research: how they should be contributing to New Zealand's development” (Auckland Medical Research Foundation, Auckland, 6 May 2010).

290 Turner, above n 165, at 253.
} 
The applicability and relevance of the science must also be considered in terms of the problem being addressed. Different approaches may be necessary, and more uncertainty and risk may surround the evidence and outcomes. For example, is the science needed in a crisis (an outbreak of an infectious disease) or is it relevant to longer term planning (increasing immunisation coverage generally)? Both examples address immunisation, but the former may involve the development and implementation of prior legislative tools for the control and containment of a disease. ${ }^{291}$ Restriction to human rights may be necessary and be more likely to be accepted by the public during an epidemic. The latter, however, would receive greater public opposition if human rights were restricted while other viable options remained.

\footnotetext{
${ }^{291}$ For example, the Health Act 1956, s 117(1)(d) permits the Governor-General to makes such regulations as necessary including "the vaccination of persons for the prevention of quarantinable diseases and other diseases, and the adoption of any other measures for the prevention and mitigation of disease."
} 


\section{Stage Two: Values and Immunisation Policy}

This chapter discusses the second stage of the framework in greater detail. The second stage of the framework is an examination of values relevant to the issue. When thinking about values, cultural values are of particular importance in New Zealand. Therefore, values must be thought of in this regard, and values are not limited to individual or majority values. This chapter draws attention to some of the more significant or sensitive values in the immunisation debate. Where applicable, these values are discussed with reference to common arguments for or against immunisation.

Public health is an important social good and a legitimate reason for State intervention into people's lives. However, it is not the only good that must be considered when determining immunisation policy. ${ }^{292}$ For example, there is a general expectation in democratic societies that the rights of individuals to act autonomously will be respected by the State. This expectation is reinforced by legislative instruments directed at protecting human rights and freedoms. $^{293}$

The underlying principle is the right to be treated as human. Immanuel Kant wrote: "Act so that you treat humanity, whether in your own person or that of another, always as an end and never as a means only." 294 This is read to mean that people are to be treated as people and that the moral status that they have as a person is to be respected. Elias J, citing Lord Cooke, describes this as a self-evident right "inherent in the concept of civilisation" that is "recognised rather than created by international human rights instruments". 295

\footnotetext{
${ }^{292}$ Ross Silverman and Thomas May "Private Choice versus Public Health: Religion, Morality, and Childhood Vaccination Law" (2001) 1 Margins 505.

${ }^{293}$ New Zealand Bill of Rights Act 1990, Human Rights Act 1994, Privacy Act 1993, Universal Declaration of Human Rights [1948] PITSE 8 (adopted 10 December 1948), UNGA Resolution 217A(III).

294 JD Hodson The Ethics of Legal Coercion (D Reidel Publishing, Dordrecht, 1983) at 1.

${ }^{295}$ Taunoa v Attorney-General [2007] NZSC 70, [2008] 1 NZLR 429 at [74] per Elias J (SC) citing Higgs v Minister of National Security [2000] 2 AC 228 at 260 per Lord Cooke.
} 


\section{A Public Health as a Community Value}

Public health has been defined as the art and science of preventing disease, prolonging life and promoting health through the organised efforts of society. ${ }^{296}$ Modern public health policy seeks to maximise the benefits for the greatest number of people while protecting individual and communal rights. Immunisation, along with access to clean water, is considered as having the greatest impact on public health. ${ }^{297}$

The community aspect of vaccination is unique in public health in that an intervention undertaken by the individual — usually a child, who assumes the risk for adverse eventsconfers a benefit not only to the individual but also to the wider population. A health policy requiring an individual to undergo a medical procedure with the aim of achieving a public goal is challenging.

It is widely accepted that one of the objectives of immunisation programmes is not only to protect the individual who receives the vaccine but to protect the population from the disease. $^{298}$ The goal of any immunisation programme is that enough people develop immunity to prevent or slow the spread of the disease within a population. This concept allows those who are not physically capable of receiving vaccines to be protected. Artificial immunity stimulated by vaccines may not be effective in the very young or the elderly and can be dangerous to the immunocompromised, or in very rare cases, those with allergies to vaccines.

This value of promoting public health stands as a reason for requiring immunisation that is independent of any arguments that vaccination also protects the individual child from disease. On the downside are the curtailing of values protected by law (human rights and freedoms, particularly the ability to make our own choices) and the chance of an adverse reaction.

${ }^{296}$ D Acheson Public Health in England: The Report of the Committee of Inquiry into the Future Development of the Public Health Function (Her Majesty's Stationery Office, London, 1998).

${ }^{297}$ Andre and others, above n 288.

${ }^{298}$ DJ Nokes and RM Anderson "Vaccine safety versus vaccine efficacy in mass immunization programmes" (1991) 338 Lancet 1309-1312. 


\section{Vaccination as a Civic Duty}

Supporters of immunisation programmes often claim vaccination is a civic duty. The community aspect of vaccination is emphasised. In the words of John Donne: "No man is an island, entire of itself; every man is a piece of the continent, a part of the main." ${ }^{299}$ Gary Leeds notes that even a liberal approach to freedom recognises that the law acts as a constraint on the individual to some degree so that others may have a degree of freedom that would otherwise be absent. It is arguable, continues Leeds, that people who rely on each other for mutual benefit "should not be permitted to act as entirely self-governing entities". As the individual cannot be separated from the group, the community insists that the individual conform to specific behaviours. By deriving a benefit from the community, individuals have "a responsibility to conform to reasonable legislative judgments, so long as laws do not unduly interfere with their liberty".300

If we adopt a utilitarian point of view to the civic duty argument-vaccinating the individual for the good of society - there is a tendency to push aside individual values, gloss over the risk of adverse effects while emphasising the scientific benefit of vaccines, and "focus on society and its values in a communitarian way". ${ }^{301}$ This, in turn, says Calabresi, leads us "to think of all of society more as one family". 302

The communitarian idea of society as a family and imposing duties upon the individual members of the family for the greater good falters when compared with legal obligations with respect to an individual's biological or legal family. State-mandated vaccination would be imposing more stringent obligations upon an individual in favour of an unknown person or group of people than it places upon the individual with respect to his or her own biological or legal family. Although, under New Zealand law, there is a duty to provide the

\footnotetext{
${ }^{299}$ John Donne No Man is an Island (Souvenir Press, London, 1988).

${ }^{300}$ Leeds, above $\mathrm{n} 262$, at 22-25.

${ }^{301}$ Guido Calabresi "Do we own our bodies" (1991) 1(5) Health Matrix at 15 in Dickens, above n 209, at 11. ${ }^{302}$ Ibid.
} 
necessaries of life, ${ }^{303}$ this does not extend to a person being obligated to undergo a medical procedure for the benefit of a family member; for example, blood transfusion or bone marrow donation. Why should a person be required to undergo a vaccination event for the benefit of a person who cannot assume the risk for themselves?

To argue that vaccines are distinguishable from blood transfusion or bone marrow transplantation because the individual who receives the vaccine has the benefit of acquiring protection from the disease does not always hold true. No vaccine is 100 per cent effective. Some people do not develop immunity following a vaccine event and for others immunity may decrease over time. ${ }^{304}$

There is a counter argument to not imposing collective or communitarian values, which, when stated in Marx's terms, suggests "it is not what you possess that counts because you do not own that. Rather, it belongs to the state, or if the state determines, to someone in need." 305 Precedent in support of a such a proposition does exist in New Zealand in the form of compulsory military training for males at intervals between 1909 and $1972 .{ }^{306}$ In such a situation, the individual's body is no longer their own. They are obliged to undertake military training as their body belongs to the collective. Additionally, New Zealand has, in its short history, had State-mandated vaccination, ${ }^{307}$ and coercive powers still do exist in relation to epidemics. The argument is perhaps stronger for immunisation as, despite vaccines not being effective for all individuals, the majority do receive the benefit of protection.

\footnotetext{
${ }^{303}$ Crimes Act 1961, s 151 (for persons responsible for vulnerable adults); Crimes Act 1961, s 152 (for parent or guardian responsible for persons under the age of 16 years).

${ }^{304}$ Immunisation Advisory Centre "Efficacy and effectiveness" < www.immune.org.nz>.

${ }^{305}$ Health Act 1956, s 70.

${ }^{306}$ See, for example, Defence Act 1909 (9 EDW VII 1909 No 28), s 35.

${ }^{307}$ For example, the Vaccination Act 1863. That Act was repealed by the Vaccination Act 1871 (35 Victoriae 1871 No 51), which made the practice of inoculation illegal and replaced it with vaccination and public vaccinators. Compulsory vaccination reinstated by Public Health Act 1876 (40 Victoriae 1876 No 60), Public Health Act 1900 (64 VICT 1900 No 25), s 144.
} 


\section{The Good Samaritan}

In the same communitarian vein, another consideration is the notion of the Good Samaritan. Although there are not many situations in which the State asks that people help others, there are some. Calabresi asks whether we own our bodies and uses the example of antiabortion laws. He argues that forced continued pregnancy, although being described as a life-preserving exercise may be objectionable to some, requires, at least to some extent, that women be Good Samaritans. Further, duties are placed on women to look after themselves so that their unborn child will be born healthy. This duty, too, could be considered a Good Samaritan duty. ${ }^{308}$

A similar argument can be made for immunisation. Elizabeth Wicks contends that legal moralism or legal paternalism are not relevant to bodily autonomy. The focus of regulation should be the legal protection of others rather than protection of the body itself. ${ }^{309}$ This approach fits with the idea of a regulatory framework for immunisation: an act conferred upon an individual is for the protection of others. Further, if it is accepted that population immunity is in the public interest, then the State has a responsibility to work towards achieving that goal.

\section{Prevention is Better than Cure}

At a practical level, the proverb "Prevention is better than cure" rings strong with communicable diseases and publicly funded healthcare. Vaccination is often cited as one of the most cost-effective public health interventions. ${ }^{310}$ In an environment where public money available for healthcare is not generally found in abundance, prevention over cure cannot be overstated, and must ultimately factor into policy decisions.

\footnotetext{
${ }^{308}$ Calabresi, above n 301, at 2-3.

309 Rita D'Alton-Harrison “The State and the Body: Legal Regulation of Bodily Autonomy, written by Elizabeth Wicks" (2017) 25(1) E J Health Law 113-117 reviewing Elizabeth Wicks The State and the Body: Legal Regulation of Bodily Autonomy (Hart Publishing, Oxford, 2016).

${ }^{310}$ Andre and others, above n 288.
} 


\section{B Making Decisions for Children}

Parents being free to make decisions for their children is generally considered an important value. However, this value is circumscribed a little by the Care of Children Act 2004, which places equal emphasis on parental responsibilities, and on guardianship as increasingly a co-operative decision-making process as the child gets older. ${ }^{311}$ Nevertheless, interference with parental decision-making is therefore a central issue with any immunisation programme, particularly, State-mandated vaccination. A government's interference in people's lives must be weighed against the public health benefits. The main consideration is whether the benefits of the vaccine are sufficient for the government to impose regulations that supersede parental autonomy or impose unwanted responsibilities. ${ }^{312}$

According to Frederick Zimmerman, autonomy is a fundamental principle in ethics and is of central importance to public health officials who must balance improving health outcomes with individual freedoms. Public health aims to move people towards healthy behaviour, but it is also ethically bound to respect autonomy. ${ }^{313}$

Autonomy in the context of immunisation needs to be framed slightly differently than a general understanding that people should be free to make their own choices because immunisation decisions for children are usually made by their parents. Further, as immunisation is to prevent a future disease, preventive intervention requires a different assessment and different legal principles apply than in a situation when the life of a child is at real risk, a life-threatening situation. A consideration for the policymaker is whether the appropriate policy response should be different for urgent and non-urgent situations.

The legal position in New Zealand with respect to medical treatment in life-threatening situations is clear. State intervention is permitted when it is necessary to protect a child's physical or mental health. Such intervention is more commonly seen with medical neglect.

${ }^{311}$ Care of Children Act 2004, s 16.

312 Gillian Haber and others "The HPV Vaccine Mandate Controversy" (2007) 20 J Pediatr Adolesc Gynecol $325-331$ at 326 .

313 Frederick Zimmerman "Public Health Autonomy: A Critical Reappraisal" (2017) 47(6) The Hastings Centre Report 38-45. 
Medical neglect arises when a child's parent or legal guardian fails to provide medical treatment that the child requires. The reasons parents or guardians may refuse treatment range from religious convictions to beliefs about the lack of necessity of treatment or the desire to use alternative therapeutic options.

There is no consensus that refusal to provide a child with vaccination - a non-life-saving intervention-constitutes medical neglect. No court in New Zealand has examined the issue. The issue raises questions about the move towards early intervention in relation to children at risk. Arguably, the risk factors for early intervention would not reach the level of neglect.

A study published in 2017 looked at the relationship between vaccine refusal and medical neglect under child welfare laws in the United States. ${ }^{314}$ The study found that some states had a legal precedent for considering that parental vaccine refusal constituted medical neglect; however, the proposition was based on a small number of cases. The authors urged caution before invoking child welfare laws to improve immunisation coverage, suggesting that lawmakers debate the issue and incorporate their decision into state legislation.

In New Zealand, s 37 of the Care of Children Act 2004 provides that a health practitioner will not be subject to civil, criminal, or disciplinary proceedings for giving a blood transfusion to a person under the age of 18 years without parental consent so long as the transfusion is required promptly.

Immunisation is a situation in which parents must make a medical decision for their child in a non-life-threatening situation. Here, the circumstances are different. The medical intervention does not fall within one of the three categories identified by Shireen Arani, these being life-saving, life-prolonging, or quality-of-life enhancing. ${ }^{315}$ Another category

\footnotetext{
${ }^{314}$ Efthimios Parasidis and Douglas Opel "Parental refusal of childhood vaccines and medical neglect laws" (2017) 107(1) Am J Public Health 68-71.

${ }^{315}$ Shireen Arani "State intervention in cases of obesity-related medical neglect" (2002) 82 B U L Rev 875 at 878 .
} 
is needed. Luke Morrison argues that a "preventive or protective" category is appropriate. $^{316}$ This category covers the situation in which the child has no medical requirements at the time and the treatment being refused is aimed at protecting the child's health rather than treating a condition they have. Morrison gives the example of immunisation falling within this category as there is a likelihood that the risk of disease will never eventuate, so the treatment cannot be quality-of-life enhancing.

Article 18 of the United Nations Convention of the Rights of the Child states: "Parents ... have the primary responsibility for the upbringing and development of the child. The best interests of the child will be their basic concern." Article 24 acknowledges that parties to the Convention must "recognize the right of the child to the enjoyment of the highest attainable standard of health".

There is conflict here. It is well settled in New Zealand that a court's prime consideration must be the best interests of the child. Section 4 of the Care of Children Act 2004 states that the welfare and best interests of a child must be the "first and paramount consideration" as does the Oranga Tamariki Act 1989, s 6. If it is accepted that immunisation decisions should be made with reference to the child's best interests, two questions arise: What is in the best interests of the child? How can parental decision-making be prioritised (as noted in art 18) yet the best interests of the child remain paramount?

Examining the two questions posed by reference to informed consent and what the courts have found to be in the best interests of the child could go some way to providing an acceptable, albeit not all-encompassing, solution.

Requiring informed consent initiates a decision-making process that involves a parent being provided with relevant medical information. Medical information will not be the only factor that a parent considers in the process. The process will invariably include a parent's views on medical treatment generally, possibly including their ideas on alternative

\footnotetext{
$\overline{{ }^{316} \text { Luke Morrison "Legal responses to non-life-threatening medical neglect" (LLM dissertation, University }}$ of Otago, 2011) at 3.
} 
medicine, as well as religious beliefs, autonomy, risk and trust. The way the parent views these issues impacts on what they think is in the best interest of the child, and, ultimately, whether they provide consent.

It should be noted, however, that what is in the best interests of the child is more objective than this, and parental choice can be overridden by the Care of Children Act 2004. For example, where it is found that a child may be at risk of harm, an application can be made that a child be placed into the guardianship of the court or the Chief Executive of Oranga Tamariki. ${ }^{317}$

Further, under that Act, the emphasis has swung from guardians' rights to responsibilities, with a duty to do what is in the child's welfare and best interests. The rights of parents are to be understood as responsibilities that they are obliged to exercise in terms of the welfare of the child as their first and paramount consideration. This principle, the welfare principle, is consistent with relevant articles in the United Nations Declaration of the Rights of the Child. ${ }^{318}$

\section{Informed Consent}

Informed consent is a value that is vital to immunisation policy because consent is usually required for medical procedures or interventions, including vaccinations. Vaccine providers are not legally permitted to proceed with immunisation in the absence of express consent. Whether the requirement that a medical professional receives consent prior to an immunisation event will depend on the legal nature of the immunisation policy. If, for example, compulsory immunisation is established in law, consent may not be required.

This section deals with some of the factors relevant to consent. Consideration of these factors will help the policymaker decide whether consent is a value that can be over-ridden with a hard immunisation law or whether consent is a value of utmost importance that should be protected with soft immunisation policy.

317 Care of Children Act 2004, s 31; Oranga Tamariki Act 1989, s 110.

${ }^{318}$ BD Inglis New Zealand Family Law in the 21st Century (Brookers, Wellington, 2007) at 263. 
The doctrine of informed consent assumes that a person is free to exercise their own free will when making decisions about medical treatment and care. ${ }^{319}$ In other words, the power to make decisions regarding a person's health generally rests with the individual. Consent derives from the principle of autonomy and forms an important part of both domestic and international law. ${ }^{320}$ The right of informed consent to medical intervention has "been the gold standard in the ethical practice of medical care since World War II." ${ }^{321}$

Ethical obligations relevant to informed consent in New Zealand are supported by legislative instruments including the Code of Health and Disability Services Consumers' Rights 1996, the Health and Disability Commissioner Act 1994, the Health Information Privacy Code 1994, the Privacy Act 1993, and the Privacy Amendment Act 2013.

Aside from the ethical reasons for obtaining consent, the practice of medicine carries legal implications, and there can be legal liability for failure to do so. A patient's consent to treatment negates what would otherwise be assault. ${ }^{322}$ Unjustified failure to obtain consent may leave the medical practitioner open to the tort of battery, ${ }^{323}$ liability in negligence, ${ }^{324}$ or liability under the Code of Patients' Rights. ${ }^{325}$

\footnotetext{
${ }^{319}$ Simon Whitney and others "A typology of shared decision making, informed consent, and simple consent" (2004) 140 Ann Internal Med 54-59 at 54.

${ }^{320} \mathrm{WHO}$ "Considerations regarding consent in vaccinating children and adolescents between 6 and 17 years old" <www.who.int> at 2; Convention on the Rights of the Child 1577 UNTS 3 (opened for signature 20 November 1989, came into force 2 September 1990).

${ }^{321}$ Barbara Loe Fisher "Parents should be allowed to opt out of vaccinating their children" in Mary E Williams (ed) Vaccinations (At Issue Series, Greenhaven Press, San Diego, 2003).

${ }^{322}$ Crimes Act 1961 ss 188-90 and 196.

${ }^{323}$ Damages for personal injury could not be claimed under ACC legislation.

${ }^{324}$ Rogers $v$ Whittaker (1992) 175 CLR 479, adopted into New Zealand in B v Medical Council [1995] 3 NZLR 810.

325 Health and Disability Commissioner (Code of Health and Disability Services Consumers' Rights) Regulations 1996, made under the Health and Disability Commissioner Act 1994, Part 2 ss 19-23.
} 
The right to control what is done to one's own body is a well-established principle in New Zealand law. Where something is an established principle, then the policymaker needs very good reason to depart from the principle when considering a legal intervention that is at odds with it. The famous jurist Benjamin Cardozo wrote: "Every human being of adult years and sound mind has a right to determine what shall be done with his own body." "326 However, different legal principles apply to informed consent when a parent is making an immunisation decision for a child.

For children under the age of 16 years, the power to consent to medical treatment rests with parents. In New Zealand, for the purposes of "any medical, surgical, or dental treatment or procedure", this power falls to guardians ${ }^{327}$ unless the child is Gillick competent ${ }^{328}$ or a court decides the issue, for example, under its wardship powers.

The Code of Health and Disability Services Consumers' Rights 1996 provides that New Zealand healthcare consumers have a legal right to information to enable them to make decisions and give informed consent. ${ }^{329}$ For immunisation, guardians need to be aware of the benefits and risks of vaccines, both to their own child and to the community, to be able to make an informed choice and give informed consent. ${ }^{330}$

An argument put forward by those critical of vaccines is that parents cannot give informed consent because governments, pharmaceutical companies and the medical profession are not providing them with all the information they require to understand the most important issues. ${ }^{331}$ This argument raises two questions. First, what level of information is required

\footnotetext{
${ }^{226}$ Schloendorff $v$ Soc'y of NY Hosp 105 NE 92, 93 (NY 1914).

${ }^{327}$ Care of Children Act 2004, s 36(3).

328 Jonathan Law (ed) A Dictionary of Law (8th ed, Oxford University Press, Oxford, 2015). Gillickcompetence: A Gillick competent child is a child under 16 who has been deemed by a medical professional to have sufficient maturity and understanding to consent to a medical treatment. Gillick-competent children can be treated without parental consent or knowledge. See also, Gillick $v$ West Norfolk and Wisbech Area Health Authority [1985] 3 All ER 402 (HL).

${ }^{329}$ Health and Disability Commissioner (Code of Health and Disability Services Consumers' Rights) Regulations 1996, 1st sch, cl 2, Rights 5-7.

${ }^{330}$ Immunisation Handbook, above n 178, at 42.

${ }^{331}$ See, for example, Ted Kuntz "First do no harm" (2016) 6(3) Narrat Inq Bioeth at 171.
} 
for a parent to be able to give informed consent under a soft immunisation policy? Second, would a hard immunisation law remove recognised conventions on the provision of information, as, theoretically, the provision of information would have no bearing on a decision that has been taken out of a parent's hands?

Only the first question is addressed here. A similar argument was examined by the High Court in Smith v Attorney-General albeit not in the context of vaccination. In that case, $\mathrm{Mr}$ Smith argued that he was deprived of his right to refuse to undergo treatment because he was not provided with all information necessary to give fully informed consent. The cause of action was an alleged breach of s 11 of the Bill of Rights Act 1990. The Judge noted that no cases for "quality of consent" had been found in argument. The issue for the Court was what level of information must be provided to a patient to ensure that they are able to exercise their right to refuse medical treatment. Is a broad understanding of the nature of the medical treatment sufficient or does s 11 protect a patient from a negligent failure to provide information that might influence their decision? ${ }^{332}$ After discussing analogous cases from England and Canada, ${ }^{333}$ Miller $\mathrm{J}$ determined that s 11 does not provide a right to full information about proposed medical treatment. Its purpose is to protect people from "becoming the non-consensual object of another's treatment". A broad understanding of the nature of the proposed treatment is sufficient. ${ }^{334}$

A broad understanding aligns to a degree with the earlier discussion on the abundance of information and the policymaker using only generally accepted science to inform policy. Both a broad understanding and generally accepted science prevent unnecessary complexity and confusion that can arise when a multitude of single sources are examined

\footnotetext{
332 Smith v Attorney-General HC Wellington CIV-2005-485-1785, 9 July 2008 at [101]-[103] per Miller J.

${ }^{333}$ Chester v Afshar [2004] UKHL 41 (rare surgical complication); Freeman v Home Office (No 2) [1984] QB 524 (forced injections while in prison); Sidaway v Bethlem Royal Hospital Governors [1984] 1 All ER 1018 (informed consent not relevant in negligence claims); Chatterton v Gerson [1981] QB 432 (patient sued doctor for trespass alleging doctor failed to completely explain surgical risks); Reiblv Hughes [1980] 2 SCR 880 (alleged failure to inform patient of surgical risks).

${ }^{334}$ Smith v Attorney-General, above n 332, at [119].
} 
in minute detail. Taking a broad view provides a more accurate assessment because outliers are not accorded greater influence than they deserve.

\section{Best Interests of the Child}

In New Zealand, the court has a special jurisdiction in family law, usefully described as a "protective jurisdiction". This jurisdiction is structured to protect the welfare and best interests of members of the community who are unable to fully or partially look after their own interests. This jurisdiction extents to minors, whose legal capacity is limited by their age. The protection and promotion of the welfare and best interests of the child is the paramount consideration of this jurisdiction. ${ }^{335}$

The Oranga Tamariki Act 1989, one of the principal statutes guiding the protective jurisdiction, places importance on the family unit having the primary role in caring for and protecting the child. ${ }^{336}$ This role naturally extends to making health-related decisions for the child. The Care of Children Act 2004 also recognises the role of parents and guardians in making health decisions for children. ${ }^{337}$

Health-related decision-making is a subjective process. The Oranga Tamariki Act 1989 recognises individuality and states that in promoting the well-being of children, appropriate regard should be had to the "needs, values, and beliefs of particular cultural and ethnic groups". ${ }^{338}$ These factors ought not to be thought of as only applying to the immediate dayto-day welfare of the child but also over the long term.

When thinking long-term, consideration must be given to what the child might want when they reach the age when they can make their own decisions. Parents, as competent adults, can make seemingly unwise decisions that impact on their own well-being, even to the extent of sacrificing their own health for their beliefs. Despite parents being "free to

\footnotetext{
335 Inglis, above n 318, at 227. See, for example, Oranga Tamariki Act 1989, s 6.

${ }^{336}$ See, for example, Oranga Tamariki Act, ss 5 and 13.

${ }^{337}$ Care of Children Act 2004, s 16(2)(c).

${ }^{338}$ Oranga Tamariki Act 1989, s 4.
} 
become martyrs themselves", ${ }^{339}$ the law does not accommodate parents attempting to sacrifice their child's welfare for a cause. In this respect, parents may have difficulty extricating their own beliefs about immunisation programmes to the detriment of the child, both in terms of the child's health but also in terms of the child's own views as they develop over time.

In immunisation decision-making, the long-term welfare and best interests of the child is of course inextricably linked to decisions made in the short-term. Immunisation decisions need to be made relatively quickly to meet the requirements of the Immunisation Schedule to provide the child with the best possible protection from disease. This is non-problematic when parents are in consensus. Where there is disagreement, however, parents may turn to the courts for a resolution.

There are few instances where New Zealand courts have been asked to authorise immunisation of a child contrary to the wishes of one of the parents. In determining what is in the best interest of the child, the courts appear to put to one side the less orthodox approach in favour of the parent whose approach aligns with the majority public view (supported by medical evidence) on the benefits and risks of immunisation. For example, in $A \cup S,{ }^{340}$ one parent supported conventional immunisation while the other favoured alternative medicine. The Judge acknowledged that the preponderance of medical opinion was in favour of the immunisation programme but was careful to frame the issue as the parents' approach to healthcare for the child and not immunisation itself. The Judge, in finding that immunisation could proceed, thought that the risk, even if limited, was not one that the child should be exposed to. Further, because the result of contracting the disease was so severe, every protection should be afforded the child.

Another factor is the concept of dignity and competing duties when determining what is in the best interests of the child. Dignity has achieved a prominent place in the discussion of

339 Prince $v$ Massachusetts 321 US 158, 170 (1944).

${ }^{340} A$ v S FC Christchurch FAM-1999-009-2203, 5 September 2005. 
values and human rights. Andrea Pin writes that human dignity has come to support political reforms and judicial decisions that seek to give effect to such rights. ${ }^{341}$ The case of Charlie Gard, which has become an embodiment of the debate over "his parents' right to choose for their child and whether his doctors had an obligation to intervene in his care", ${ }^{342}$ was a situation in which the medical team treating Charlie disagreed with his parents as to what was in his best interests. The High Court (UK) found that the dignity of 11-month-old Charlie would best be respected by refusing a request by his parents to take him from the United Kingdom to the United States for experimental treatment of a disease for which there was no known medical treatment. ${ }^{343}$

That case raises questions of balance among parties with legitimate interests including that of doctors who have professional duties of care. Mass immunisation programmes may impinge on a doctor's duty to give priority to the welfare of the patient. It is arguable whether State-mandated immunisation programmes would outweigh that duty, with Parliament's law-making power being supreme.

The State is not only concerned with preventing health risks including discouraging people from engaging in behaviour likely to harm others but, importantly, it is tasked with promoting the healthy development and socialisation of children. Intrusive regulation of children may be justified as the success of future society depends on the upbringing and values instilled in children of today. ${ }^{344}$

\footnotetext{
${ }^{341}$ Andrea Pin "Balancing Dignity, Equality and Religious Freedoms: A Transnational Topic" (2017) 19 Ecc LJ 292 at 292.

${ }^{342}$ Lindsey Bever "“Our beautiful little boy has gone': Parents of Charlie Gard say he has died" The Washington Post (online ed, 28 July 2017).

${ }^{343}$ Great Ormond Street Hospital v Constance Yates, Chris Gard and Charles Gard [2017] EWHC 972. The case progressed through the British judicial hierarchy and an appeal to the European Court of Human Rights (Gard and others $v$ The United Kingdom No. 39793/17, 27 June 2017). The decision in the court of first instance was upheld on each appeal.

344 Dorit Rubinstein Reiss and Lois Weithorn "Responding to the Childhood Vaccination Crisis: Legal Frameworks and Tools in the Context of Parental Vaccine Refusal” (2015) 63 Buff L Rev 881 at 905.
} 
Although the State usually does not interfere with parental decision-making, particularly health-related decisions for children, parental decision-making is not without bounds, and the State does have a protective role. However, care needs to be taken when considering whether protective State intervention is justified. Intervention can have serious effects on both family relationships and the children in those relationships. ${ }^{345}$

\section{Bodily Integrity}

A key point of any discussion on legislative intervention to increase immunisation coverage is the significance accorded to the values of bodily integrity and personal autonomy.

Sections 10 and 11 of the New Zealand Bill of Rights Act 1990 deal with the right to be free from medical and scientific experimentation without consent and the right to refuse to undergo medical treatment. Although the rights are distinct, s 10 dealing with experimentation and s 11 dealing with treatment, they are both often taken together and arise from the core concept of personal autonomy. ${ }^{346}$

The sections fall within a group of rights that recognise the right to dignity and security of person. ${ }^{347}$ These rights are directed at securing bodily integrity and are very important as they are rooted in historical atrocities, such as medical experimentation. ${ }^{348}$ Just prior to the introduction of the Bill of Rights Act 1990 was the release of the Cartwright Inquiry. ${ }^{349}$ At the time, public health issues, particularly patients' rights, were front and centre in the minds of the public.

\footnotetext{
${ }^{345}$ Inglis, above $\mathrm{n} 318$, at 238 .

${ }^{346}$ Butler and Butler, above n 232, at [11.1.3].

${ }^{347}$ Bill of Rights Act 1990, Part 2.

${ }^{348}$ Butler and Butler, above $\mathrm{n} 232$, at [11.6.1] and [11.7.1].

${ }^{349}$ Committee of Inquiry into Allegations Concerning the Treatment of Cervical Cancer at National Women's Hospital and into Other Related Matters The report of the Committee of Inquiry into Allegations Concerning the Treatment of Cervical Cancer at National Women's Hospital and into Other Related Matters (Government Printing Office, New Zealand, 1988).
} 


\section{$1 \quad$ Medical and Scientific Experimentation}

Medical experimentation on humans is recognised as being important for the advancement of knowledge and for the good of society, ${ }^{350}$ yet, fortunately, it is not without constraint. An argument put forward by those critical of vaccines is that they do not want their children subject to scientific experiments. This argument can be advanced on two inter-related fronts, both of which are founded on moral and ethical questions of personal autonomy and bodily integrity.

First, the argument is generally grounded in parental fears of adverse effects and links to disease, the proposition that the long-term effects of vaccines are not known, and widespread vaccination may result in evidence of a previously unknown adverse event. ${ }^{351}$ Further, vaccines produce an immune response, but it is unclear how long the artificially acquired response lasts. ${ }^{352}$

Second, scientific uncertainty could be used to argue that compulsory vaccination programmes are a scientific experiment and are therefore in breach of s 10. Such an argument can find support in the well-accepted dogma that science is a continuing process, a continually evolving experiment, in its quest to find the unattainable truth.

The idea that vaccines are used experimentally outside clinical settings is not without foundation. In 2018, health workers began an immunisation campaign in the Democratic

${ }^{350}$ Trials of War Criminals before the Nuremberg Military Tribunals under Control Council Law (1949) 10(2) US Government Printing Office at 181-182 (the Nuremberg Code); World Medical Association Declaration of Helsinki: Ethical Principles for Medical Research Involving Human Subjects (Helsinki, Finland, 1964); Council of the Organization of Medical Sciences International Ethical Guidelines for Biomedical Research Involving Human Subjects <www.cioms.ch>; The National Commission for the Protection of Human Subjects of Biomedical and Behavioral Research, The Belmont Report Ethical Principles and Guidelines for the Protection of Human Subjects of Research (30 June 2008) <www.ohsr.od.nih.gov>.

${ }^{351}$ Richard K Zimmerman "Ethical Analysis of HPV Vaccine Policy Options” (2006) 24 Vaccine 4812 at 4813.

${ }^{352}$ N Principi and S Esposito "Mumps outbreaks: A problem in need of solutions" (2018) 76(6) J Infect 503506. 
Republic of Congo aimed at containing an outbreak of the Ebola virus using an experimental vaccine. The experimental vaccine proved effective in limited trials during the 2014-2016 Ebola epidemic in West Africa. ${ }^{353}$ As the vaccine had not been approved or licensed its use was dependent on informed signed consent. The Government of the Democratic Republic of Congo agreed to deploy the vaccine under a compassionate use protocol. ${ }^{354}$

The World Health Organisation is conscious of expediting the availability of vaccines in public health emergencies and have developed an Emergency Use Assessment and Listing Procedure for candidate vaccines in times of public emergency. The rationale is that the public may "tolerate less certainty about the efficacy and safety ... given the morbidity and/or mortality of the disease and the shortfall of treatment and/or prevention options".355

Additionally, a pilot study is being conducted in Ghana, Kenya and Malawi testing a malaria vaccine. ${ }^{356}$ It is noted that it is important to "clarify how data collected through the [Malaria Vaccine Implementation Programme] might be used to answer identified questions and inform future policy recommendations for vaccine use beyond the pilots".

Butler and Butler state that s 10 protects "any form of 'test' or gathering of evidence that a scientist will use to gain new knowledge or to prove his or her hypothesis." 357 Further, the definitions of medical and scientific experimentation include "experiments regarding the collection of personal data (even data collected without interfering with the body at all) for a medical or scientific purpose." ${ }^{358}$ Art 6 of The Declaration of Helsinki states that

\footnotetext{
${ }^{353}$ BBC "Ebola outbreak: Experimental vaccinations begin in DR Congo" $B B C$ (online ed, London, 21 May 2018) <www.bbc.com>.

${ }^{354}$ WHO "WHO supports Ebola vaccination of high risk populations in the Democratic Republic of the Congo" <www.who.int>.

${ }^{355}$ WHO "Emergency use assessment and listing procedure (EUAL) for candidate vaccines for use in the context of a public health emergency" <www.who.int>.

${ }^{356}$ SAGE "Summary of the Meeting of the Strategic Advisory Group of Experts on immunization, 1718 April 2018" < www.who.int>.

357 Butler and Butler, above n 232, at [11.7.2] (emphasis added).

${ }^{358}$ At [11.7.12] (emphasis added).
} 
"even the best proven interventions must be evaluated continually through research for their safety, effectiveness, efficiency, accessibility and quality."359

It may seem odd to view a vaccination programme as a form of medical or scientific experimentation. Nevertheless, there is evidence to suggest that in some ways that is what is happening.

According to the Ministry of Health, "The National Immunisation Register contains all registered immunisation enrolments and events of children born since 2005." ${ }^{360}$ HealthEd, a government website providing health information to the public, says that the National Immunisation Register records the following details about children: their name, home address, date of birth, sex and ethnicity; their unique health number; their family doctor, nurse and Well Child Tamariki Ora provider; their local district health board; the immunisations that they have been given; and the parents' contact details. The National Immunisation Register also records if a parent decides not to have their child immunised. ${ }^{361}$

Epidemiology and health services research commonly draws on data from medical records, databases and registers. Studies have been published that use data extracted from the National Immunisation Register.

There is little case law on the ambit of s 10 . However, the case law that does exist throws some light on the kind of medical activities that might be considered medical experimentation. For example, in McGrath v Police ${ }^{362}$ the Court held that the taking of a blood sample for the purposes of blood alcohol analysis was not unlawful experimentation

\footnotetext{
${ }^{359}$ Declaration of Helsinki, above n 350, art 6 (emphasis added).

${ }^{360}$ Ministry of Health "National Immunisation Register" <www.health.govt.nz>.

${ }^{361}$ HealthEd "Immunise your child on time - English version" <www.healthed.govt.nz $>$. The Ministry of Health and the Health Promotion Agency provide the resources described on the HealthEd website.

362 McGrath v Police HC Auckland CRI-2011-404-110, 20 December 2011 per Allan J.
} 
and in breach of s 10 . Allan J, referring to $R v$ Salmond, ${ }^{363}$ said that, "Subsequent analysis is not the same thing as experimentation for the purposes of the section."364

Blood or tissue samples or breath alcohol tests taken as evidence or for diagnostic or treatment purposes would be a strain on the language of s $10 .{ }^{365}$ However, if blood or tissue samples were collected from numerous people, analysed, and entered into a database before being examined for study purposes to gain new knowledge for general application, then such action could be regarded as scientific experimentation without consent. The argument is that the recording of multiple data points and subsequent study turns a single activity from one that may not attract s 10 protection to one that does. Vaccination events are recorded on the Immunisation Register and data from the Register are used in studies; therefore, it follows that the vaccination event could be regarded as scientific or medical experimentation.

A counter argument is that the research subject and future researchers who use the collected data are too far removed; there is no interaction between the two. However, Butler and Butler argue that because there is no protection to the right to privacy in the Bill of Rights Act 1990, s 10 should be given a wide interpretation that encompasses the use of medical records. ${ }^{366}$

A patient prescribed risperidone while on a compulsory in-patient treatment order under the Mental Health (Compulsory Assessment and Treatment) Act 1992 was found not to have been subject to medical or scientific experimentation in PF $v$ Capital and Coast District Health Board. ${ }^{367}$ The Judge held that the treatment was not experimental because it was known to have therapeutic benefits, undesirable side-effects did not make it

\footnotetext{
${ }_{363} R v$ Salmond [1992] 3 NZLR 8 (CA) at 25-26.

${ }^{364}$ McGrath v Police, above n 362, at [38] per Allen J.

${ }^{365}$ Butler and Butler, above n 232, at [11.7.15].

${ }^{366}$ At [11.8.38].

${ }^{367}$ PF v Capital and Coast District Health Board [2013] NZHC 1792.
} 
experimental, administration was expected to relieve symptoms, and there was nothing unorthodox, unusual, or experimental about the treatment. ${ }^{368}$

With respect, "known to have therapeutic benefits" and "not being unorthodox or unusual" ought not to have been regarded as the test for whether treatment is experimental. Clinical trials comparing two drugs both known to have therapeutic benefits would not be regarded as unorthodox or unusual but would clearly be classed as a scientific or medical experiment.

From a reading of what little case law exists in New Zealand on the scope of s 10, there is support for the argument that, because vaccination events are recorded on a register and the data contained within is used for research purposes, vaccination could be regarded as a scientific or medical experiment and in breach of s 10. Those cases in which the judge held that subsequent analysis did not constitute experimentation are distinguishable from the issues that arise with vaccination.

\section{Medical Treatment}

Section 11 of the Bill of Rights Act 1990 provides everyone with the right to refuse to undergo any medical treatment. The Code of Health and Disability Services Consumers' Rights 1996 also protects the right to refuse services and withdraw consent. ${ }^{369}$ Vaccination would fall under the definition of medical treatment.

The Court of Appeal has noted that s 11 has no equivalent in other human rights instruments and appears to have "developed as an element of the general right to privacy and the right to bodily integrity, which the common law has long recognised as a fundamental right." 370 In $R v B$, Richardson $\mathrm{J}$ stated that $\mathrm{s} 11$ protects bodily integrity and encapsulates a value that runs throughout the law in New Zealand. ${ }^{371}$ In the United States, Vacco v Quill clarified

\footnotetext{
${ }^{368}$ At [32].

${ }^{369}$ Code of Health and Disability Services Consumers' Rights 1996, right 7(7).

${ }^{370}$ New Health New Zealand Inc $v$ South Taranaki District Council [2016] NZCA 462 at [71].

${ }^{371} R \vee B$ [1995] 2 NZLR 172 (CA) at 182.
} 
that the right to refuse medical treatment rests in the right "to bodily integrity and freedom from unwanted touching". 372

In a case somewhat analogous to vaccination, s 11 was analysed in Health New Zealand Inc v South Taranaki District Council. ${ }^{373}$ That case was about fluoridation of public water supplies. The decision centred on the Court's interpretation of s 11. The Court held that fluoridation was legal and the limited definition of "medical treatment" did not encompass fluoridation. The decision has been upheld by the Court of Appeal ${ }^{374}$ and the Supreme Court. $^{375}$

In Health New Zealand Inc v South Taranaki District Council, the Court found that s 11 is not engaged where the State undertakes public health measures intended to benefit the public at large. ${ }^{376}$ This is because, reasoned Hansen J, "were it otherwise, the individual's right to refuse would become the individual's right to decide outcomes for others." 377 Further: ${ }^{378}$

Were medical treatment for the purpose of s 11 to extend to public health initiatives, an individual right to refuse could cut across the obligation of the state to promote the health of its citizens.

This line of reasoning is similar to that in Jacobson v Commonwealth of Massachusetts, where Justice Harlan said, "the spectacle would be presented of the welfare and safety of an entire population being subordinated to the notions of a single individual." ${ }^{379}$ Jacobson

\footnotetext{
372 Vacco v Quill 521 US 793, 807 (1997).

${ }^{373}$ New Health New Zealand Inc v South Taranaki District Council [2014] NZHC 395, [2014] 2 NZLR 834 (Council judgment); [2014] NZHC 2487 (Medicines Act judgment); [2015] NZHC 2138, [2015] NZAR 1513 (Regulations judgment).

${ }^{374}$ New Health New Zealand Inc v South Taranaki District Council [2016] NZCA 462, [2017] 2 NZLR 13.

${ }^{375}$ New Health New Zealand Inc v South Taranaki District Council [2018] NZSC 59.

${ }^{376}$ Health New Zealand Inc v South Taranaki District Council [2014] NZHC 395 at [86]. See also New Health New Zealand Inc v South Taranaki District Council [2016] NZCA 462, [2017] 2 NZLR 13 at [87].

${ }^{377}$ Health New Zealand Inc v South Taranaki District Council [2014] NZHC 395 at [86].

${ }^{378}$ Ibid, at [87].

${ }^{379}$ Jacobson v Commonwealth of Massachusetts 197 US 11, 25 S Ct 358 (1905).
} 
v Massachusetts was a landmark ruling in 1905 by the United States Supreme Court upholding the right of states to compel vaccination.

With respect, this policy reasoning is not satisfactory. If it is accepted that immunisation programmes have, as is often-cited, the aim of protecting those unable to undergo vaccination because of contraindications (elderly, immunocompromised), then the end requires that the outcome of an entire population is decided by a handful of individuals that the policy seeks to protect. It would be highly unusual to prioritise the rights of elderly or immunocompromised above the rights of others. Further, such an approach would cut across the obligation of the State to protect and promote human rights and fundamental freedoms. ${ }^{380}$

A broad reading of s 11, which incorporates public health measures, is more appropriate as it allows for the public to challenge public health measures and requires the State to justify any action. Challenge and justification will only increase the quality and legitimacy of State intervention for public health. Butler and Butler state that the "right to challenge public health measures is one of the most important rights within the ambit of the right to refuse medical treatment." 381

Where there is a question of competing rights, a s 5 analysis is the better place to consider limiting the right than reading limits into the right itself, ${ }^{382}$ for example, in s 11 . The scope of the right ought not to be limited at the definition stage. Immunisation policy involves both broad public rights, rights of the community, and rights of the individual. Accordingly, it is not appropriate to limit s 11 at this stage of the inquiry. Conflicting rights should be dealt with at the s 5 stage. This is where the State should justify any limitations that they place on the right for the greater public good. Support for this proposition can be found in the Court of Appeal judgment of Ministry of Health $v$ Atkinson, where the Court said: "We

\footnotetext{
${ }^{380}$ Bill of Rights Act 1990, long title.

${ }^{381}$ Butler and Butler, above n 232, at [11.9.8].

${ }^{382}$ At [6.6.18].
} 
consider that purpose is best achieved by an approach in which matters of justification are dealt with at the s 5 stage ...."383

Clear and explicit language from Parliament is necessary to authorise what would be a serious encroachment on a fundamental right. ${ }^{384}$ The absence of any qualifiers in s 11 suggest that Parliament intended the section to be given a wide definition. Support for such a proposition is found in s 6 of the Bill of Rights Act $1990 .^{385}$ The Supreme Court said: ${ }^{386}$

Reading down s 11 to exclude public health measures would leave open the possibility that compulsory mass medication as a public health measure would not be within the scope of s 11.

If immunisation as a public health measure does not engage s 11, then the State has no reason and indeed no responsibility to examine whether intervention is "reasonably and demonstrably justified" under s 5, a requirement for actions that are in breach of the Bill of Rights Act 1990. It follows that any intervention cited as a public health measure by authorities would not require justification. Butler and Butler argue that it is only under a s 5 analysis that the court can "balance the right of the individual with the rights of the majority and the values of society." "This approach", they continue "allows for the courts to react adequately to social change." 387

\section{Freedom of Choice}

Public health measures that are impossible or impractical to refuse would appear to be at odds with s 11 . The inability to refuse medical treatment limits bodily integrity by eroding

\footnotetext{
${ }^{383}$ Ministry of Health $v$ Atkinson [2012] NZCA 184, [2012] 3 NZLR 456 at [117] per France J.

${ }^{384}$ New Health New Zealand Inc v South Taranaki District Council [2018] NZSC 59 at [292].

385 Section 6 reads: "Wherever an enactment can be given a meaning that is consistent with the rights and freedoms contained in this Bill of Rights, that meaning shall be preferred to any other meaning."

${ }^{386}$ New Health New Zealand Inc v South Taranaki District Council [2018] NZSC 59 at [98].

${ }^{387}$ Butler and Butler, above n 232, at [6.6.18].
} 
a person's ability to exercise choice about their body. ${ }^{388}$ The Supreme Court in New Health New Zealand Inc v South Taranaki District Council considered argument on this point in a case involving the fluoridation of public water. ${ }^{389}$ A key consideration in cases involving the imposition of preventive treatment is the question of choice.

If a government passed a law compelling vaccination, then the public have no practical choice but to comply. This restricts their choice set to a single option, which is not a choice at all.

A voluntary vaccination policy provides options to both those able to receive vaccines and those unable. For those able, they can either choose to receive a vaccine or not. For those unable (the very young, the elderly, and the immunocompromised), they have the option of avoiding contact with people potentially infected with a vaccine-preventable disease through environment and relationship planning. Such an approach may appear unduly harsh; however, planning to avoid contact with a potentially life-threatening disease for an individual's own health benefit could be argued to be less harsh than compulsory vaccination of a child who may never encounter the disease. Additionally, if the immunocompromised, elderly, or child do contract a disease, medical treatment is available. Contracting a disease is not the end of the road as options remain.

The situation does not change substantially in an epidemic. What changes are people's fears and perceptions of risk. In times of emergency, the State has police powers that can be implemented to compel vaccination for certain diseases. However, as the risk of harm would be clearly apparent, it is unlikely that people would be opposed to vaccination at this time. They are more likely to seek out vaccination than to turn it away; perhaps not for the greater good, but to protect their child from a real risk of harm.

\footnotetext{
${ }^{388}$ Rose Goss "A Decay of Rights: The Decision in Health New Zealand Inc v South Taranaki District Council" (LLB(Hons) Dissertation, Victoria University of Wellington, 2014).

${ }^{389}$ New Health New Zealand Inc v South Taranaki District Council [2017] NZSCTrans 28 (16 November 2017).
} 


\section{Privacy}

Privacy in this section is being thought of as a person's right to respect for private life. This includes the right to freedom of religion and the right to freedom of expression.

\section{Religion}

Section 13 of the Bill of Rights Act 1990 provides everyone with the right to freedom of religion and beliefs, and s 15 provides the right to manifest that religion or those beliefs. The Code of Patients' Rights provides that health consumers have the right to services that consider the needs, values, and beliefs of different religious groups. ${ }^{390}$ These rights stem from The International Covenant on Political and Civil Rights, which states: "Everyone shall have the right to freedom of thought, conscience and religion."391 These rights are limited when it is "necessary to protect public safety, order, health, or morals or the fundamental rights and freedoms of others." 392

Arguments opposing vaccination on religious grounds that claim to be scientific in standing are incompatible with progression through stage one of the framework. Religious arguments do not adhere to an underlying scientific methodology that is reproducible, falsifiable or generally accepted. This does not mean that religious opposition to vaccination can be dismissed, rather, religion finds a place among the discussion of values. The first question for the policymaker is whether religious beliefs are, prima facie, being breached with legislative action to increase immunisation coverage.

Religious values and beliefs of health consumers are not without limitation. The Court of Appeal in $\operatorname{Re} J$ (An Infant): $B \& B v D G S W$ acknowledged that, for guardians, rights are limited "so as to exclude doing or omitting anything likely to place at risk the life, health,

\footnotetext{
${ }^{390}$ Health and Disability Commissioner (Code of Health and Disability Services Consumers' Rights) Regulations 1996, a regulation made under the Health and Disability Commissioner Act 1994, Part 2 ss 19 23 and Right 1(3).

${ }^{391}$ International Covenant on Civil and Political Rights 999 UNTS 171 (opened for signature 16 December 1966, entered into force 23 March 1976), art 18(1).

${ }^{392}$ Article 18(3).
} 
or welfare of their children". ${ }^{393}$ That case concerned an urgent blood transfusion for an infant of a Jehovah's Witness family. The issue for the Court was the parents' right to manifest their religion (because of their beliefs they were unable to give consent for the transfusion) versus the infant's right not to be deprived of life.

Andrew Butler argues that the right to life of the infant was not being imperilled by the State - to attract protection, the act must be done by the executive or judicial branches of the government under s 3(a) of the Bill of Rights Act 1990 - but by choices made by the parents in the name of religion. ${ }^{394}$ The analysis should have proceeded, suggests Butler, not with the Court considering the right of the child not to be deprived of life, but the parents' right to manifest their religion. This would necessarily involve the State justifying its actions, which, one would think, would be met by its overwhelming obligation to protect the life of the child. ${ }^{395}$ State-mandated vaccination would not be open to the same critique because any legislative action would meet the s 3(a) requirement.

In Re J (An Infant): $B \& B v D G S W$, the circumstances necessitating the blood transfusion were not directly analogous to immunisation. $M v$ Auckland District Health Board ${ }^{396}$ is a little closer. That case was also a blood transfusion case involving a child whose parents were Jehovah's Witnesses and could not provide consent for religious reasons. The distinguishing feature between the two cases was that in $M v$ Auckland District Health Board the child required liver and kidney transplants. These operations were necessary but were not urgent to the same extent as in $\operatorname{Re} J(A n$ Infant): $B \& B v D G S W$. The circumstances required the provision of blood products in preparation for the transplant, throughout the operation and possibly after it. In those circumstances, the case did not fit under the provisions of s 37 of the Care of Children Act 2004.

\footnotetext{
${ }^{393} \operatorname{Re} J$ (An Infant): $B \& B v D G S W$ [1996] 2 NZLR 134 (CA) at 146.

${ }^{394}$ Andrew S Butler "Limiting Rights" (2002) 33 VUWLR at 547.

${ }^{395}$ Ibid.

${ }^{396}$ M v Auckland District Health Board [2012] NZHC 1563.
} 
The Court ultimately made an order placing the child under the guardianship of the court. This approach was an agreeable one and cleverly resolved the conflict between the parents' right to manifest their religious beliefs and the court's duty to do what is in the best interests of the child. By moving consent from the parents to the court, the agonising conflict between the firmly held religious beliefs of the parents and the pressing needs of the child was resolved.

A point to note is that people do hold the religious belief that if they submit their child to a blood transfusion or vaccination the child will go to hell when they die. While this view may appear outrageous to some, people do believe it. If the State enacted a law that removed religious freedom and required immunisation, the law could have a devastating impact on some families. The law would effectively require a parent to take action that they believe sentences their child to hell fire and damnation for all eternity.

In the United States, the courts have frequently found that public health overrides religious beliefs in cases concerning childhood vaccinations. ${ }^{397}$ A determining factor is whether the religious belief is sincerely held. It is not enough that a person is a bona fide member of a recognised religious organisation. ${ }^{398}$ The same standard ought to be incorporated into any immunisation policy in New Zealand.

\section{Freedom of Expression}

The ability to speak freely is protected by s 14 of the Bill of Rights Act 1990, which ensures that: "Everyone has the right to freedom of expression, including the freedom to seek, receive, and impart information and opinions of any kind in any form."

Countering misinformation in an open way may dissuade some previously unsure about vaccines, those fence-sitters, from relying on vaccine-critical advice. The Ministry of Health in New Zealand has adopted such an approach by providing consumers with

\footnotetext{
397 Silverman and May, above n 292, at 507.

398 Sherr v Northport-East Northport Union Free Sch Dist 672 F Supp 81, 91 (EDNY 1987).
} 
answers and resources to the more commonly cited worries about vaccines; for example, safety and efficacy. ${ }^{399}$ The Immunisation Handbook 2017 contains a section titled "Addressing myths and concerns about immunisation", 400 although that section is directed at ways healthcare providers can respond to misinformation. The Handbook also recognises that because of the explosion of anti-vaccination material available on the internet in recent years, it is "no longer practical to prepare official rebuttals to each new article." ${ }^{201}$ Further, the Immunisation Advisory Centre provides information about making an informed choice. The Centre acknowledges the difficulties consumers have in identifying accurate information and aims to assist "readers in identifying web sites providing information on vaccine safety that comply with good information practices." To this end, the Centre notes that the Global Advisory Committee on Vaccine Safety "has recommended a list of criteria that sites providing information on vaccine safety should adhere to," and the World Health Organisation has "reviewed a number of sites for adherence to the credibility and content criteria." Links are provided.

Despite best intentions to reduce the potential for harm created by the dissemination of anti-vaccination material, it may be necessary to rein in private providers of misinformation who do not follow good information practices using more forceful means. One option falls within the ambit of freedom of expression. Because of the plethora of websites critical of vaccines, it seems improbable that a government would be able to constrain the spread of all potentially harmful misinformation. However, stopping all misinformation may not be necessary. Action taken against only the most vocal opponents may be sufficient; acting as a deterrent against others. This option creates conflict between the recognised right to freedom of expression and the State's responsibility to protect the health of the public.

Butler and Butler, referring to $R v$ Secretary of State for the Home Department, ex $p$ Simms,${ }^{402}$ write that one of the fundamental principles justifying free speech is that it acts

\footnotetext{
${ }^{399}$ Ministry of Health "Vaccine safety" <www.health.govt.nz>.

${ }^{400}$ Immunisation Handbook, above n 178, at 97.

401 At 107.

${ }^{402} R v$ Secretary of State for the Home Department, ex p Simms [2000] 2 AC 115 (HL) at 126.
} 
as "a safety valve for society". This is to prevent ideas otherwise being "driven underground and conspiracy is encouraged". ${ }^{403}$ However, Amanda Naprawa questions whether the "marketplace of ideas [is] served by allowing misleading anti-vaccination speech?"404

Unlike international instruments, the Bill of Rights Act 1990 does not stipulate limitations or restrictions. Art 19 of the International Covenant on Civil and Political Rights provides that the "exercise of the right to freedom of expression carries with it special duties and responsibilities" and that it may be "subject to certain restrictions" as long as they are "provided by law" and are "necessary". One of the limitations is for the "protection of ... public health". ${ }^{405}$

\section{Mill wrote: ${ }^{406}$}

We have a right, and it may be our duty, to caution others against him, if we think his example or conversation likely to have a pernicious effect on those with whom he associates.

A distinction needs to be drawn between those who sincerely but mistakenly promote untruthful anti-vaccination material and those with a commercial interest in promotion. Controlling false or misleading commercial anti-vaccination material would deter or eliminate a proportion of anti-vaccination supporters and prohibit those seeking to profit by taking advantage of parental fears. ${ }^{407}$ Such a measure may be sufficient to increase immunisation coverage.

\footnotetext{
${ }^{403}$ Butler and Butler, above n 232, at [13.6.15].

${ }^{404}$ Amanda Naprawa “Don't give your kid that shot!: the public health threat posed by antivaccine speech and why such speech is not guaranteed full Protection under the first amendment" (2013) 11 Cardozo Pub Law Pol Ethics J 473 at 478.

405 International Covenant on Civil and Political Rights, above n 391, art 19(3).

406 John Stuart Mill On Liberty (Oxford University Press, Oxford, 2015) at 139.

${ }^{407}$ Naprawa, above n 404, at 510-511.
} 
The near impossible task of enforcing a restriction on anti-vaccination speech means that this option is not realistic. Additionally, opposition at both domestic and international levels would create serious ramifications for political longevity. Freedom of expression is not advanced further in this thesis.

\section{E Equality}

1 Linking Beneficiary Payments to Immunisation Status

In New Zealand, s 19(1) of the Bill of Rights Act 1990 provides everyone with the right to be free from discrimination on the grounds specified in the Human Rights Act 1993. A proposed immunisation policy linking beneficiary payments to immunisation status would require consideration of s 19. A policy of this nature has been adopted in Australia ${ }^{408}$ and suggested in New Zealand. ${ }^{409}$

Putting aside the moral argument of punishing those most in need of help, particularly the children of parents on a benefit, a hurdle to overcome is discrimination. One of the grounds of discrimination in the Human Rights Act 1993 is employment status. Employment status includes being the recipient of a benefit. ${ }^{410}$ Section 19(1) of the Bill of Rights Act 1990 is qualified by sub (2), which states that measures taken in good faith to assist or advance persons or groups of persons disadvantaged because of discrimination that is unlawful does not constitute discrimination.

Section 19(2) allows for affirmative action. The subsection acts as a barrier to the argument that one group is being given an unfair advantage over another. In the immunisation debate, defending mandatory vaccination of beneficiaries by reference to s 19(2) would appear untenable. It is difficult to see how trampling other rights accorded beneficiaries for the sake of compulsory immunisation is to their advantage.

\footnotetext{
408 Social Services Legislation Amendment (No Jab, No Pay) Act 2015.

${ }^{409}$ Health Committee Inquiry into how to improve completion rates of childhood immunisation, and Briefings from the Chief Coroner on the coronial process, from Dr Michael Tatley on the adverse reaction process, and from Professor Sir Peter Gluckman on how to improve completion rates of childhood immunisation (March 2011) at 18.

${ }^{410}$ Human Rights Act 1993, s 21(1)(k)(ii).
} 
A strong argument against linking payments to immunisation status is that there is no consensus that the evidence confirms beneficiaries have lower immunisation coverage than other subgroups of the population. It follows that compulsory immunisation will not achieve the desired end.

\section{Compulsory Vaccination of Healthcare Workers}

Compulsory vaccination of healthcare workers also requires consideration of potential discrimination.

Stuart McLennan argues that annual influenza vaccination should be compulsory for all health care workers with direct patient contact unless a medical contraindication exists. ${ }^{411}$ Such an approach aligns with current government thinking. A Ministry of Health position paper recommended the influenza vaccine for all healthcare workers. ${ }^{412}$

A reduction in vaccine-preventable diseases could be achieved by the Government passing health and safety legislation requiring people to receive vaccinations if their employment brings them into contact with those high-risk groups. McLennan argues that a compelling case can been made that the duties imposed on District Health Boards and healthcare workers under health and safety legislation require making annual influenza vaccinations an occupational requirement. ${ }^{413}$ This approach has been followed to a degree. A staff member's employment was terminated, and three others were suspended, for defying a

\footnotetext{
${ }^{411}$ Stuart McLennan and others "The Health and Safety in Employment Act and the influenza vaccination of healthcare workers" (2007) 120(1250) NZ Med J U2442.

${ }^{412}$ Ministry of Health "Position statement addressing influenza immunisation of healthcare workers" (March 2018) 〈www.health.govt.nz>.

${ }^{413}$ The Health and Safety in Employment Act 1992 was repealed and replaced by the Health and Safety at Work Act 2015 on 4 April 2016. The provisions under which McLennan made his analysis were not carried over.
} 
Waikato District Health Board policy requiring all employees to receive an influenza vaccination or wear a facemask. ${ }^{414}$

There is mixed evidence for whether influenza vaccination among healthcare workers reduces transmission to patients. In the United Kingdom, two studies found that overall mortality was reduced among long-term care residents when staff were offered vaccinations. ${ }^{415}$ A Cochrane systematic review ${ }^{416}$ found that, in older people in long-term care, rates of laboratory-confirmed influenza, pneumonia and death from pneumonia did not reduce when healthcare workers were vaccinated. However, rates of influenza-like illness (bacterial and viral infections), hospital admissions and overall mortality were reduced.

\section{F Summary}

This chapter canvassed some of the rights and freedoms relevant to the immunisation debate that are protected by law or legal principle. When considering new immunisation policy or law, the policymaker should identify and think about values that are relevant, and determine the impact that the new policy or law may have on them.

If the policymaker decides, after noting that rights or freedoms protected by law or legal principle, will be impacted, the next step in the framework is to consider whether proposed action is none-the-less justifiable. The following chapter addresses this point.

\footnotetext{
$\overline{{ }^{414} \text { New Zealand Herald "Worker fired over hospital's hardline vaccination policy" The New Zealand Herald }}$ (online ed, Auckland, 3 August 2015).

${ }^{415}$ WF Carman and others "Effects of influenza vaccination of health-care workers on mortality of elderly people in long-term care: a randomised controlled trial" (2000) 355(9198) Lancet 93-97; J Potter and others "Influenza vaccination of health care workers in long-term-care hospitals reduces the mortality of elderly patients" (1997) 165(1) J Infect Dis 1-6.

${ }^{416}$ RE Thomas and others "Influenza vaccination for healthcare workers who work with the elderly" (2010) 2 Cochrane Database Syst Rev CD005187.
} 


\section{Stage Three: Justified Limitations}

This chapter discusses the third and final stage of the framework. The final stage asks whether imposing limits on rights protected by law or legal principle can be demonstrably justified in a free and democratic society. It is acknowledged that: ${ }^{417}$

Parliamentary sovereignty means that Parliament can, if it chooses, legislate contrary to fundamental principles of human rights. The constraints upon its exercise are ultimately political, not legal. But the principle of legality means that Parliament must squarely confront what it is doing and accept the political cost.

Section 5 of the Bill of Rights Act 1990 is concerned with placing justified limits on the rights and freedoms contained within the Act. Section 5 recognises that rights and freedoms are not absolute, and they may, at times, be limited. ${ }^{418}$ In $R v \mathrm{~B}$, Sir Ivor Richardson observed that "individual freedoms are necessarily limited by membership of society and by the rights of others and the interests of the community." 419

As noted earlier, the approach used to determine whether a limit placed on a protected right or freedom is justified is the methodology suggested by Tipping $\mathrm{J}$ in $R v$ Hansen. This approach applies to the whole of the values examination and should not be thought of as being limited to only those values enshrined in the Bill of Rights Act 1990. Also included are moral and cultural aspects underpinning welfare and best interest values. Further, when thinking about values protected by law, values must necessarily be interpreted to include cultural and communal values, not just individual values.

Each step of the process is discussed in turn.

\footnotetext{
${ }^{417}$ A v Auckland District Law Society [2005] 3 NZLR 552 at [33] per Randerson J.

${ }^{418}$ See, for example, Claudia Geiringer "On a road to nowhere: implied declarations of inconsistency and the New Zealand Bill of Rights Act” (2009) 40 VUWLR 613-647.

${ }^{419} R v B$ [1995] 2 NZLR 172 (CA) at 182.
} 


\section{A Sufficiently Important}

The purpose of vaccination is to reduce the incidence and spread of potentially deadly vaccine-preventable diseases. The question is whether policy options to achieve increased immunisation coverage serve a purpose sufficiently important to justify curtailing protected rights and freedoms.

Supporters of immunisation programmes argue that because vaccination confers a benefit not only to the individual undergoing the vaccination event but also more broadly to the wider community, vaccination is not only a civic duty but one that is sufficiently important to warrant State intervention. This argument is founded on the idea that an individual's failure to act causes harm to others in the community. In contrast, those opposed to vaccination argue that coercive measures do not give adequate thought to principles of autonomy, bodily integrity and dignity.

\section{The Harm Principle}

The State possesses supreme coercive authority over individuals or groups that are part of society. ${ }^{420}$ Coercion is necessary because "the freedom of some must at times be curtailed to secure the freedom of others". ${ }^{421}$ A constraining factor, however, is the "Harm Principle", a prominent moral principle reflected in social policy. This principle seeks to protect individual autonomy while recognising that "the exercise of one person's autonomy can threaten another person's freedom to structure their own life and values." ${ }^{422}$

The most famous proponent of the Harm Principle is John Stuart Mill, who summarised the principle as "the only purpose for which power can be rightfully exercised over any member of a civilized community, against his will, is to prevent harm to others." ${ }^{23}$ Further, Mill wrote: $:^{424}$

\footnotetext{
${ }^{420}$ Harold J Laski The State in Theory and Practice (Routledge, New York, 2009).

${ }^{421}$ Isaiah Berlin Four Essays on Liberty (Oxford University Press, London, 1969) at 126.

422 Silverman and May, above n 292, at 510.

${ }^{423}$ Mill, above n 406, at 13.

${ }^{424}$ At 76.
} 
Acts injurious to others require a totally different treatment. Encroachment on their rights; ... even selfish abstinence from defending them against injury - these are fit objects of moral reprobation, and, in grave cases, of moral retribution and punishment.

This position was affirmed in the United States by the Supreme Court in Jacobson $v$ Massachusetts, in which the Court upheld as constitutional a law requiring smallpox vaccinations in the city of Cambridge: ${ }^{425}$

[T]he liberty secured ... does not import an absolute right in each person to be, at all times and in all circumstances, wholly freed from restraint .... Upon the principle of self-defense, of paramount necessity, a community has the right to protect itself against an epidemic of disease which threatens the safety of its members.

Silvermann and May argue that if failure to vaccinate only imposes risks upon the individual forgoing vaccination, then State-mandated vaccination cannot be justified on moral grounds. However, if refusal poses risk to others, then State intervention overriding other freedoms is justified. ${ }^{426}$ This line of reasoning is reflected in Roe $v$ Wade, ${ }^{427}$ in which the United States Supreme Court, noting Jacobson, observed that medical privacy was not unlimited and must be balanced against important State interests in regulation.

There is a large body of evidence to suggest that vaccines in New Zealand, in common with other countries, are a significant preventative public health intervention that successfully reduce the incidence of vaccine-preventable disease. Preventing disease also has significant benefits in terms of cost savings to the health sector and the taxpayer. The objective of preventing disease is sufficiently important to justify the administration of vaccines. That said, however, justification may not be met for all vaccines.

\footnotetext{
425 Jacobson v Commonwealth of Massachusetts 197 US 11, 25 S Ct 358 (1905) at 25-27.

426 Silverman and May, above n 292, at 511.

${ }^{427}$ Roe v Wade 410 US 113, 93 S Ct 705 (1973).
} 


\section{Different Diseases Require Different Approaches}

Any vaccination programme must address a substantial public health danger. It is not enough that a vaccine may be available to counter a potential low-risk disease. Generally, the disease must have high morbidity and mortality, be spread through the air and be highly contagious. ${ }^{428}$ Emphasis ought to be given to the values of autonomy, dignity and bodily integrity. To properly give effect to these values, it is necessary to distinguish those types of diseases that justify treating a person without their consent.

Rights might be necessarily limited to circumstances where failure to treat an individual for a disease puts others in the community at serious risk. An example is poliomyelitis, a severely debilitating disease with a high incidence of morbidity and mortality. ${ }^{429}$ A different approach would be required where the risk for contracting the disease is dependent on behavioural and lifestyle choices, for example HPV. Because the HPV vaccine prevents against a disease that is transmitted primary through sexual contact, compulsory vaccination for HPV raises slightly different issues to diseases transmitted via other routes. State-mandated HPV vaccination as a condition to school entry would appear to be unreasonable. It would be unethical to impose vaccination for a condition based on speculation about future lifestyle-related behaviours. ${ }^{430}$

\section{B Rational Connection}

The question to be determined under this limb is whether any limit to a protected right is rationally connected with its purpose.

\section{Preventing Disease}

Opponents to vaccines argue that the scientific evidence related to the benefits of vaccination is contested and that risks are downplayed. The World Health Organisation, the Centers for Disease Control and the New Zealand Immunisation Advisory Centre

\footnotetext{
${ }^{428}$ FM Hodges and others "Prophylactic interventions on children: balancing human rights with public health" (2002) 28(1) J Med Ethics 10.

${ }^{429}$ WHO "Poliomyelitis" < www.who.int>.

${ }^{430}$ Hodges and others, above $n 428$.
} 
consider the benefits of immunisation outweigh the risks. Additionally, as discussed earlier, a multitude of international studies have found no evidence between the administration of vaccines and the often-cited association with autism.

Despite opposition, the conclusion can be reached, without difficulty, that there is a rational connection between the administration of vaccines and a reduction in the incidence and spread of disease.

\section{Targeting Subgroups of the Population}

Discrimination towards beneficiaries under the Human Rights Act 1993 or healthcare workers under health and safety legislation are examples of subgroups of the population being singled out for compulsory immunisation based on uncertain scientific evidence.

The State needs to be careful that they do not impose more stringent obligations on these groups because there is no solid scientific evidence to conclude that this is indeed the case. For beneficiaries, particularly, it is difficult to hold that it is reasonable to impose mandatory vaccination on the basis that they are more at risk because the evidence does not support the proposition. Because there is insufficient evidence to suggest that beneficiaries have lower immunisation coverage than any other subgroup of the population, policies targeting this group would be unlikely to have a substantial effect on increasing immunisation coverage. The evidence in support of a rational connection between compulsory immunisation of beneficiaries and increasing immunisation coverage is weak.

An alternative interpretation is that art 12 and s 6 create a disparity in the minimum standards of health between beneficiaries and healthcare workers and other members of the community. Requiring vaccination of these subgroups signifies that their health is more important than the health of others, which would be at odds with international conventions and domestic legislation. On the other hand, the definition of "public health" in s 6 of the New Zealand Public Health and Disability Act 2000 is defined broadly as meaning "the 
health of all of ... a community or section of such people. ${ }^{431}$ However, affirmative action would involve trampling other rights and, once again, cannot be justified in the face of uncertain scientific evidence.

Finally, if the rationale for targeting beneficiaries is because of a reciprocal obligation based on the premise of responsible citizenship, it is difficult to justify the State not holding all parents to the same standard. ${ }^{432}$

\section{Reasonably Necessary}

The question under this heading is whether a policy option that restricts rights is no more than is reasonably necessary to achieve its purpose. In $R v$ Hansen, Blanchard $\mathrm{J}$ noted that "a choice could be made from a range of means which impaired the right as little as was reasonably necessary". ${ }^{433}$ As noted in RJR-MacDonald Inc v Canada, “... the law must be carefully tailored so that rights are impaired no more than necessary." $" 434$

\section{Options Available}

Art 12 of the International Covenant on Political and Civil Rights provides everyone with the right to a minimum standard of health. New Zealand gives effect to this human rights obligation through the New Zealand Public Health and Disability Act 2000. This should not be read as requiring the State to introduce compulsory immunisation to achieve a public health aim, particularly when there are alternatives that do not override or extinguish other existing rights.

A review of the scientific evidence suggests that alternatives to compulsory immunisation are available, are not hypothetical and do not lack credibility. Policy initiatives have been in place for some time. Through continued promotion of non-coercive actions,

\footnotetext{
${ }^{431}$ Emphasis added.

${ }^{432}$ Kerr, above $\mathrm{n} 11$, at 70 .

${ }^{433} R$ v Hansen [2007] NZSC 7, [2007] 3 NZLR 1 at [79] per Blanchard J.

${ }^{434}$ RJR-MacDonald Inc v Canada [1995] 3 SCR 199 at [160].
} 
immunisation coverage has been increasing since the Government made it a key health priority.

One potential non-coercive option would be to address the financial barriers to immunisation. Difficulties associated with accessing vaccine providers in the form of travel costs and childcare arrangements have been identified as barriers to immunisation uptake. If, for example, there was a strong evidential basis showing an association between beneficiaries and low immunisation coverage, increasing the amount of the benefit may be a non-coercive option worth considering.

\section{Police Powers During Times of Emergency}

Legislation is frequently used to serve collective interests. Fluoridation of public water and smoke-free legislation are conventional, albeit controversial, public health measures. Although public health authorities emphasise the focus on health, historical and legal analysis show that the true nature of the public health setting falls within the police powers of the State. ${ }^{435}$

The courts have limited the exercise of police powers of the State, holding that such power cannot be exercised in "an arbitrary, unreasonable manner" or "go so far beyond what was reasonably required for the safety of the public". ${ }^{436}$

For immunisation, police powers conferred to public health officials are evident in legislation available during times of emergency. In New Zealand, such powers include, for the purposes of preventing the outbreak or spread of any infectious disease, requiring people to undergo compulsory reporting and examination, ${ }^{437}$ compulsory testing, ${ }^{438}$ compulsory quarantine, ${ }^{439}$ and, in some instances, compulsory preventive treatment. ${ }^{440}$

\footnotetext{
${ }^{435}$ Dickens, above n 209, at Introduction xv.

436 Jacobson v Commonwealth of Massachusetts 197 US 11, 25 S Ct 358 (1905) at 28.

${ }^{437}$ Health Act 1956, s 70(1)(e).

${ }^{438}$ Section 70(1)(ea).

${ }^{439}$ Section 70(1)(f).

${ }^{440}$ Section 70(1)(fa).
} 
Infectious diseases are defined in s 2 of the Health Act 1956 to include those diseases listed in Part 1 and 2 of Schedule 1. Ten of the 11 diseases for which preventative vaccines are administered to children are included in the Schedule. These are tetanus, diphtheria, pertussis (whooping cough), poliomyelitis, hepatitis B, haemophilus influenzae b, measles, mumps, rubella, and varicella-zoster (chicken pox). Also included, but not administered to children as part of the routine immunisation programme is influenza.

\section{$D$ Limit in Proportion to its Objective}

There is a preponderance of evidence supporting the conclusion that the significant advantages of vaccines outweigh the negligible risk of a serious adverse reaction following administration of a vaccine. Arguments opposing vaccination are often based on anecdote or belief of adverse effects rather than scientific evidence. This is not to say serious adverse effects do not occur. Rather, they do not occur in the frequency often claimed. Further, studies in support of adverse effects have been found to be fraught with bias, fraudulent, or of low quality.

\section{$1 \quad$ Imposing Risk}

One of the difficulties with using science to inform immunisation policy is the risk associated with the intervention-the vaccination event in this instance. As discussed earlier, imposing risk involuntarily can provoke outrage. New legislation or government policy initiatives are adopted in an environment of scientific complexity and uncertainty. This reality is problematic. Andrew Butler asks: ${ }^{441}$

What impact should the human rights dimension have on the approach to uncertainty particularly where the impact on rights and freedoms is clear, but the benefits from the limits imposed are speculative?

Vaccination is a public health intervention that carries a risk, albeit small, for adverse events. Consent is about risk, particularly who is entitled to make decisions for those who

${ }^{441}$ Butler, above n 394, at 559. 
bear the risk. A Health Committee inquiry into improving immunisation completion rates was conscious of imposing risk and wrote in their report: ${ }^{442}$

There are rare but significant reactions to immunisation, and there must be room for exempting those who object to it.

The Government's response to the report was equally liberal, with the Ministry of Health noting: ${ }^{443}$

... while targets are important to reduce vaccine preventable diseases, immunisation is a choice in New Zealand. Efforts to achieve on-target immunisation must respect the individual's, parent's, and guardian's rights to make an informed choice and decision.

Finally, the normal tenets of medical ethics, based on a risk/benefit analysis, suggest that it is inappropriate to administer any pharmaceutical product that is without benefit to the recipient, because all drugs carry a risk of occasional adverse-effects. ${ }^{444}$ An example is helpful to illustrate this point. Gardasil (HPV vaccine) was previously only known to be effective for girls but was also administered to boys. The known benefits were nil for boys, suggesting that the risks, however, small, outweighed the benefits.

\section{E Summary}

This chapter considered whether limiting some of those values discussed in the previous chapter is justified. The test outlined in Hansen $v R$ was used as the framework to this end. The key factors for the policymaker are: whether policy (particularly legislative intervention) is necessary; whether there is a rational connection between the policy/law

442 Health Committee, above $\mathrm{n} 409$, at 8.

${ }^{443}$ New Zealand Government Government Response to the Report of the Health Committee on Inquiry into how to improve completion rates of childhood immunisation, and Briefings from the Chief Coroner on the coronial process, from Dr Michael Tatley on the adverse reaction process, and from Professor Sir Peter Gluckman on how to improve completion rates of childhood immunization (22 June 2011) <www.parliament.nz>, Response 23 to Recommendation 6 at 5.

${ }^{444}$ Stephanie Pywell "Infant vaccination: A conflict of ethical imperatives" in Austen Garwood-Gowers and others (ed) Contemporary Issues in Healthcare Law and Ethics (Elsevier, London, 2005) 213-232 at 221. 
and the problem being addressed; whether implementation is reasonably necessary; and whether the limit is in proportion to its objective. Reference back to the science that was found to be robust and appropriate in stage one of the framework (discussed in Chapter VI) helps guide the policymaker when conducting this third stage. 


\section{Conclusion}

This thesis has canvassed the difficulties associated with the use of science to inform health policy. A decision-making framework has been described. This framework may help resolve the multitude of issues that arise and ought to be considered when choosing among health policy options. Immunisation of children was used as a case study to illustrate application of the framework when applied to a real-world health policy issue.

During the initial discussion on the relationships between science, policy and society, it was evident that a key problem at this interface is the blurring of science and values arguments. Such blurring of boundaries means that it can be difficult for both the public and the policymaker to draw a clear distinction between arguments based on science and those that appeal to values. This lack of distinction is particularly problematic as it makes it hard for rational discussions to take place and options to be presented if those involved are unable to understand and agree on the nature of the information that can be used to help solve a problem. To separate science and values, the decision-making framework was briefly introduced to guide the reader through subsequent discussion.

The issues that arise with using science in policy were outlined. These issues included how an emotive public can be influenced by false balance in the media and an abundance of easily accessible information on the internet. With little to no restriction on what information can be uploaded to the internet, special interest groups are able to cherry-pick scientific studies that support their own agenda and cast doubt on reliable science that opposes their views. Such a tactic can be used to create doubt in the minds of the public, who then perceive science to be less certain than it is. The flow on effect is that policymakers (who cannot help but be influenced by public sentiment) may act in a kneejerk manner to an emotive public either calling for or against legislative change.

The issues outlined are generally applicable to health-related policy decisions. The issues do, however, manifest in different ways dependent on the specific policy question being addressed. Immunisation of children is the topic of this thesis; therefore, how the issues create problems in the immunisation debate was examined. The link between the 
administration of vaccines and the introduction of a medical condition (for example, autism), religious beliefs and distrust of government were three ideas used to highlight the general issues when thinking about immunisation policy. Imposing risk, misusing science or promoting pseudo or junk science, how the public can be influenced by the media, particularly social media and the use of anecdote in place of scientific interpretation, and the changing social structures (the post-world) were ideas that were strongly evident. These ideas are a complex mix of both science and values, and confusion can arise when injected into difficult social debates.

Barriers to immunisation were considered in a discussion that drew on evidence obtained through various scientific disciplines, and included family characteristics, healthcare system factors, immunisation policy and Treaty considerations. When thinking about how science can be used to inform immunisation policy, it must be remembered that vaccine science (that is, how vaccines work and how immunisation is artificially stimulated) is not the only science relevant. Of importance are those social and cultural studies that seek to find reasons for vaccine-hesitancy among different groups in society. This may include barriers to immunisation uptake such as socio-economic factors that contribute to disparity among ethnic groups, geography, and the home environment. Drivers such as low (or higher) education and poverty are but some of those factors resulting in poor immunisation coverage in some areas of New Zealand. Multi-disciplinary studies provide information that can be collated to understand the bigger picture.

Understanding the multifactorial drivers behind low immunisation coverage is vital before policy can be developed to address the issue. Failing to understand the problem means that any policy would be implemented with a "hope for the best" approach. This is not satisfactory. A targeted approach is required, and this necessarily requires having a true understanding of the scope and nature of the problem.

Five policy options were proposed. These options are, of course, not the only options available. They were simply used as examples to help describe aspects of the framework as and when necessary. 
The three stages of the framework were then outlined, these being the science, values, and justified limitation stages. Greater explanation was provided for areas of the framework that required it, particularly the interpretation and approach to values. This approach was taken to avoid potential doubling up of information when it came to discussion using the framework in the immunisation debate.

Against that background, the framework was detailed and applied to the immunisation debate. The first stage, the science stage, sought to separate science from values by drawing on components of the scientific method. What was called a gate-keeper analysis turned the policymaker's mind to the legitimacy and robustness of the science being put forward to guide policy options. At this stage of the framework, anything held out as having a bearing on policy is considered. The gatekeeper is not limited to true scientific findings. For example, religious beliefs (intelligent design) can enter the framework at this point. What the framework does is look at what is being offered and critique it against several criteria. These criteria are the nature of the evidence being submitted. The following questions are relevant. Is it a layperson's anecdotal evidence or evidence from a scientific study (including anecdotal evidence from social science studies)? Has the evidence been obtained by a process with an underlying scientific methodology? Is the evidence generally accepted within the scientific community or is it a rogue study that goes against the consensus? Has the evidence been published in a peer-reviewed journal or is it merely somebody's honest but misguided ramblings on an internet blog? Finally, who is the author of the study? Are they at risk of bias or conflict of interest?

After science had been separated from values, the second stage of the framework considered values-based arguments relevant to the immunisation debate. The discussion on values could not be all-encompassing; therefore, some of the more polarising issues were addressed by way of example.

The underlying tension in formulating immunisation policy is the competition between the interests of the individual to refuse immunisation and the interests of the State in controlling 
the spread of disease. In this context, the discussion on values looked at public health as a community value, particularly the ideas that vaccination is a civic duty and that prevention is better than cure. Also, arguments about who makes decisions for children and questions about consent were addressed.

Stage three of the framework considered whether a policy option that sought to restrict rights and freedoms protected by law or legal principle could nevertheless be justified. This analysis considered whether a policy measure was sufficiently important, had a rational connection to its purpose, was reasonably necessary, and was in proportion to its objective. The harm principle, different diseases requiring different approaches and police powers during times of emergency where a few of the ideas covered.

As this thesis has demonstrated, the incorporation of science into public health policy is a difficult task. This is due in part because of the multitude of ideas that both policymakers and the public have about the usefulness of science to guide topics that have nearly inseparable values components. Immunisation of children is one such contentious issue, with immunisation policy necessarily contemplating complex and polarising themes. The challenge between reconciling scientific evidence on the benefits of vaccines to both the individual and the wider public with fiercely held individual beliefs that draw on ideas about bodily integrity, freedom of choice, consent, and parental autonomy cannot be overstated.

Adding a further layer of complexity are those problems inherent in the public's understanding, or perhaps better put, misunderstanding, of science. Further, when science is misused by special interest groups to advance their own agenda, or the public is misinformed by well-meaning but naïve vocal promoters of the risks of vaccination, doubt can be created in the minds of the public. This doubt can lead to fear and fear can result in public opposition to traditional sources of knowledge and authority, such as the scientific community and political structures. This makes it very difficult, if not impossible, to promote a course of action that appears to rely heavily on scientific input at the expense of individual or communal values. 
More and more frequently science is being called on to improve people's lives and provide solutions to the problems we face. Science, however, cannot be the only factor driving decision-making. Policy must incorporate and reflect the ideals, principles and beliefs that individuals, communities and society value if it is to be accepted and effective. By adopting the framework described in this thesis, the policymaker ought to be able to overcome the challenges that arise when science and values are interwoven in complex societal debates in which individual ideas about both science and values are not aligned. 


\section{Bibliography}

A Primary Sources

1 New Zealand Cases

A v Auckland District Law Society [2005] 3 NZLR 552.

$A v S$ FC Christchurch FAM-1999-009-2203, 5 September 2005.

B v Medical Council [1995] 3 NZLR 810.

Lewers v Northland District Health Board [2011] NZERA Auckland 303.

Mv Auckland District Health Board [2012] NZHC 1563.

McGrath v Police HC Auckland CRI-2011-404-110, 20 December 2011.

Ministry of Health v Atkinson [2012] NZCA 184, [2012] 3 NZLR 456.

New Health New Zealand Inc v South Taranaki District Council [2014] NZHC 2487

(Medicines Act judgment).

New Health New Zealand Inc v South Taranaki District Council [2014] NZHC 395, [2014] 2 NZLR 834 (Council judgment).

New Health New Zealand Inc v South Taranaki District Council [2015] NZHC 2138, [2015] NZAR 1513 (Regulations judgment).

New Health New Zealand Inc v South Taranaki District Council [2016] NZCA 462.

New Health New Zealand Inc v South Taranaki District Council [2017] NZSCTrans 28 (16 November 2017).

New Health New Zealand Inc v South Taranaki District Council [2018] NZSC 59.

PF v Capital and Coast District Health Board [2013] NZHC 1792.

$R v B$ [1995] 2 NZLR 172 (CA).

$R v$ Hansen [2007] NZSC 7, [2007] 3 NZLR 1.

$R v$ Salmond [1992] 3 NZLR 8 (CA).

Re J (An Infant): B\&B v DGSW [1996] 2 NZLR 134 (CA).

Smith v Attorney-General HC Wellington CIV-2005-485-1785, 9 July 2008.

Taunoa v Attorney-General [2007] NZSC 70, [2008] 1 NZLR 429 (SC).

Taylor v Attorney-General [2015] NZHC 1706, [2015] NZHC 1706. 


\section{International Cases}

Case C-621/15 N.W, L.W, C.Wv Sanofi Pasteur MSD SNC, Caisse primaire d'assurance maladie des Hauts-de-Seine, Carpimko (ECJ 21 June 2017).

Chatterton v Gerson [1981] QB 432.

Chester v Afshar [2004] UKHL 41.

Freeman v Home Office (No 2) [1984] QB 524.

Gard and others v The United Kingdom No 39793/17, 27 June 2017.

Gillick $v$ West Norfolk and Wisbech Area Health Authority [1985] 3 All ER 402 (HL).

Great Ormond Street Hospital v Constance Yates, Chris Gard and Charles Gard [2017] EWHC 972.

Higgs v Minister of National Security [2000] 2 AC 228.

Jacobson v Commonwealth of Massachusetts 197 US 11, 25 S Ct 358 (1905).

Philips v City of New York 27 F Supp 3d 310 (2014).

Prince v Massachusetts 321 US 158, 170 (1944).

$R v$ Secretary of State for the Home Department, ex p Simms [2000] 2 AC 115 (HL).

Reibl v Hughes [1980] 2 SCR 880.

RJR-MacDonald Inc v Canada [1995] 3 SCR 199.

Roe v Wade 410 US 113, 93 S Ct 705 (1973).

Rogers $v$ Whittaker (1992) 175 CLR 479.

Schloendorff $v$ Soc'y of NY Hosp 105 NE 92, 93 (NY 1914).

Sherr v Northport-East Northport Union Free Sch Dist 672 F Supp 81, 91 (EDNY 1987).

Sidaway v Bethlem Royal Hospital Governors [1984] 1 All ER 1018.

Vacco v Quill 521 US 793, 807 (1997).

\section{Legislation}

Care of Children Act 2004.

Code of Health and Disability Services Consumers' Rights 1996.

Crimes Act 1961.

Defence Act 1909 (9 EDW VII 1909 No 28).

Hazardous Substances and New Organisms Act 1996.

Health Act 1956. 
Health and Disability Commissioner Act 1994.

Health and Disability Commissioner (Code of Health and Disability Services Consumers' Rights) Regulations 1996.

Health Information Privacy Code 1994.

Health Practitioners Competence Assurance Act 2003.

Human Rights Act 1994.

Medicines Act 1981.

Medicines Regulations 1984.

New Zealand Bill of Rights Act 1990.

Oranga Tamariki Act 1989.

Privacy Act 1993.

Privacy Amendment Act 2013.

Public Health Act 1876 (40 Victoriae 1876 No 60).

Public Health Act 1900 (64 VICT 1900 No 25).

Public Health and Disability Act 2000.

Royal Society of New Zealand Act 1997.

The Health and Safety at Work Act 2015.

The Health and Safety in Employment Act 1992.

Vaccination Act 1863.

Vaccination Act 1871 (35 Victoriae 1871 No 51).

4 International Legislation

NDCC $\S 23-07-17.1$.

A New Tax System (Family Assistance) Act 1999 (Cth).

Ala Code $§ 16-30-3$.

CO Rev Stat $\S 25-4-901$.

HRS § 302A-1156.

New York Codes, Rules and Regulations Title 10, 66-1.10: Exclusion in event of disease outbreak, subsection (a).

Social Services Legislation Amendment (No Jab, No Pay) Act 2015.

W Va Code $\S 16-3-4$. 


\section{International Instruments}

Convention on the Rights of the Child 1577 UNTS 3 (opened for signature 20 November 1989, entered into force 2 September 1990).

International Covenant on Civil and Political Rights 999 UNTS 171 (opened for signature 16 December 1966, entered into force 23 March 1976).

International Covenant on Economic, Social and Cultural Rights 999 UNTS 171 (opened for signature 19 December 1966, entered into force 23 March 1976).

International Health Regulations (2005) 2509 UNTS 79 (opened for signature 23 May 2005, entered into force 15 June 2007).

Universal Declaration of Human Rights [1948] PITSE 8 (adopted 10 December 1948).

\section{B Secondary Sources}

1 Books

Andrew Butler and Petra Butler New Zealand Bill of Rights Act: A Commentary (2nd ed, LexisNexis, Wellington, 2015).

Austen Garwood-Gowers and others (ed) Contemporary Issues in Healthcare Law and Ethics (Elsevier, London, 2005).

Austin Sarat, Lawrence Douglas and Martha Umphrey (eds) The Place of Law (The University of Michigan Press, Ann Arbor, 2006).

BD Inglis New Zealand Family Law in the 21st Century (Brookers, Wellington, 2007).

Ben Goldacre Bad Science (Fourth Estate, London, 2009).

Bernard M Dickens (ed) Medicine and the Law (Dartmouth Publishing Company, Hants, 1993).

David Estlund Democratic Authority: A Philosophical Framework (Oxford University Press, Oxford, 2011).

Elizabeth Wicks The State and the Body: Legal Regulation of Bodily Autonomy (Hart Publishing, Oxford, 2016).

F David Peat From certainty to uncertainty: the story of science and ideas in the twentieth century (Joseph Henry Press, Washington, DC, 2002).

Geoffrey Palmer and Mathew Palmer Unbridled Power: New Zealand's Constitution and Government (4th ed, Oxford University Press, Melbourne, 2004). 
Harold J Laski The State in Theory and Practice (Routledge, New York, 2009).

Harper Lee To Kill a Mockingbird (Arrow Books, London, 1997).

Institute of Medicine (US) Forum on Microbial Threats Infectious Disease Movement in a Borderless World: Workshop Summary (National Academies Press, Washington DC, 2010).

Isaiah Berlin Four Essays on Liberty (Oxford University Press, London, 1969).

J Cook and Lewandowsky The Debunking Handbook (University of Queensland, St Lucia, Australia, 2012).

JD Hodson The Ethics of Legal Coercion (D Reidel Publishing, Dordrecht, 1983).

JF Burrows and RI Carter Statute Law in New Zealand (4th ed, LexisNexis, Wellington, 2009).

John Donne No Man is an Island (Souvenir Press, London, 1988).

John Stuart Mill On Liberty (Oxford University Press, Oxford, 2015).

Jonathan Law (ed) A Dictionary of Law (8th ed, Oxford University Press, Oxford, 2015).

Karl R Popper The Logic of Scientific Discovery (Martino Fine Books, Mansfield, CT, 2014).

L Langer and others The Science of Using Science: Researching the Use of Research Evidence in Decision-Making (University College London, London, 2016).

M Bucchi and B Trench (eds) Handbook of Public Communication of Science and Technology (Routledge, New York, 2006).

Mary E Williams (ed) Vaccinations (At Issue Series, Greenhaven Press, San Diego, 2003).

Naomi Oreskes and Erik Conway Merchants of Doubt: How a Handful of Scientists Obscured the Truth on Issues from Tobacco Smoke to Global Warming (Bloomsbury Press, New York, 2010).

OECD Scientific advice for policy making: The role and responsibility of expert bodies and individual scientists (OECD Publishing, Paris, 2015).

Paul Cairney The Politics of Evidence-based Policy Making (Macmillan Publishers, London, 2016).

Paul Hazard The European Mind: The Critical Years (1680-1715) translated by J Lewis May (Yale University Press, New Haven, 1953). 
Richard H Thaler and Cass R Sustein Nudge: Improving decisions about health, wealth, and happiness (Penguin, London, 2009).

Robert Frodeman (ed) Earth matters: the earth sciences, philosophy, and the claims of the community (Prentice Hall, Upper Saddle River, NJ, 1999).

Roger Berkowitz The Gift of Science: Leibniz and the Modern Legal Tradition (Harvard University Press, Cambridge, MA, 2005).

Roger Pielke Jr The Honest Broker: Making Sense of Science in Policy and Politics (Cambridge University Press, Cambridge, 2007).

Science and Creationism: A View from the National Academy of Sciences (2nd ed, National Academies Press, Washington, DC, 1999).

Shaun Hendy Silencing Science (Bridget Williams Books, Wellington, 2016).

Sheila Jasanoff The Fifth Branch: Science Advisors as Policy-makers (Harvard University Press, Cambridge, MA, 1990).

Stanley A Plotkin, Walter A Orenstein and Paul A Offit (eds) Vaccines (6th ed, Elsevier Health Sciences, London, 2012).

Susan Selby (ed) Law and Science (Aldershot, Burlington, VT, 2008).

VT Covello and others (eds) Effective risk communication: The role and responsibility of governmental and non-governmental organizations (Plenum Press, New York, 1989).

\section{Government Publications}

Committee of Inquiry into Allegations Concerning the Treatment of Cervical Cancer at National Women's Hospital and into Other Related Matters The report of the Committee of Inquiry into Allegations Concerning the Treatment of Cervical Cancer at National Women's Hospital and into Other Related Matters (Government Printing Office, New Zealand, 1988).

Health Committee Health Committee Inquiry into how to improve completion rates of childhood immunisation, and Briefings from the Chief Coroner on the coronial process, from Dr Michael Tatley on the adverse reaction process, and from Professor Sir Peter Gluckman on how to improve completion rates of childhood immunisation (March 2011). 
Ministry of Health "New Zealand Health Strategy Future Direction” (Ministry of Health, Wellington, April 2016).

Ministry of Health "Public Health Legislation: Promoting Public Health, Preventing Ill Health and Managing Communicable Diseases: Discussion Paper" (Ministry of Health, Wellington, 2002).

Ministry of Health "The National Childhood Immunisation Coverage Survey 2005" (Ministry of Health, Wellington, April 2007).

Ministry of Health Immunisation Handbook (2nd ed, Ministry of Health, Wellington, 2017).

Ministry of Health National Standards for Vaccine Storage and Transportation for Immunisation Providers 2017 (Ministry of Health, Wellington, 2017).

New Zealand Government Government Response to the Report of the Health Committee on Inquiry into how to improve completion rates of childhood immunisation, and Briefings from the Chief Coroner on the coronial process, from Dr Michael Tatley on the adverse reaction process, and from Professor Sir Peter Gluckman on how to improve completion rates of childhood immunisation (22 June 2011) $<$ www.parliament.nz> .

Welfare Working Group Reducing Long-Term Benefit Dependency (Welfare Working Group, Report, February 2011).

3 International Reports

D Acheson Public Health in England: The Report of the Committee of Inquiry into the Future Development of the Public Health Function (Her Majesty's Stationery Office, London, 1998).

\section{Journal Articles}

A Imdad and others "Religious exemptions for immunization and risk of pertussis in New York State, 2000-2011” (2013) 132(1) Pediatrics 37-43.

A Jain and others "Autism occurrence by MMR vaccine status among US children with older siblings with and without autism" (2015 313(15) JAMA 1534-1540. 
A Kata "Anti-vaccine activists, Web 2.0, and the postmodern paradigm-an overview of tactics and tropes used online by the anti-vaccination movement" (2012) 30(25) Vaccine 3778-3789.

A Kennedy and others "Vaccine attitudes, concerns, and information sources reported by parents of young children: results from the 2009 HealthStyles survey" (2011) 127(Suppl 1) Pediatrics S92-S99.

A Taddio and others "Reducing the pain of childhood vaccination: an evidence-based clinical practice guideline (summary)" (2010) 182(18) CMAJ 1989-1995.

AL Benin and others “Qualitative analysis of mothers' decision-making about vaccines for infants: the importance of trust" (2006) 117 Pediatrics 1532-1541.

AL Wroe and others "Understanding and predicting parental decisions about early childhood immunizations" (2004) 23(1) Health Psych 33.

AM Kennedy and others "Vaccine beliefs of parents who oppose compulsory vaccination" (2005) 120 Public Health Rep 252-258.

Amanda Naprawa "Don't give your kid that shot!: the public health threat posed by antivaccine speech and why such speech is not guaranteed full Protection under the first amendment” (2013) 11 Cardozo Pub Law Pol Ethics J 473.

Ana Iltis and Kirstin Matthews "NTD policy priorities: Science, values, and agenda setting” (2017) 11(5) PLoS Negl Trop Dis e0005431.

Andrea Pin "Balancing Dignity, Equality and Religious Freedoms: A Transnational Topic" (2017) 19 Ecc LJ 292.

Andrew S Butler "Limiting Rights" (2002) 33 VUWLR 547.

Andrew Wakefield and others "Ileal-lymphoid-nodular hyperplasia, non-specific colitis, and pervasive developmental disorder in children" (1998) 351 Lancet 637-641.

B Guyer and others "Immunization coverage and its relationship to preventive health care visits among inner-city children in Baltimore" (1994) 94(1) Pediatrics 53-58.

BZ Erdogan "Celebrity endorsement: a literature review" (1999) 15(4) J Mark 291-314.

Cameron Grant and others "Eliminating ethnic disparities in health through immunisation: New Zealand's chance to earn global respect” (2009) 122(1291) NZ Med J 6-9.

Cameron Grant and others "Factors associated with immunisation coverage and timeliness in New Zealand" (2010) 60(572) Br J Gen Pract e113-e120. 
Cameron Grant and others "Primary care practice and health professional determinants of immunisation coverage" (2011) 47 J Paediatr Child Health 531-549.

Centers for Disease Control and Prevention "Ten great public health achievementsUnited States, 1900-1999” (1999) 48(12) Morb Mortal Wkly Rep 241-243.

Charitha Gowda and Amanda Dempsey "The rise (and fall?) of parental vaccine hesitancy" (2013) 9(8) Hum Vaccin Immunother 1755-1762.

Chephra McKee and Kristin Bohannon "Exploring the Reasons Behind Parental Refusal of Vaccines" (2016) 21(2) J Pediatr Pharmacol Ther 104-109.

Chris Burton and Tom Love "The scientific method(s) of primary care" (2004) 54(504) Br J Gen Pract 553.

Chris Clarke "A question of balance: The autism-vaccine controversy in the British and American elite press" (2008) $30 \mathrm{~J}$ Sci Comm 77-107.

Claudia Geiringer "On a road to nowhere: implied declarations of inconsistency and the New Zealand Bill of Rights Act” (2009) 40 VUWLR 613-647.

D Lennon and others "Immunisation coverage in North Health. Comparative results from North Health's 1996 immunisation coverage survey" (Northern Regional Health Authority, Auckland, 1997).

DA Gust and others "Parent attitudes toward immunizations and healthcare providers the role of information" (2005) 29 Am J Prev Med 105-112.

DA Gust and others "Parental perceptions surrounding risks and benefits of immunization" (2003) 14 Semin Pediatr Infect Dis 207-212.

David Budtz Pedersen "The political epistemology of science-based policy-making" (2014) (51) Soc Sci Public Policy 547.

Dewesh Kumar and others "Vaccine hesitancy: understanding better to address better" (2016) 5 Isr J Health Policy Res 2.

Dietram Scheufele "Communicating science in social settings" (2013) 110(Suppl 3) Proc Natl Acad Sci USA 14040-14047.

DJ Nokes and RM Anderson "Vaccine safety versus vaccine efficacy in mass immunization programmes" (1991) 338 Lancet 1309-1312.

DJ Opel and others "Validity and reliability of a survey to identify vaccine-hesitant parents" (2011) 29 Vaccine 6598-6605. 
DM Kahan "The cognitively illiberal state" (2007) 60(1) Stanford Law Rev 115-154.

Dorit Rubinstein Reiss and Lois Weithorn "Responding to the Childhood Vaccination Crisis: Legal Frameworks and Tools in the Context of Parental Vaccine Refusal" (2015) 63 Buff L Rev 881.

Efthimios Parasidis and Douglas Opel "Parental refusal of childhood vaccines and medical neglect laws" (2017) 107(1) Am J Public Health 68-71.

Erik Persson "What are the core ideas behind the Precautionary Principle" (2016) 557-558 Sci Total Environ 134-141.

Eve Dubé and others "Vaccine hesitancy: an overview" (2013) 9(8) Hum Vaccin Immunother 1763-1773.

Felicity Goodyear-Smith and others "Comparison of general practitioner and practice nurse perceived barriers to immunization uptake” (2005) 32(3) NZ Fam Phys 164-171.

Felicity Goodyear-Smith and others "Determining immunisation coverage rates in primary health care practices: a simple goal but a complex task" (2008) 77(7) Int J Med Inf 477-485.

FM Hodges and others "Prophylactic interventions on children: balancing human rights with public health" (2002) 28(1) J Med Ethics 10.

Frank B Cross "Paradoxical Perils of the Precautionary Principle" (1995) 53(3) Wash Lee Law Rev 851-928.

Frederick Zimmerman "Public Health Autonomy: A Critical Reappraisal" (2017) 47(6) The Hastings Centre Report 38-45.

Gary C Leeds “The abortion controversy” (1990) 35 Vill L Rev 581.

Gillian Haber and others "The HPV Vaccine Mandate Controversy" (2007) 20 J Pediatr Adolesc Gynecol 325-331.

GL Freed and others "Parental vaccine safety concerns in 2009" (2010) 125 Pediatrics 654-659.

Gordon Gauchat "Politicization of Science in the Public Sphere: A Study of Public Trust in the United States, 1974 to 2010” (2012) 77(2) Am Sociol Rev 167-187.

Guido Calabresi "Do we own our bodies" (1991) 1(5) Health Matrix 15. 
Heidi J Larson and others "Tracking the global spread of vaccine sentiments: the global response to Japan's suspension of its HPV vaccine recommendation" (2014) 10(9) Hum Vaccin Immunother 2543-2550.

Helen Petousis-Harris and others "Barriers to childhood immunisation among New Zealand mothers" (2002) 29(6) NZ Fam Phys 396-401.

Helen Petousis-Harris and others "Fact or fallacy? Immunisation arguments in the New Zealand print media” (2010) 34(5) Aust NZ Med J Public Health 521-526.

Helen Petousis-Harris and others "Family physician perspectives on barriers to childhood immunisation" (2004) 22(17-18) Vaccine 2340-2344.

Helen Petousis-Harris and others "Family practice nurse perspectives on barriers to immunising children" (2005) 23(21) Vaccine 2725-2730.

Helen Petousis-Harris and others "Immunisation education in the antenatal period" (2004) 31(5) NZ Fam Phys 303-306.

Helen Wilson and George Thomson “'Balancing acts': The politics and processes of smokefree area policymaking in a small state" (2011) 101(1) Health Policy 79-86.

IM Shui and others "Parents concerned about vaccine safety: Differences in race/ethnicity and attitudes" (2006) 31 Am J Prev Med 244-251.

Ivor Richardson "The role of judges as policy makers" (1985) 15(1) VUWLR 46-52.

J Leask and others "Communicating with parents about vaccination: a framework for health professionals" (2012) 12 BMC Pediatr 154.

J Lexchin and others "Pharmaceutical industry sponsorship and research outcome and quality: systematic review” (2003) 326 BMJ 1167.

J Potter and others "Influenza vaccination of health care workers in long-term-care hospitals reduces the mortality of elderly patients" (1997) 165(1) J Infect Dis 1-6.

JD Grabenstein "What the world's religions teach, applied to vaccines and immune globulins" (2013) 31(16) Vaccine 2011-2013.

JH Tanne "Celebrity illnesses raise awareness but can give wrong message" (2000) 321(7269) BMJ 1099.

JL Schwartz and AL Caplan "Vaccination refusal: ethics, individual rights, and the common good" (2011) 38(4) Prim Care 717-728. 
Johannes Knoll and Jörg Matthes "The effectiveness of celebrity endorsements: a metaanalysis" (2017) 45(1) J of the Acad Mark Sci 55-75.

John Coggon and José Miola “Autonomy, liberty, and medical decision-making” (2011) 70(3) Camb Law J 523-547.

Jorge Wagensberg "On the existence and uniqueness of the scientific method" (2014) 9(3) Biol Theory 331-346.

Juliet Rumball-Smith and Timothy Kenealy "Childhood immunisations in Northland, New Zealand: declining care and the journey through the immunisation pathway" (2016) 129(1438) NZ Med J 15-21.

Kathryn M Edwards and Jesse M Hackell; The Committee on Infectious Diseases; The Committee on Practice and Ambulatory Medicine "Countering Vaccine Hesitancy" (2016) 138(3) Pediatrics e20162146.

KF Brown and others "UK parents' decision-making about measles-mumps-rubella (MMR) vaccine 10 years after the MMR-autism controversy: a qualitative analysis" (2012) 30 Vaccine 1855-1864.

KM Madsen and others "A population-based study of measles, mumps, and rubella vaccination and autism" (2002) 347(19) N Engl J Med 1477-1482.

L Dales and others "Time trends in autism and in MMR immunization coverage in California” (2001) 285 JAMA 1183-1185.

LE Taylor and others "Vaccines are not associated with autism: an evidence-based metaanalysis of case-control and cohort studies" (2014) 32(29) Vaccine 3623-3629.

M Sekine and others "Japanese crisis of HPV vaccination" (2016) 2(2) Int J Pathol Clin Res 1-3.

Mary Footer "Post-Normal Science in the Multilateral Trading System: Social Science Expertise and the EC-Biotech Panel” (2007) 6 World Trade Rev 280.

Marysia Laskowski "Nudging towards Vaccination: A Behavioral Law and Economics Approach to Childhood Immunization Policy" (2016) 94(3) Tex L Rev 601.

Masaaki Sawada and others "HPV vaccination in Japan: results of a 3-year follow-up survey of obstetricians and gynecologists regarding their opinions toward the vaccine" (2018) 23(1) Int J Clin Oncol 121-125. 
Melanie Marti and others "Assessments of global drivers of vaccine hesitancy in 2014Looking beyond safety concerns" (2017) 12 PLoS ONE e0172310.

MJ Simis and others "The lure of rationality: Why does the deficit model persist in science communication?” (2016) 25(4) Public Underst Sci 400-414.

$\mathrm{N}$ Kash and others "Safety and efficacy data on vaccines and immunization to human papillomavirus" (2015) 4(4) J Clin Med 614-33.

N Principi and S Esposito "Mumps outbreaks: A problem in need of solutions" (2018) 76(6) J Infect 503-506.

Naomi Altman and Martin Krzywinski “Association, correlation and causation” (2015) 12(10) Nature Methods 899.

NE MacDonald; SAGE Working Group on Vaccine Hesitancy "Vaccine hesitancy: Definition, scope and determinants" (2015) 33(34) Vaccine 4161-4164.

Nikki Turner "The challenge of improving immunization coverage: the New Zealand example" (2012) 11(1) Expert Rev Vaccines 9-11.

Nikki Turner and others "The cost of immunising at the general practice level" (2010) 1(4) J Prim Health Care 286-296.

Nikki Turner and others "The use and misuse of media headlines: lessons from the MeNZB immunisation campaign" (2009) 122(1291) NZ Med J 22-27.

Paul Stehr-Green and others "Immunisation coverage in New Zealand: Results of the regional immunisation coverage surveys” 1992 92(Suppl 2) Communicable Diseases NZ.

PH Viale "Celebrities and medicine: a potent combination” (2014) 5(2) J Adv Pract Oncol $82-4$.

PJ Smith and others "Children who have received no vaccines: who are they and where do they live?” (2004) 114 Pediatrics 187-195.

$\mathrm{R}$ Prislin and others "Immunization status and sociodemographic characteristics: the mediating role of beliefs, attitudes, and perceived control" (1998) 88 Am J Public Health 1821-1826.

RE Spier "Perception of risk of vaccine adverse events: a historical perspective" (2001) 20(Suppl 1) Vaccine S78-S84. 
RE Thomas and others "Influenza vaccination for healthcare workers who work with the elderly" (2010) 2 Cochrane Database Syst Rev CD005187.

Rebecca Bucchieri "Religious freedom versus public health: the necessity of compulsory vaccination for schoolchildren" (2015) 25 BU Pub Int LJ 265.

Richard K Zimmerman "Ethical Analysis of HPV Vaccine Policy Options" (2006) 24 Vaccine 4812.

Robert Field "Vaccine declinations present new challenges for public health" (2008) 33 P T 542.

Roland J Lamarine "Alternative medicine: more than a harmless option" (2001) 71(3) J Sch Health 114.

Ross Silverman and Thomas May "Private Choice versus Public Health: Religion, Morality, and Childhood Vaccination Law" (2001) 1 Margins 505.

Rt Hon Sir Ivor Richardson "The New Zealand Bill of Rights: Experience and potential, including the implications for commerce" [2004] Canta LR 10.

S Mueller and others "Measuring disparities in immunisation coverage among children in New Zealand" (2012) 18(6) Health Place 1217-1223.

Sara Brownell and others "Science Communication to the General Public: Why We Need to Teach Undergraduate and Graduate Students this Skill as Part of Their Formal Scientific Training" (2013) 12(1) J Undergrad Neurosci Educ E6-E10.

Sheila Jasanoff "Knowledge elites and class war" (1999) 401 Nature at 531.

Sheila Jasanoff “The Life Sciences and the Rule of Law” (2002) J Mol Bio 319.

Shireen Arani "State intervention in cases of obesity-related medical neglect" (2002) 82 B U L Rev 875.

Shoaib Fahad Hussain and others "Eradicating polio in Pakistan: an analysis of the challenges and solutions to this security and health issue" (2016) 12 Global Health 63.

Silvio Funtowicz and Jerome Ravetz "Science for the post-normal age" (1993) 25(7) Futures 739-755.

Simon Whitney and others "A typology of shared decision making, informed consent, and simple consent" (2004) 140 Ann Internal Med 54-59.

SL Gryll and M Katahn "Situational factors contributing to the placebos effect" (1978) 57(3) Psychopharmacology (Berl) 253-261. 
SL Hanley and others "HPV vaccination crisis in Japan" (2015) 385 Lancet 2571.

Stefan Riedel "Edward Jenner and the history of smallpox and vaccination" (2005) 18(1) Proc (Bayl Univ Med Cent) 21-25.

Stuart Gilmour and others "HPV vaccination programme in Japan" (2013) 382(9894) Lancet 768.

Stuart McLennan and others "The Health and Safety in Employment Act and the influenza vaccination of healthcare workers" (2007) 120(1250) NZ Med J U2442.

SW Roush and TV Murphy; Vaccine-Preventable Disease Table Working Group "Historical comparisons of morbidity and mortality for vaccine-preventable diseases in the United States" (2007) 298(18) JAMA 2155-2163.

$\mathrm{T}$ Oraby and others "The influence of social norms on the dynamics of vaccinating behaviour for paediatric infectious diseases" (2014) 281(1780) Proc R Soc B 20133172.

Tania Bubela and others "Science communication reconsidered" (2009) 27 Nat Biotechnol 514-518.

Taskforce on community preventive services "Recommendations regarding interventions to impose vaccination coverage in children, adolescents, and adults" (2000) 18(Suppl 1) Am J Prevent Med S92-S96.

Taylor and others "Autism and measles, mumps, and rubella vaccine: No epidemiologic evidence for a causal association" (1999) 353 Lancet 2026-2029.

The Editors of The Lancet "Retraction-Ileal-lymphoid-nodular hyperplasia, non-specific colitis, and pervasive developmental disorder in children" (2010) 375 Lancet 445.

Tim Dare "Disagreement Over Vaccination Programmes: Deep or Merely Complex and Why Does It Matter?” (2014) 26(1) HEC Forum 43.

V Demicheli and others "Vaccines for measles, mumps and rubella in children" (2012) Feb 15(2) CD004407 Cochrane Database Syst Rev doi: 10.1002/14651858.CD004407.pub3.

WF Carman and others "Effects of influenza vaccination of health-care workers on mortality of elderly people in long-term care: a randomised controlled trial" (2000) 355(9198) Lancet 93-97. 
William Samuelson and Richard Zeckhauser "Status quo bias in decision making” (1988) 1 J Risk Uncertain 7-59.

WJ Sutherland and others "A Collaboratively-Derived Science-Policy Research Agenda" (2012) 7(3) PLoS ONE e31824.

Y Uno and others "Early exposure to the combined measles-mumps-rubella vaccine and thimerosal-containing vaccines and risk of autism spectrum disorder" (2015) 33(21) Vaccine 2511-2516.

Yutaka Ueda and others "Japan's failure to vaccinate girls against human papillomavirus" (2015) 212 Am J Obstet Gynecol 405-406.

\section{International Documents}

Council of the Organization of Medical Sciences International Ethical Guidelines for Biomedical Research Involving Human Subjects <www.cioms.ch>.

Rose Wilson and others HPV vaccination in Japan: The continuing debate and global impacts April 2015 (Report of The CSIS Global Health Policy Center).

The National Commission for the Protection of Human Subjects of Biomedical and Behavioral Research, The Belmont Report Ethical Principles and Guidelines for the Protection of Human Subjects of Research (30 June 2008) <www.ohsr.od.nih.gov>.

Trials of War Criminals before the Nuremberg Military Tribunals under Control Council Law (1949) 10(2) US Government Printing Office at 181-182 (the Nuremberg Code).

Workshop on Alternative Medicine Alternative medicine: Expanding medical horizons: A report to the National Institutes of Health on alternative health medical systems and practices in the United States September 1992 (Report of The Office of Alternative Medicine).

World Medical Association Declaration of Helsinki: Ethical Principles for Medical Research Involving Human Subjects (Helsinki, Finland, 1964).

\section{Letters}

George Bernard Shaw to Charles Gane (Secretary of the National Anti-Vaccination League) regarding vaccination policy (22 February 1906). 


\section{Newspaper/Magazine Articles}

Atul Gawande "The Mistrust of Science" The New Yorker (online ed, 10 June 2016).

BBC "Ebola outbreak: Experimental vaccinations begin in DR Congo" BBC News (online ed, London, 21 May 2018).

BBC "Philippines to probe dengue vaccine scare" BBC News (online ed, London, 4 December 2017).

Benjamin Mueller "Judge Upholds Policy Barring Unvaccinated Students During Illnesses" New York Times (online ed, New York, 22 June 2014).

Emily Cooper “Furious Dr Lance O'Sullivan asks why healthcare workers were at anti-vax film - 'It is incompatible for you to be here"' OneNewsNow (online ed, Auckland, 24 May 2017).

Ian Sample "Doctor wins 2017 John Maddox prize for countering HPV vaccine misinformation" The Guardian (online ed, United Kingdom, 30 November 2017).

Jack the Insider "Paleo and the new Scientology" The Australian (online ed, 18 March 2015).

Jane Ridley "10 anti-vaccine celebs who should come with a surgeon general's warning" New York Post (online ed, New York, 9 February 2015).

Lena H Sun "Trump energizes the anti-vaccine movement in Texas" The Washington Post (online ed, Washington, 20 February 2017).

Lindsey Bever “'Our beautiful little boy has gone': Parents of Charlie Gard say he has died" The Washington Post (online ed, 28 July 2017).

OneNewsNow "Should Kiwi kids who aren't vaccinated be banned from pre-school? Labour's Andrew Little says it's 'well worth looking at" OneNewsNow (online ed, Auckland, 14 March 2017).

Michael Mosley "Is coconut oil a superfood?" BBC News (online ed, London, 9 January 2018).

New Zealand Herald "Worker fired over hospital's hardline vaccination policy" The New Zealand Herald (online ed, Auckland, 3 August 2015).

Nick Enfield "We're in a post-truth world with eroding trust and accountability. It can't end well" The Guardian (online ed, United Kingdom, 16 November 2017). 
Paul Cairney "The politics of evidence-based policymaking" The Guardian (online ed, United Kingdom, 10 March 2016).

Thomas Friedman “Where Did 'We the People' Go?” The New York Times (online ed, New York, 21 June 2017).

Tim McGirk "Taliban Assassins Target Pakistan's Polio Vaccinators" The National Geographic (online ed, 3 March 2015).

8 Papers

Growing Up in New Zealand "Who is saying what about immunisation: evidence from Growing Up in New Zealand” (Policy Brief 6, Auckland, June 2015).

9 Speeches/Conference Papers

K Kappel "Democratizing Science: What could it mean?" (Democratizing Science Conference 2012, University of Copenhagen, Copenhagen, 14 December 2012).

Paul Nurse "The new enlightenment" (The Richard Dimbleby Lecture 2012, 28 February 2012).

Peter Gluckman "Medical, life sciences and social sciences research: how they should be contributing to New Zealand's development" (Auckland Medical Research Foundation, Auckland, 6 May 2010).

Susan Glazebrook "The New Zealand Bill of Rights Act 1990: its operation and effectiveness" (Paper presented to the South Australian State Legal Convention, 22-23 July 2004).

\section{Theses/Dissertations}

Jessica Kerr "Immunisation and the law: Slippery slope to a healthy society" (LLB(Hons) Dissertation, Victoria University of Wellington, 2005).

Luke Morrison "Legal responses to non-life-threatening medical neglect" (LLM dissertation, University of Otago, 2011).

Nicola Turner "Factors associated with immunisation coverage for the childhood immunisation programme in New Zealand: 1999 to 2012" (PhD, The University of Auckland, 2014). 
Rose Goss "A Decay of Rights: The Decision in Health New Zealand Inc v South Taranaki District Council" (LLB(Hons) Dissertation, Victoria University of Wellington, 2014).

\section{Internet Materials}

Auckland Regional Public Health Service "Managing the mumps outbreak" <www.arphs.govt.nz>.

CDC "Contraindications and Precautions" <www.cdc.gov>.

CDC "Possible side effects from vaccines" <www.cdc.gov>.

CDC "State School and Childcare Vaccination Laws" <www.cdc.gov>.

CDC "Thimerosal in vaccines" <www.cdc.gov>.

Committee on Publication Ethics "COPE statement on inappropriate manipulation of peer review processes" <publicationethics.org>.

European Commission "Communication from the Commission on the precautionary principle" <eur-lex.europa.eu>.

Hon Andrew Little and Hon David Parker "Government to provide greater protection of rights under the NZ Bill of Rights Act 1990" <www.beehive.govt.nz>.

Immunisation Advisory Centre "About" <www.immune.org.nz>

Immunisation Advisory Centre "Vaccine safety" <www.immune.org.nz>

Institute of Environmental Science and Research "Pertussis Report 14 October-10 November 2017" <www.surv.esr.cri.nz>.

$\mathrm{K}$ Prewitt and others "Using science as evidence in public policy: report on the use of social science knowledge in public policy" National Research Council of the United States National Academies of Science (2012) <www.nap.edu〉.

Ministry of Health "Adverse Event Information to be released to the Health Select Committee" <www.health.govt.nz>.

Ministry of Health "Health targets: Increased immunization" <www.health.govt.nz>.

Ministry of Health "National Review of Outreach Immunisation Services: Summary and Recommendations (May 2016)"〈www.health.govt.nz>.

Ministry of Health "Zero Fees for Under-13s" <www.health.govt.nz>.

Peter Gluckman "Briefing Note: The New Zealand Science Advisory System" Office of the Prime Minister's Chief Science Advisor <www.pmcsa.org.nz>. 
Peter Gluckman "How science informs current thinking in government" Office of the Prime Minister's Chief Science Advisor <www.pmcsa.org.nz>.

Peter Gluckman "Interpreting science - implications for public understanding, advocacy and policy formation. A discussion paper" Office of the Prime Minister's Chief Science Advisor <www.pmcsa.org.nz>.

Peter Gluckman "Making decisions in the face of uncertainty: Understanding risk" Office of the Prime Minister's Chief Science Advisor (November 2016) <www.pmcsa.org.nz>.

Peter Gluckman "Scientific advice in a troubled world" Office of the Prime Minister's Chief Science Advisor <www.pmcsa.org.nz>.

Peter Gluckman "The role of evidence in policy formation and implementation" Office of the Prime Minister's Chief Science Advisor <www.pmcsa.org.nz>.

Peter Gluckman "Towards better use of evidence in policy formation: a discussion paper" Office of the Prime Minister's Chief Science Advisor <www.pmcsa.org.nz>.

Sanofi Pasteur "Sanofi updates information on dengue vaccine" <www.sanofipasteur.com>.

The Treasury "Costing of Political Party Policies" <www.treasury.govt.nz>.

United Kingdom Government "Measles, mumps, rubella (MMR): use of combined vaccine instead of single vaccines" <www.gov.uk>.

United States Food and Drug Administration "Thimerosal and Vaccines" <www.fda.gov>. WHO "Constitution of the World Health Organization: Principles" <www.who.int>.

WHO "Global Advisory Committee on vaccine safety statement on safety of HPV vaccines" (17 December 2015) <www.who.int>.

WHO "Global vaccine safety" <www.who.int>.

WHO "Safety update of HPV vaccines" <www.who.int>. 